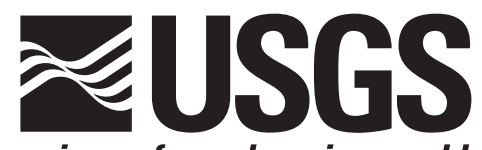

Prepared in cooperation with the U.S. Environmental Protection Agency, Office of Solid Waste and Emergency Response, Office of Superfund Remediation and Technology Innovation

\title{
Use of Borehole-Radar Methods to Monitor a Steam-Enhanced Remediation Pilot Study at a Quarry at the Former Loring Air Force Base, Maine
}

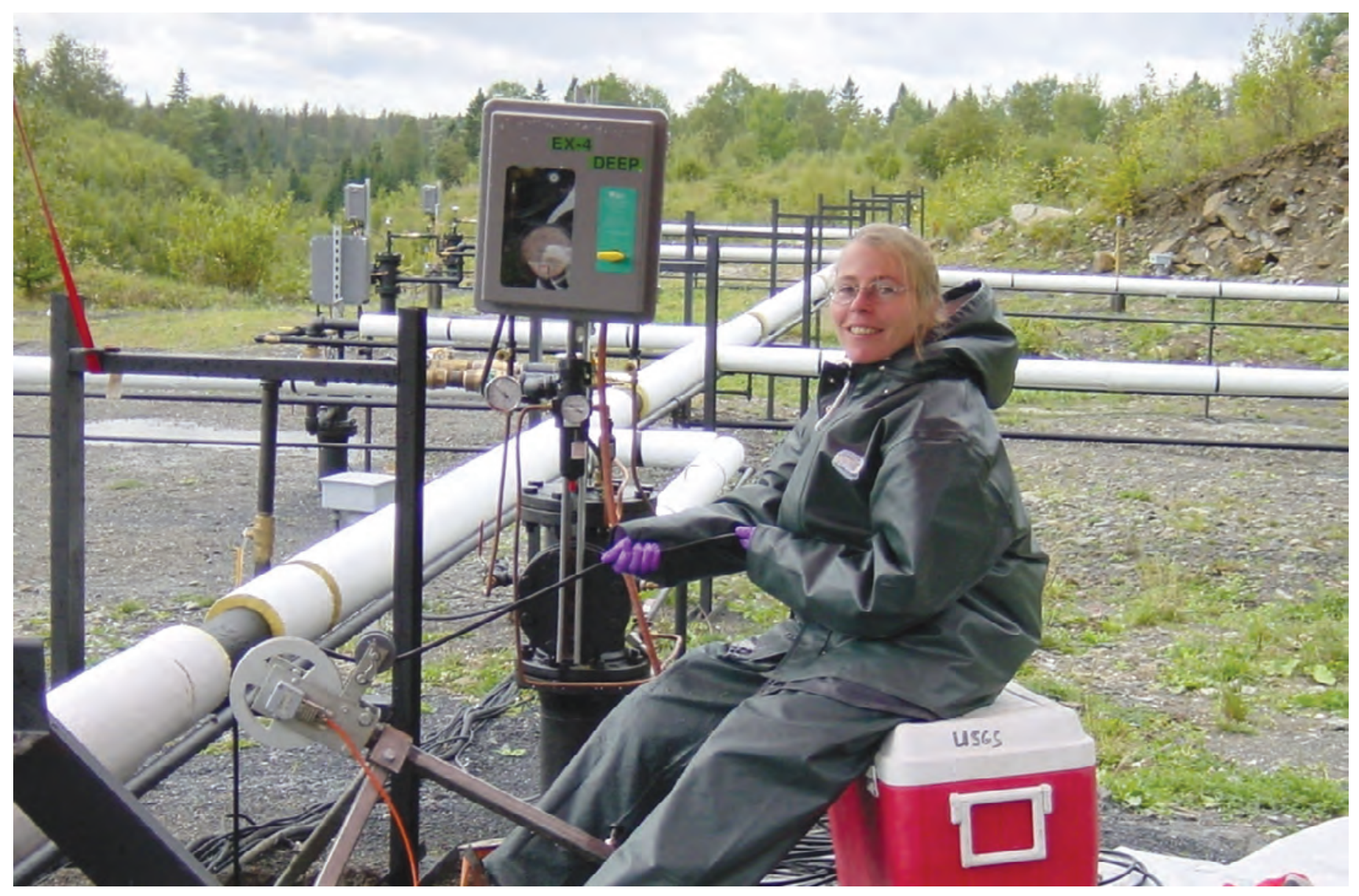

Scientific Investigations Report 2006-5191 
Cover. Borehole-radar data collection at the steam-enhanced remediation site, former Loring Air Force Base, Maine, September 2002. (Photo by Peter Joesten.) 


\section{Use of Borehole-Radar Methods to Monitor a Steam-Enhanced Remediation Pilot Study at a Quarry at the Former Loring Air Force Base, Maine}

By Colette Grégoire, Peter K. Joesten, and John W. Lane, Jr.

Prepared in cooperation with the U.S. Environmental Protection Agency,

Office of Solid Waste and Emergency Response, Office of Superfund

Remediation and Technology Innovation

Scientific Investigations Report 2006-5191 


\section{U.S. Department of the Interior DIRK KEMPTHORNE, Secretary}

\section{U.S. Geological Survey \\ Mark D. Myers, Director}

\section{U.S. Geological Survey, Reston, Virginia: 2007}

For product and ordering information:

World Wide Web: http://www.usgs.gov/pubprod

Telephone: 1-888-ASK-USGS

For more information on the USGS--the Federal source for science about the Earth, its natural and living resources, natural hazards, and the environment:

World Wide Web: http://www.usgs.gov

Telephone: 1-888-ASK-USGS

Any use of trade, product, or firm names is for descriptive purposes only and does not imply endorsement by the U.S. Government.

Although this report is in the public domain, permission must be secured from the individual copyright owners to reproduce any copyrighted materials contained within this report.

Suggested citation: Grégoire, Colette, Joesten, P.K., and Lane, J.W. Jr., 2007, Use of borehole-radar methods to monitor a steam-enhanced remediation pilot study at a quarry at the former Loring Air Force Base, Maine: U.S. Geological Survey Scientific Investigations Report 2006-5191, 35 p. 


\section{Acknowledgments}

This work was supported by the USEPA Office of Solid Waste and Emergency Response, Office of Superfund Remediation and Technology Innovation, and by the USGS Toxic Substances Hydrology Program. Colette Grégoire received support from Katholieke Universiteit Leuven, Belgium. The authors gratefully acknowledge the assistance of Mike Nalipinski and Eva Davis of the USEPA; Greg Crisp, formerly of SteamTech Environmental Services, Inc.; and Peter Forbes of the U.S. Air Force Center for Environmental Excellence. The authors also acknowledge and appreciate assistance from the following USGS employees: Chris Kochiss, Eric White, and Marcel Belaval, for field work; Fred Day-Lewis for providing Matlab codes for the tomographic inversions; and Carole Johnson and Fred Day-Lewis for contributions and technical assistance. 
This page has been left blank intentionally. 


\section{Contents}

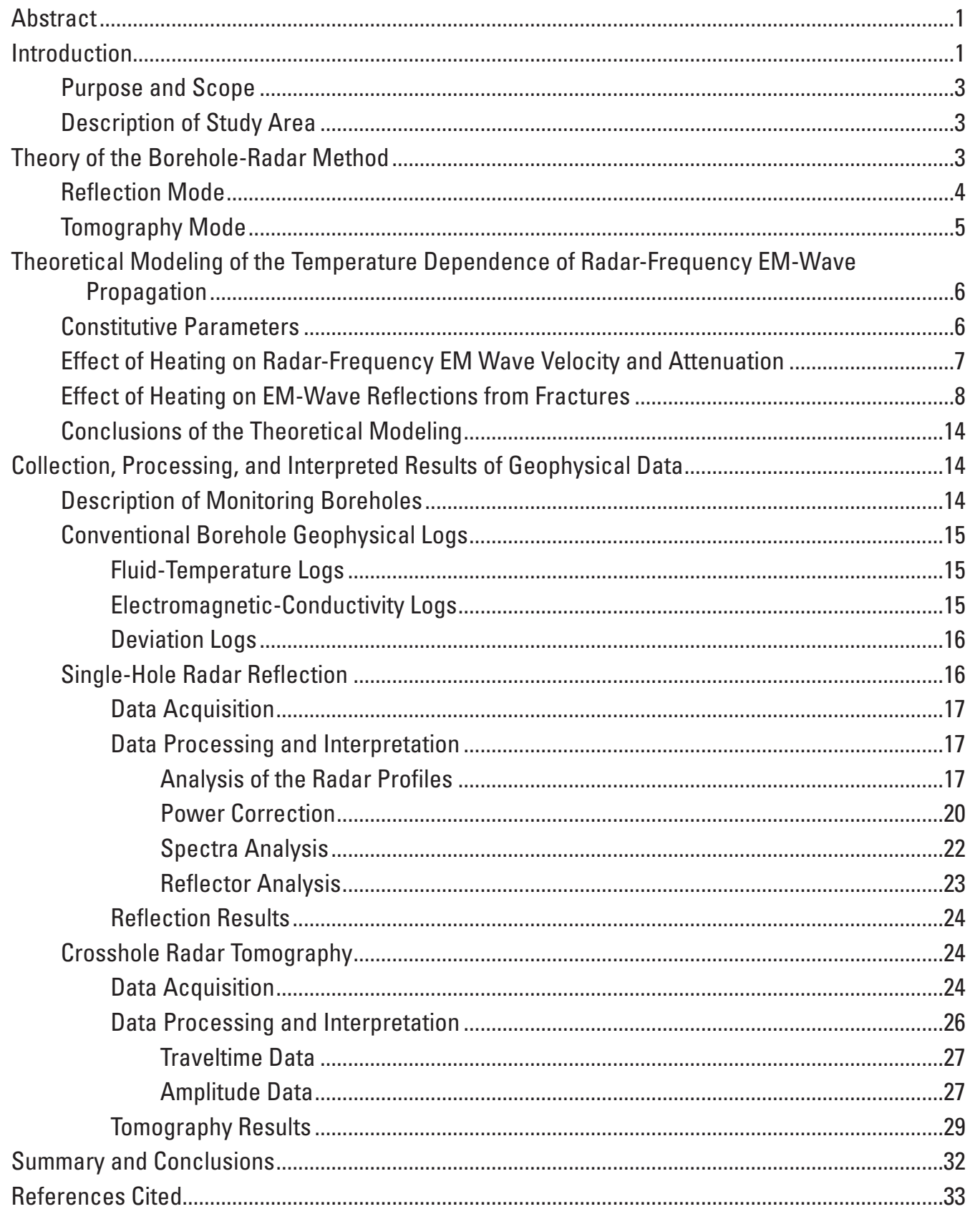




\section{Figures}

1. Map showing location of the boreholes at the former Loring Air Force Base quarry site, Limestone, Maine.

2. Diagram showing $(A)$ transmitter and receiver antenna arrangement for single-hole radar reflection logging, and $(B)$ typical reflection patterns from planar and point reflectors

3. Diagram showing configurations for collection of crosshole radar tomography data. $(A)$

Crosshole "levelrun" data collection. $(B)$ Tomography data collection

4-12. Graphs showing:

4. (A) Relative dielectric permittivity, and (B) electrical conductivity of water as a function of temperature.

5. Model results for the $(A)$ relative dielectric permittivity, and $(B)$ electrical conductivity of fractured limestone, and the resultant $(C)$ velocity, and $(D)$ attenuation of 100-megahertz radar waves as a function of temperature and conductivity $(\sigma)$ in siemens per meter $(\mathrm{S} / \mathrm{m})$.

6. Theoretical results for radar-wave traveltimes as a function of temperature and conductivity $(\sigma)$, in siemens per meter $(\mathrm{S} / \mathrm{m})$ for an antenna-separation distance of 7.5 meters.

7. Effects of the $(A$ and $B)$ conductivity of limestone, $(C$ and $D)$ conductivity of water, and $(E$ and $F$ relative dielectric permittivity of water on radar-wave velocity and attenuation

8. Reflectivity of a 10-millimeter-thick fracture as a function of temperature, and the ratio of the reflectivity at temperature to the reflectivity at 20 degrees Celsius $\left({ }^{\circ} \mathrm{C}\right)$ for formation conductivities of $(A$ and $B) 0.01$ siemens per meter and $(C$ and $D) 0.03$ siemens per meter.

9. (A) Reflectivity of a 5-millimeter-thick fracture as a function of temperature, and $(B)$ the ratio of the reflectivity at temperature to the reflectivity at 20 degrees Celsius $\left({ }^{\circ} \mathrm{C}\right)$ for a formation conductivity of 0.01 siemens per meter

10. (A) Reflectivity of a 2-millimeter-thick fracture as a function of temperature, and $(B)$ the ratio of the reflectivity at temperature to the reflectivity at 20 degrees Celsius $\left({ }^{\circ} \mathrm{C}\right)$ for a formation conductivity of 0.01 siemens per meter

11. (A) Reflectivity of a 1-millimeter-thick fracture as a function of temperature, and $(B)$ the ratio of reflectivity at temperature to the reflectivity at 20 degrees Celsius $\left({ }^{\circ} \mathrm{C}\right)$ for a formation conductivity of 0.01 siemens per meter..

12. Effect of water salinity on the radar reflection. $(A)$ Reflectivity of a 10-millimeter water-filled fracture. (B) Reflectivity of a 10-millimeter-thick water-filled fracture. Concentration of the saline solution is $0.5845 \mathrm{~g} / \mathrm{L} \mathrm{NaCl}$. (C) Ratio of the reflectivity with $0.5845 \mathrm{~g} / \mathrm{L} \mathrm{NaCl}$ to the reflectivity with $0.2923 \mathrm{~g} / \mathrm{L} \mathrm{NaCl}$

13-15. Logs showing:

13. Temperature data collected in boreholes $(A) \mathrm{JBW}-7816$ and $(B) \mathrm{JBW}-7817 \mathrm{~A}$ during August, September, and November 2002 at the former Loring Air Force Base quarry, Limestone, Maine.

14. The 100-megahertz omni-directional borehole-radar reflection data collected in borehole JBW-7816 during August, September, and November 2002 at the former Loring Air Force Base quarry, Limestone, Maine..

15. The 100-megahertz omni-directional borehole-radar reflection data collected in borehole JBW-7817A during August, September, and November 2002 at the former Loring Air Force Base quarry, Limestone, Maine... 
16-29. Plots showing:

16. Peak-to-peak amplitude of the direct radar wave of single-hole radar reflection data collected during August, September, and November 2002 at the former Loring Air Force Base quarry, Limestone, Maine.

17. Power term calculated for selected single-hole radar reflection data sets from boreholes JBW-7816 and JBW-7817A during August, September, and November 2002 at the former Loring Air Force Base quarry, Limestone, Maine....21

18. Mean frequency spectra calculated for each single-hole radar reflection data set from boreholes JBW-7816 and JBW-7817A during August, September, and November 2002 at the former Loring Air Force Base quarry, Limestone, Maine....22

19. Example of reflector analysis of single-hole radar reflection data:

$(A)$ reflector in section of radar profile, $(B)$ mean signal in the time domain, and $(C)$ amplitude spectrum in the frequency domain

20. Amplitude spectra calculated for the selected reflectors from single-hole radar reflection data collected during August, September, and November 2002 at the former Loring Air Force Base quarry, Limestone, Maine.

21. Ratio of the maximum amplitudes in the frequency domain of selected reflectors in single-hole radar reflection data from boreholes JBW-7816 and JBW-7817A collected during August, September, and November 2002 at the former Loring Air Force Base quarry, Limestone, Maine.

22. Calibrated crosshole radar levelruns. Differences in traveltimes:

(A) September-August 2002 and (B) November-August 2002 at the former Loring Air Force Base quarry, Limestone, Maine.

23. (A) Traveltimes of crosshole radar tomography data collected during August, September, and November 2002; and (B) radar-wave velocity in August, September, and November 2002 at the former Loring Air Force Base quarry, Limestone, Maine .

24. Differences in crosshole radar tomography traveltimes: $(A)$ SeptemberAugust-2002 and (B) November-August 2002; at the former Loring Air Force Base quarry, Limestone, Maine

25. Results of the difference of the traveltime-difference tomography data:

(A) September-August 2002 and (B) November-August 2002 at the former Loring Air Force Base quarry, Limestone, Maine.

26. Peak-to-peak amplitude of the crosshole radar levelrun data:

$(A)$ unprocessed data and $(B)$ calibrated data collected during August, September, and November 2002 at the former Loring Air Force Base quarry, Limestone, Maine

27. Attenuation measurements from calibrated crosshole radar tomography data collected during August, September, and November 2002 at the former Loring Air Force Base quarry, Limestone, Maine.

28. Attenuation differences in crosshole radar tomography data:

(A) September-August 2002 and (B) November-August 2002 at the former Loring Air Force Base quarry, Limestone, Maine.

29. Results of the inversion of the attenuation-differences in crosshole radar tomography data: $(A)$ September-August 2002 and $(B)$ November-August 2002 at the former Loring Air Force Base quarry, Limestone, Maine.. 


\section{Tables}

1. Power correction for selected reflectors seen in single-hole radar reflection data collected during 2002 in boreholes JBW-7816 and JBW-7817A at the former Loring Air Force Base study area, Limestone, Maine

2. Amplitude ratios calculated at central frequency for the selected reflectors identified in single-hole radar reflection data collected during 2002 in boreholes JBW-7816 and JBW-7817A at the former Loring Air Force Base study area, Limestone, Maine

\section{Conversion Factors and Abbreviations}

\begin{tabular}{|c|c|c|}
\hline Multiply & $\mathrm{By}$ & To obtain \\
\hline \multicolumn{3}{|c|}{ Length } \\
\hline centimeter $(\mathrm{cm})$ & 0.3937 & inch (in.) \\
\hline millimeter (mm) & 0.03937 & inch (in.) \\
\hline meter $(\mathrm{m})$ & 3.281 & foot $(\mathrm{ft})$ \\
\hline
\end{tabular}

Temperature in degrees Celsius $\left({ }^{\circ} \mathrm{C}\right)$ may be converted to degrees Fahrenheit $\left({ }^{\circ} \mathrm{F}\right)$ as follows:

$$
{ }^{\circ} \mathrm{F}=\left(1.8 \times^{\circ} \mathrm{C}\right)+32
$$

Vertical coordinate information is referenced to the North Geodetic Vertical Datum of 1929 (NGVD 29).

Electrical conductivity in millisiemens per meter $(\mathrm{mS} / \mathrm{m})$ may be converted to millimhos per meter (mmho/m) as follows: $1 \mathrm{mmho} / \mathrm{m}=1 \mathrm{mS} / \mathrm{m}$.

Electrical conductivity in siemens per meter $(\mathrm{S} / \mathrm{m})$ may be converted to electrical resistivity in ohm-meters $(\Omega \mathrm{m})$ as follows: $\Omega \mathrm{m}=1 /(\mathrm{S} / \mathrm{m})$.

\section{List of Acronyms}

$\begin{array}{ll}\text { AFB } & \text { Air Force Base } \\ \mathrm{dB} / \mathrm{m} & \text { Decibel per meter } \\ 0 & \text { Degree } \\ \mathrm{EM} & \text { Electromagnetic } \\ \mathrm{g} / \mathrm{L} & \text { Grams per liter } \\ \mathrm{GPR} & \text { Ground-penetrating radar } \\ \mathrm{m} / \mu \mathrm{s} & \text { Meter per microsecond } \\ \mathrm{mg} / \mathrm{L} & \text { Milligram per liter } \\ \mathrm{MHz} & \text { Megahertz } \\ \mathrm{NaCl} & \text { Sodium chloride } \\ \mathrm{NAPL} & \text { Non-aqueous phase liquid } \\ \mathrm{ns} & \text { Nanosecond } \\ \mathrm{PCE} & \text { Tetrachloroethene } \\ \mathrm{PVC} & \text { Polyvinyl chloride }\end{array}$




$\begin{array}{ll}\text { SER } & \text { Steam-enhanced remediation } \\ \text { SIRT } & \text { Simultaneous iterative reconstruction technique } \\ \text { S/m } & \text { Siemen per meter } \\ \text { TCE } & \text { Trichloroethene } \\ \mu S & \text { Microsecond } \\ \text { USEPA } & \text { U.S. Environmental Protection Agency } \\ \text { USGS } & \text { U.S. Geological Survey }\end{array}$


This page has been left blank intentionally. 


\title{
Use of Borehole-Radar Methods to Monitor a Steam- Enhanced Remediation Pilot Study at a Quarry at the Former Loring Air Force Base, Maine
}

\author{
By Colette Grégoire, Peter K. Joesten, and John W. Lane, Jr.
}

\section{Abstract}

Single-hole radar reflection and crosshole radar tomography surveys were used in conjunction with conventional borehole-geophysical methods to evaluate the effectiveness of borehole-radar methods for monitoring the movement of steam and heat through fractured bedrock. The U.S. Geological Survey, in cooperation with U.S. Environmental Protection Agency (USEPA), conducted surveys in an abandoned limestone quarry at the former Loring Air Force Base during a field-scale, steam-enhanced remediation (SER) pilot project conducted by the USEPA, the U.S. Air Force, and the Maine Department of Environmental Protection to study the viability of SER to remediate nonaqueous phase liquid contamination in fractured bedrock.

Numerical modeling and field experiments indicate that borehole-radar methods have the potential to monitor the presence of steam and to measure large temperature changes in the limestone matrix during SER operations. Based on modeling results, the replacement of water by steam in fractures should produce a decrease in radar reflectivity (amplitude of the reflected wave) by a factor of 10 and a change in reflection polarity. In addition, heating the limestone matrix should increase the bulk electrical conductivity and decrease the bulk dielectric permittivity. These changes result in an increase in radar attenuation and an increase in radarwave propagation velocity, respectively.

Single-hole radar reflection and crosshole radar tomography data were collected in two boreholes using 100-megahertz antennas before the start of steam injection, about 10 days after the steam injection began, and 2 months later, near the end of the injection. Fluid temperature logs show that the temperature of the fluid in the boreholes increased by $10^{\circ} \mathrm{C}$ (degrees Celsius) in one borehole and $40^{\circ} \mathrm{C}$ in the other; maximum temperatures were measured near the bottom of the boreholes.

The results of the numerical modeling were used to interpret the borehole-radar data. Analyses of the singlehole radar reflection data showed almost no indication that steam replaced water in fractures near the boreholes because (1) no change of polarity was observed in the radar reflections; (2) variations in the measured traveltimes were unsubstantial; and (3) most of the observed decreases in reflectivity were too small to have resulted from the replacement of water by steam. Analyses of the crosshole radar tomography data also support the conclusion that steam did not replace water in the fractures around the boreholes because traveltime-difference and attenuation-difference tomograms showed only small decreases in velocity and small increases in attenuation accompanying the steam injection.

The radar data are consistent with an increase in the conductivity of the limestone as a result of heating of the limestone matrix near the boreholes. Single-hole radar reflection data collected near the end of the steam injection near the bottom of the borehole with the largest temperature increase showed substantial attenuation. Also, reflector analysis showed small decreases in the amplitudes of radarwave reflections in data collected before injection and data collected near the end of the collection period. In the crosshole radar tomography data, decreases in velocity and small increases in attenuation also are consistent with temperature increases in the matrix.

\section{Introduction}

The Loring Air Force Base (AFB) in Limestone, Aroostook County, Maine (fig. 1), opened in 1953 as part of the U.S. Air Force Strategic Air Command. The base, which supported operations of long-range bombers, air-refueling tankers, and airborne command centers during the cold war, was closed in 1995. An abandoned limestone quarry on the base was used for storage of more than 400 drums of used solvents, mostly tetrachloroethene (PCE). Ground water in the fractured limestone bedrock underlying Loring AFB was found to be contaminated with chlorinated solvents and petroleum products. Chemical analyses from the site indicate PCE concentrations as high as $30 \mathrm{mg} / \mathrm{L}$ (milligrams per liter) 


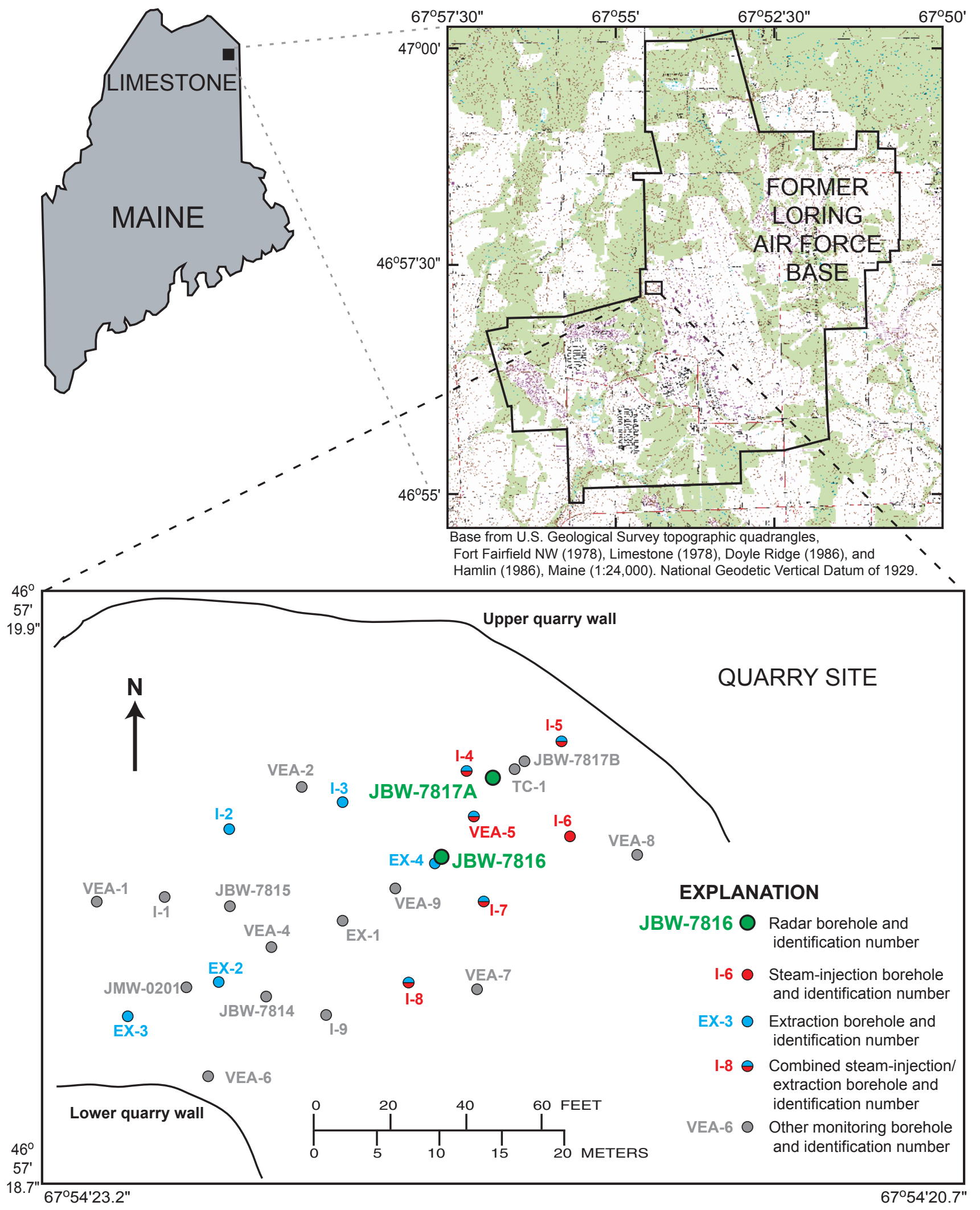

Figure 1. Location of the boreholes at the former Loring Air Force Base quarry site, Limestone, Maine. The single-hole radar refection and crosshole radar tomography surveys were carried out in boreholes JBW-7816 and JBW-7817A. 
(SteamTech Environmental Services, Inc., 2001). Smaller amounts of trichloroethene (TCE), vinyl chloride, carbon tetrachloride, benzene, toluene, naphthalene, and other diesel and gasoline products also were detected.

Remediation efforts at the site include a field-scale pilot study to evaluate the effectiveness of steam-enhanced remediation (SER) for removal of non-aqueous phase liquid (NAPL) contamination from fractured bedrock. SER is an innovative remediation technology designed to capitalize on thermodynamic changes resulting from steam injection and to promote the removal of volatile and semi-volatile organic contaminants from the unsaturated and saturated zones. Steam injection and the resulting underground heating promote (1) an increase in NAPL volatility and therefore vaporization; (2) a decrease in NAPL adsorption to rock or soil particles; (3) a decrease in interfacial tension between NAPLs and ground water; (4) a decrease in NAPL viscosity; and (5) an increase in NAPL solubility (Stewart and Udell, 1988; Udell, 1996; Davis, 1997). Field applications of SER have been documented by Newmark and Aines (1994), Itamura and Udell (1995), and SteamTech Environmental Services, Inc. (1999).

The U.S. Geological Survey (USGS), in cooperation with the U.S. Environmental Protection Agency (USEPA), conducted a study to evaluate the effectiveness of boreholeradar methods to monitor the movement of steam and transport of heat in the subsurface during the SER pilot study. Results of theoretical calculations were used to assess the effectiveness of radar methods in monitoring SER operations and to support interpretation of the radar field data.

\section{Purpose and Scope}

The purpose of this report is to (1) present numerical modeling of the effects of heat and replacement of water by steam on radar-wave velocity and attenuation, (2) describe the borehole-geophysical methods used in this study, and (3) interpret the results of single-hole radar reflection and crosshole radar tomography surveys.

Numerical modeling was used to predict the changes in radar-wave velocity and attenuation that could be expected from heating the fluid in fractures and the limestone matrix, from steam replacing water in the fractures, and from changes in the conductive properties of the fluid in fractures. The effect of heating on the reflectivity from fractures also was modeled. The modeling results provided a basis for theoretically assessing the effectiveness of radar methods to monitor SER operations, and for interpreting the radar field data.

Borehole-radar data were collected in two boreholes at the study site. Single-hole radar reflection and crosshole radar tomography data were collected in August, September, and November 2002, prior to steam injection, about 10 days after steam injection started, and near the end of steam injection, respectively. Conventional borehole-geophysical data were collected to supplement the radar data. Fluid temperature and electromagnetic (EM) conductivity were used to monitor the changes in conditions in and near the boreholes. Deviation data also were collected in the boreholes, which was critical for the accuracy of the tomographic inversions.

The radar data were processed and examined for changes in radar velocity, attenuation, and reflectivity. The results of the numerical modeling were used to interpret the changes in the radar data in terms of changes in material properties caused by the steam and heating.

\section{Description of Study Area}

The SER pilot study at the former Loring AFB was conducted at an abandoned limestone quarry in the northwest corner of the base (fig. 1). The quarry is divided topographically into three areas, or tiers, at approximate elevations of 216, 225, and $236 \mathrm{~m}$ (meters). The lowest tier is covered by water that drains to a small stream flowing to the west of the quarry. Contamination has been detected in monitoring boreholes on all three tiers.

Bedrock at the quarry is the Carys Mill Formation, principally a limestone of Paleozoic age (Stephenson and Novakowski, 2003). The Carys Mills Formation consists of interbedded layers of dark to light gray, laminated and non-laminated micritic limestone and light gray, massive calcareous slate and pelites in which calcite veins are abundant (Pavlides, 1968; Roy, 1980; Osberg and others, 1985; Lane and others, 1996). Stephenson and Novakowski (2003) identified a north-south trending anticline with a shallow plunge to the north and a steeply dipping normal fault trending northwest-southeast through the area. The dominant bedding dips east-northeast at $20-50^{\circ}$ (degrees).

Three primary fracture sets were identified in the quarry: (1) bedding-plane fractures having an aperture of approximately $0.15 \mathrm{~mm}$, (2) northeast-trending joints with apertures of $0.05 \mathrm{~mm}$, and (3) axial planar fractures with apertures of approximately $0.05 \mathrm{~mm}$. At depths shallower than $25 \mathrm{~m}$ below ground surface, fractures and joints are flanked by visible weathering zones that extend up to $12 \mathrm{~mm}$ into the surrounding rock (SteamTech Environmental Services, Inc., 2001). These fractures were considered to be the preferential pathways for the steam. The efficiency of the SER method depends on the fracture characteristics and their interconnectivity. The porosity of the unweathered matrix is about 0.02-0.5 percent (SteamTech Environmental Services, Inc., 2001).

\section{Theory of the Borehole-Radar Method}

Ground-penetrating radar (GPR) methods use highfrequency EM waves to image the subsurface. GPR waves have frequencies ranging from 10 to $2,000 \mathrm{MHz}$ (megahertz), with corresponding wavelengths ranging from meters to centimeters in earth materials. In borehole GPR surveying, 
a radar pulse is transmitted from the borehole radar antenna radially outward into the rock surrounding the borehole. When the EM wave encounters a contrast in electrical properties associated with the presence of a fracture or lithologic contact, part of the wave energy is reflected back toward the borehole while the remainder of the wave energy is transmitted further into the bedrock. Radar methods can be used in numerous transmitter-receiver configurations. Information about subsurface structure and properties is obtained by analyzing the characteristics of the EM wave recorded by the receiving antenna, including direct-arrival traveltime, direct-arrival amplitude, reflection traveltimes, reflection amplitudes, and reflection polarity. Two borehole-radar methods were used in this study: single-hole radar reflection and crosshole radar tomography.

\section{Reflection Mode}

Single-hole radar reflection methods have been used for fracture characterization at nuclear waste repositories (Olsson and others, 1988, 1992a; Sandberg and others, 1991; Olsson and others, 1992b) and in ground-water investigations (Haeni and others, 1993; Lane and others, 1994; Lane and others, 2001).
In single-hole radar reflection logging, radar transmitter and receiver antennas are connected together as one logging tool (fig. 2). The two antennas are separated by a fixed distance and moved vertically inside the borehole. EM waves propagate from the transmitter antenna radially outward, and reflected waveform data are recorded at the receiver antenna as a function of time.

Radar reflection logging can be conducted with either omni-directional or directional receiver antennas. Omnidirectional receiver antennas provide information regarding the depth and dip of reflectors, but do not allow interpretation of the strike orientation of the reflector. Directional receiver antennas can indicate reflector orientation using dual-loop antennas, which act as four different orthogonal receivers coupled with a three-component magnetometer, and a plunge sensor which monitor the orientation of the tool in the borehole. The sensitivity and effective radial penetration of directional receiver antennas, however, are inferior to those of omni-directional dipole receiver antennas (Falk, 1992; Lane and others, 2001).

An important strength of radar reflection logging is the ability to identify features that do not intercept the borehole. A second strength is the high resolution; in some cases, centimeter-scale features may be resolved. The effectiveness of the method is limited by several factors related to the
A.

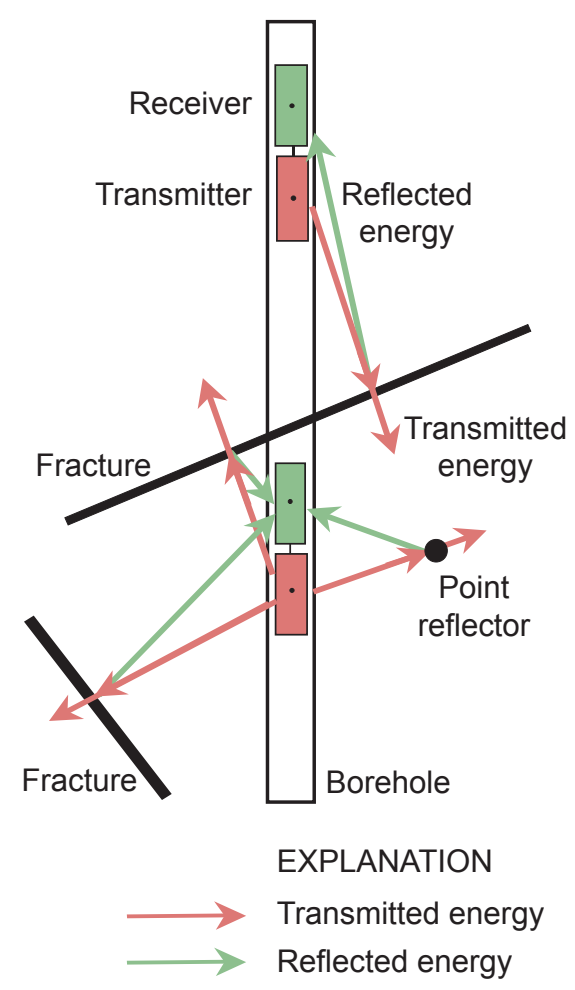

B.

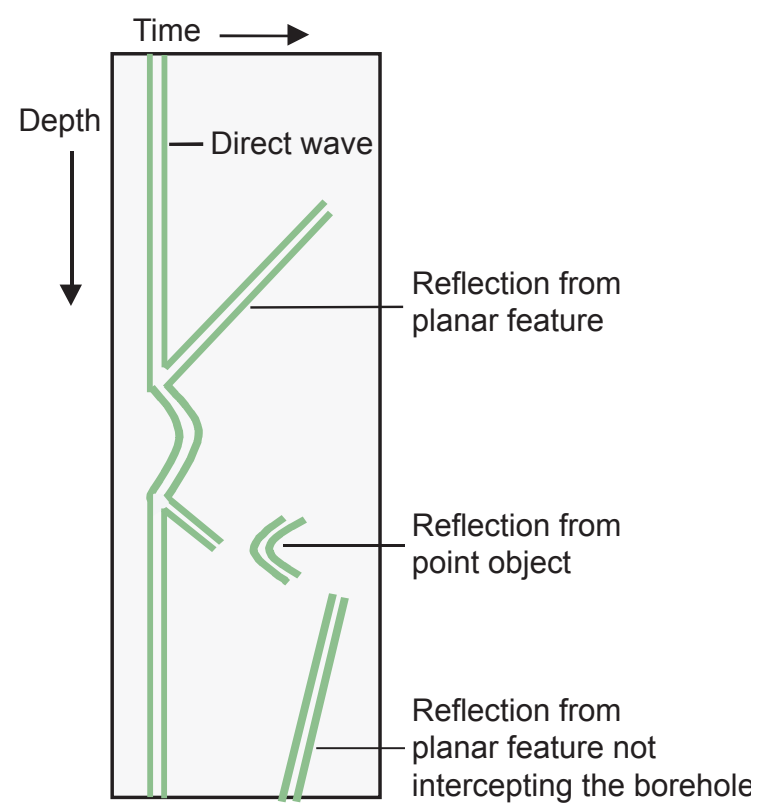

Figure 2. (A) Transmitter and receiver antenna arrangement for single-hole radar reflection logging, and $(B)$ typical reflection patterns from planar and point reflectors. 
antennas and the properties of the rock. The frequency, $f$, of waves propagated by the transmitter antenna, and the electrical conductivity, $\sigma$, of the rock are especially important. The depth of penetration of radar waves varies inversely with frequency and electrical conductivity; thus, for high frequencies or electrically conductive rocks, the radial penetration distance is lower. The resolution is related to the EM wavelength, $\lambda$, which is controlled by the frequency and the velocity, $v$, of EM waves in the rock medium (for example, Daniels, 1989):

$$
\lambda=v / f
$$

The minimum size of a detectable target is proportional to the wavelength of the transmitted signal; thus, in selecting the antenna frequency, there is a trade-off between resolution and the penetration depth. In this study, 100-MHz radar antennas were used; the wavelength was approximately $1 \mathrm{~m}$ and the radius of penetration was about $8 \mathrm{~m}$ from the borehole.

\section{Tomography Mode}

A tomogram is an image designed to estimate EM properties in the plane between two boreholes. Tomographic images are created from radar data collected in tomography (or transmission) mode between the boreholes (fig. 3). When collecting radar data in tomography mode, the transmitting antenna is moved vertically to successive positions in one borehole and the receiver is moved vertically to successive positions in a second borehole.

A crosshole survey called a "levelrun" represents a simplified configuration where both antennas are located at the same depth (fig. 3A). Levelrun surveys are faster than full tomography surveys because fewer raypaths are collected; however, they provide less information than tomographic surveys about the spatial variation of rock properties and can only detect changes with depth.

The tomography configuration (fig. 3B) covers the entire plane between the boreholes with raypaths; the number of rays depends on the length of the boreholes, distance between boreholes, and the separation distance between the antenna positions. Tomography data can be interpreted to provide information about both horizontal and vertical variations in the EM properties of the medium. The resolution of the method is limited by the number and orientations of raypaths, the offset distance between boreholes, the data quality, and regularization criteria applied in the data inversion (Bregman and others, 1989a, 1989b; Williamson and Worthington, 1993; Rector and Washbourne, 1994; Day-Lewis and others, 2002; Day-Lewis and Lane, 2004).
A.

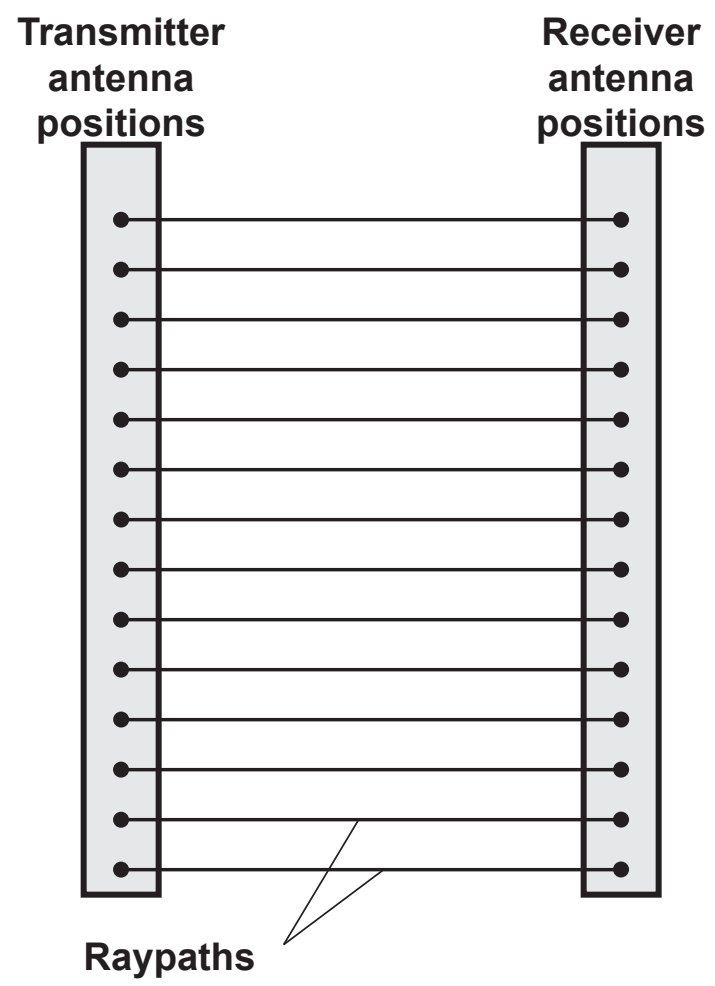

B.

$\begin{array}{cc}\text { Transmitter } & \text { Receiver } \\ \text { antenna } & \text { antenna } \\ \text { positions } & \text { positions }\end{array}$

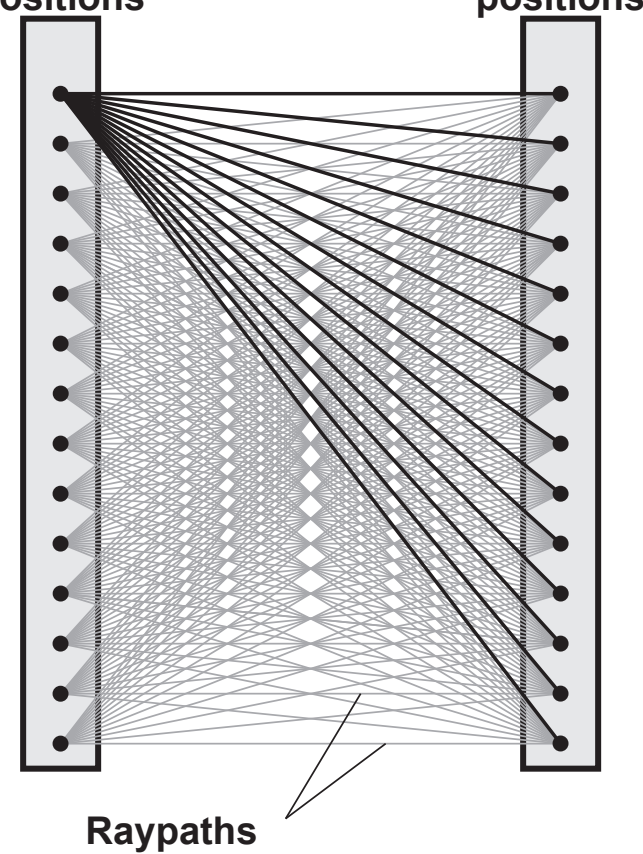

Figure 3. Configurations for collection of crosshole radar tomography data. $(A)$ Crosshole "levelrun" data collection. $(B)$ Tomography data collection. 
The traveltime and amplitude of waveform traces are recorded for each raypath. These correspond to a mean velocity and a mean attenuation, respectively, along a given path. The inter-borehole region is discretized as a pixelated grid, and the lengths of the raypaths in each cell are calculated. Using tomographic-inversion methods (for example, Dines and Lytle, 1979; Stewart, 1992), cross-sectional images of EM velocity and attenuation are estimated from traveltime and amplitude measurements, respectively.

At high frequencies (short wavelengths) and low-loss (low attenuation) mediums, the radar wave velocity and attenuation are approximated and related to the electric and dielectric properties by (for example, Davis and Annan, 1989; Reynolds, 1997):

$$
v \approx \frac{c}{\sqrt{\varepsilon_{r}}},
$$

and

$$
\alpha \approx \frac{4.343 \mu v}{\rho},
$$

where

$$
\begin{array}{ll}
v & \text { is the velocity in meters per second, } \\
c & \text { is the velocity of light in meters per second, } \\
\varepsilon_{\mathrm{r}} & \text { is the relative permittivity, } \\
\alpha & \text { is the attenuation in decibels per meter, } \\
\mu & \text { is magnetic permeability in henries } \\
& \text { per meter, }
\end{array}
$$

and

$$
\rho \quad \text { is the resistivity in ohm-meters. }
$$

The attenuation of EM waves is strongly dependent on the electrical conductivity of the medium; thus, penetration distance is low in electrically conductive materials, such as clay or shale, whereas penetration distance is high in low-conductivity materials, such as clean limestone or granitic rocks.

The quality of resolution of radar-tomography methods depends on good raypath coverage of the plane between the boreholes. The reliability of tomographic estimates of velocity or attenuation varies over the image plane, with the largest errors (artifacts) expected at the top and the bottom of the image, where the raypath coverage is poor.

\section{Theoretical Modeling of the Temperature Dependence of Radar- Frequency EM-Wave Propagation}

The physical properties that affect radar frequency EM-wave propagation are temperature dependent. Analytic theoretical models were developed to predict the changes in EM-wave propagation velocity and attenuation that could be expected from heating limestone bedrock and fracture fluid, from steam replacing water in the fractures, and from changes in the conductive properties of the fluid in fractures. The effect of heating on EM-wave reflectivity of fractures was also modeled. The modeling results were used as a basis for interpreting the results of radar reflection and tomography surveys collected at Loring AFB.

\section{Constitutive Parameters}

Measurable characteristics of radar-wave propagation include EM-wave velocity, attenuation, polarity (phase), and reflectivity. These characteristics are determined by the constitutive parameters (physical properties) of the host material. For radar-frequency EM-waves, these physical properties are the dielectric permittivity, $\varepsilon$, in farads per meter; the electrical conductivity, $\sigma$, in siemens per meter; and the magnetic permeability, $\mu$, in henries per meter. In most nonferromagnetic earth materials, the magnetic permeability is equal to that of a vacuum; therefore, the effect of magnetic permittivity on EM-wave propagation is assumed to be insignificant and can be ignored.

In practice, it is difficult to differentiate the currents resulting from polarization effects (dielectric permittivity) and those resulting from conduction effects (electrical conductivity). For this reason, effective parameters need to be defined-effective permittivity and effective conductivitywhich are complex numbers. In the case of radar, the effective permittivity, $\varepsilon_{\mathrm{e}}$, is more commonly used (for example, Grégoire, 2001):

$$
\begin{aligned}
& \varepsilon_{e}=\varepsilon_{e}{ }^{\prime}-i \varepsilon_{e}{ }^{\prime \prime} \\
& \varepsilon_{e}{ }^{\prime}=\varepsilon^{\prime}+\frac{\sigma^{\prime \prime}}{\omega} \\
& \varepsilon_{e}^{\prime \prime}=\varepsilon^{\prime \prime}+\frac{\sigma^{\prime}}{\omega},
\end{aligned}
$$

where

$\varepsilon_{e}^{\prime} \quad$ is the real part of the effective dielectric
$\varepsilon_{e}^{\prime \prime} \quad$ is the imaginary part of the effective dielectric
$\varepsilon^{\prime} \quad$ is the real part of the dielectric permittivity,
$\sigma^{\prime \prime} \quad$ is the imaginary part of the electrical
$\quad \quad$ conductivity,
$\omega \quad$ is the frequency,
$\varepsilon^{\prime \prime} \quad$ is the imaginary part of the dielectric
$\quad$ permittivity,

and
$\sigma^{\prime} \quad$ is the real part of the electrical conductivity.

In the expression for the real part of the effective dielectric permittivity, the term $\sigma^{\prime \prime} / \omega$ can be neglected for most radar applications, where the electrical conductivity is low and frequency is high, resulting in $\varepsilon_{\mathrm{e}}^{\prime} \sim \varepsilon^{\prime}$. 
The wave number, $k$, depends on the effective dielectric permittivity. The real part is the frequency-dependent phase number, $\beta$, and the imaginary part is the attenuation, $i \alpha$ (for example, Knight, 2001):

$$
k=\omega \sqrt{\mu \varepsilon_{e}}=\beta-i \alpha
$$

Taking into account the effective parameters, the wave velocity, $v$, is expressed (for example, Knight, 2001):

$$
v=\frac{\omega}{\beta}
$$

\section{Effect of Heating on Radar-Frequency EM-Wave Velocity and Attenuation}

The velocity and attenuation of radar-frequency EM-waves propagating in a medium are related to the electric properties-the dielectric permittivity and the electrical conductivity. Theoretical calculations were used to examine the effect of heating on the material properties of the material in the fractures and of the rock matrix. Mixing formulas were used to calculate the apparent permittivity and conductivity as a function of the medium porosity and the fracture-filling fluids, and these results were used to develop theoretical predictions of the effect of heating on the measurable quantities-EM-wave traveltime (velocity) and amplitude (attenuation).

The relative dielectric permittivity, $\varepsilon_{r}$, of a rock formation is a function of the permittivity of the rock matrix, the porosity, and the permittivity of the pore fluid (water, or steam if steam replaces the water). To predict the relative permittivity of the formation, we used the complex refractive index method (CRIM) (Birchak and others, 1974; Wharton and others, 1980), assuming electrical conductivity effects are negligible and EM-wave propagation velocity is controlled by the real components of the relative dielectric permittivity of the rock matrix and water (for example, Grégoire, 2001; Knight, 2001):

$$
\varepsilon_{r}^{0.5}=\phi \varepsilon_{w}^{0.5}+(1-\phi) \varepsilon_{m}^{0.5}
$$

where

$$
\begin{aligned}
& \phi \quad \text { is the porosity, } \\
& \varepsilon_{w} \quad \text { is the relative dielectric permittivity of water } \\
& \text { or steam, depending on temperature, }
\end{aligned}
$$

and

$$
\begin{aligned}
& \varepsilon_{m} \quad \text { is the relative dielectric permittivity of the } \\
& \text { rock matrix. }
\end{aligned}
$$

The permittivities of rock and water are functions of temperature. The dielectric permittivity of water decreases with increasing temperature, $T$ (in degrees Celsius) (Helgeson and Kirkham, 1974), increasing EM-wave velocity (fig. 4A):

$$
\varepsilon_{w}=-0.3972 \times T+88.7 .
$$

The bulk electrical conductivity, $\sigma$, of a water-filled porous medium depends on the electrical conductivities of the water and host matrix, both of which increase with temperature. For this study, a simple conductivity mixing model was used:
A.

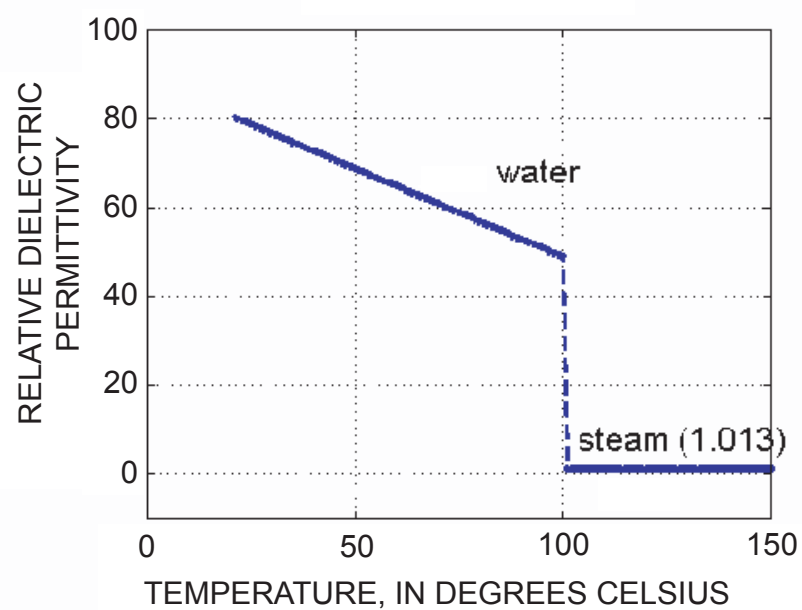

B.

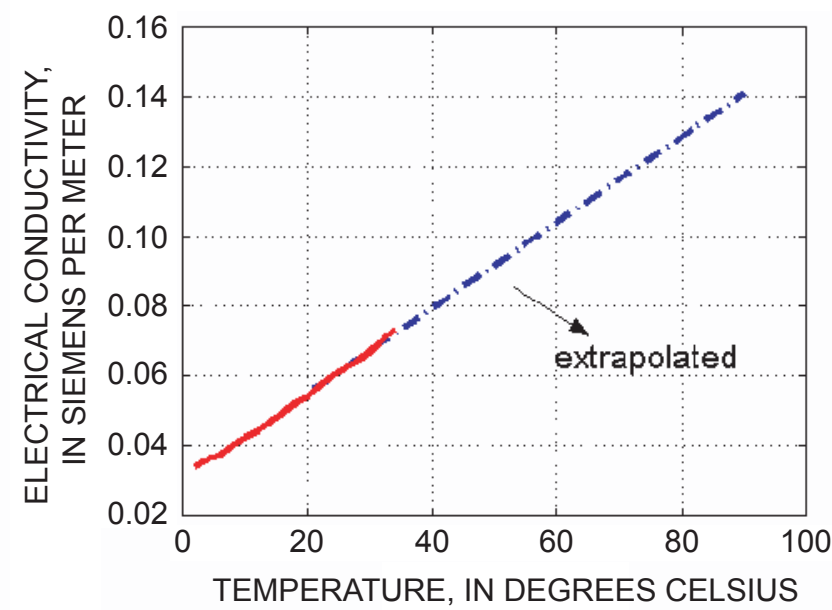

Figure 4. (A) Relative dielectric permittivity, and $(B)$ electrical conductivity of water as a function of temperature. The conductivity curve was extrapolated for temperatures above 35 degrees Celsius. 


$$
\sigma=(1-\phi) \sigma_{m}+\phi \sigma_{w}
$$

where

$\sigma_{m}$ is the electrical conductivity of the matrix,

and

$\sigma_{w} \quad$ is the electrical conductivity of the water

The pore water was modeled as a solution of sodium chloride $(\mathrm{NaCl})$, and the conductivity was modeled as a function of $\mathrm{NaCl}$ concentration and temperature following the methods described by Olhoeft (G.R. Olhoeft, Colorado School of Mines, written commun., 2002). This curve was extrapolated to a temperature of $90^{\circ} \mathrm{C}$ (fig. 4B). For a solution with a concentration of $0.2923 \mathrm{~g} / \mathrm{L}$ (grams per liter) $\mathrm{NaCl}$ (G.R. Olhoeft, Colorado School of Mines, written commun., 2002), the linear extrapolation of the best-fit line is:

$$
\sigma_{w}=0.001229 \mathrm{~T}+0.03011
$$

For a solution with a concentration of $0.5845 \mathrm{~g} / \mathrm{L} \mathrm{NaCl}$ (G.R. Olhoeft, Colorado School of Mines, written commun., 2002), the linear extrapolation of the best-fit line is:

$$
\sigma_{w}=0.0024 \mathrm{~T}+0.0587
$$

Because steam is generated, the electrical conductivity of steam is negligible.

The relative dielectric permittivity and bulk electrical conductivity of the fractured limestone were calculated using equations (7) and (9). It is difficult to predict the change in conductivity of the rock matrix that will result from the heating associated with the steam injection. The change in conductivity will probably be heterogeneous and localized depending on the fracture network. For this reason, two values were considered for the conductivity of the limestone matrix, 0.01 and $0.02 \mathrm{~S} / \mathrm{m}$ (siemens per meter), to estimate the effect of change in the conductivity on EM-wave velocity and attenuation. The first value for the conductivity of the limestone matrix is based on background EM conductivity measurements, and the second value is an estimate based on the assumption that the conductivity might increase in regions that are heated because the solubility of ionic compounds can increase with heating. For the water in the fractures, the relative dielectric permittivity and electrical conductivity of water were calculated using equations (8) and (10). The total porosity was simulated as 0.02 percent (SteamTech Environmental Services, Inc., 2001). The relative dielectric permittivity of limestone was simulated as 7.2 , which is a reasonable value for limestone.

The predicted permittivity and conductivity of the fractured limestone are shown in figure 5. Assuming a frequency of $100 \mathrm{MHz}$ and a constant value of $0.01 \mathrm{~S} / \mathrm{m}$ for the limestone matrix conductivity, the velocity and attenuation of the EM waves were calculated using equations (2) and (3). For temperatures between 20 and $100^{\circ} \mathrm{C}$, the effect of heating on the velocity and attenuation of the EM waves is low. For an increase of temperature of the limestone from 20 to $100^{\circ} \mathrm{C}$, the predicted increase in the attenuation is about $1 \mathrm{~dB} / \mathrm{m}$ (decibel per meter), less than a 15-percent change (fig. 5D). For a transmitter-receiver distance of $7.5 \mathrm{~m}$, the EM-wave traveltime would decrease about 1 ns (nanosecond) from background measurements, increasing EM-wave velocity about 1.3 percent (fig. 6). The predicted magnitudes of these changes are small because of the low primary and secondary (fracture) porosity of the limestone.

Replacement of water by steam at temperatures above $100^{\circ} \mathrm{C}$ results in a substantial increase in EM-wave velocity and a small decrease in attenuation (figs. 5C and D). The theoretical modeling predicts that, for a transmitter-receiver distance of $7.5 \mathrm{~m}$, the traveltime would decrease about $3 \mathrm{~ns}$, increasing EM-wave velocity about 4 percent, whereas EM-wave attenuation would decrease by less than $1 \mathrm{~dB} / \mathrm{m}$ (figs. 5D and 6).

Doubling the electrical conductivity of the limestone matrix from 0.01 to $0.02 \mathrm{~S} / \mathrm{m}$ at a given temperature produces a large increase in EM-wave attenuation (about $6 \mathrm{~dB} / \mathrm{m}$ ) (figs. 5C and D) and a small decrease in EM-wave velocity of about 1.5 percent (fig. 6).

The sensitivity of EM velocity and attenuation to the effects of heating on the electrical conductivity and the dielectric permittivity of water and the electrical conductivity of limestone also was simulated. The permittivity of the limestone matrix was simulated as a constant of 7.2. The initial values for the conductivity and permittivity of the water were assumed to be $0.05 \mathrm{~S} / \mathrm{m}$ and 80.75 at $20^{\circ} \mathrm{C}$, respectively. The initial value for the conductivity of the limestone matrix was assumed to be $0.01 \mathrm{~S} / \mathrm{m}$.

An increase in the conductivity of the limestone matrix from 0.01 to $0.10 \mathrm{~S} / \mathrm{m}$ results in a 25 -percent decrease in EM-wave velocity (from 106 to $80 \mathrm{~m} / \mu \mathrm{s}$ (meters per microsecond)) and an eight-fold increase in EM-wave attenuation $(40 \mathrm{~dB} / \mathrm{m})$ (figs. $7 \mathrm{~A}$ and $7 \mathrm{~B}$, respectively). An increase in matrix conductivity of $0.020 \mathrm{~S} / \mathrm{m}$ results in a decrease in EM-wave velocity of about 5 percent or $5 \mathrm{~m} / \mu \mathrm{s}$.

An increase in the conductivity of the formation water from 0.05 to $0.20 \mathrm{~S} / \mathrm{m}$ results in a small decrease in EM-wave velocity of less than 0.5 percent (about $0.5 \mathrm{~m} / \mu \mathrm{s}$ ) (fig. 7C) because of the low value assumed for the limestone porosity. The corresponding increase in EM-wave attenuation is approximately $1.5 \mathrm{~dB} / \mathrm{m}$ (fig. 7D). Model results for a decrease in the permittivity of water from 80 to 50 as a result of heating show a small increase in EM-wave velocity of about 1.5 percent (from about 106 to about $107.5 \mathrm{~m} / \mu \mathrm{s}$ ) and a slight increase in EM-wave attenuation (about $0.10 \mathrm{~dB} / \mathrm{m}$ ) (figs. $7 \mathrm{E}$ and $7 \mathrm{~F}$, respectively).

\section{Effect of Heating on EM-Wave Reflections from Fractures}

Theoretical analytic calculations were used to predict changes in EM-wave reflections that would be expected as the result of heating the fluid in a fracture. The reflection 
A.

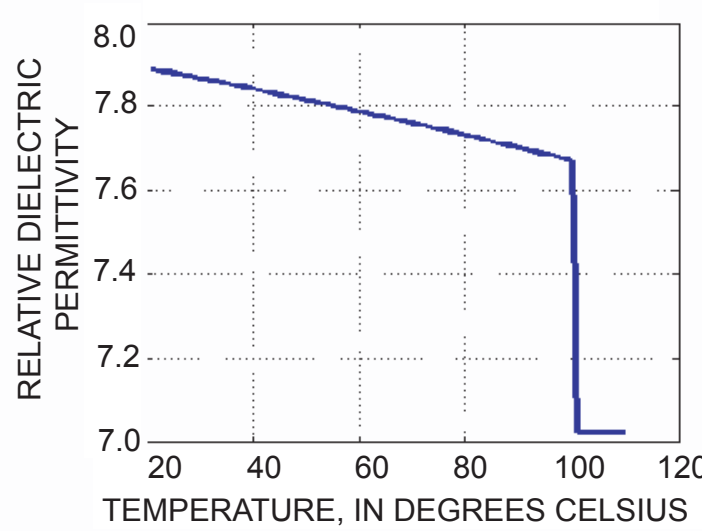

C.

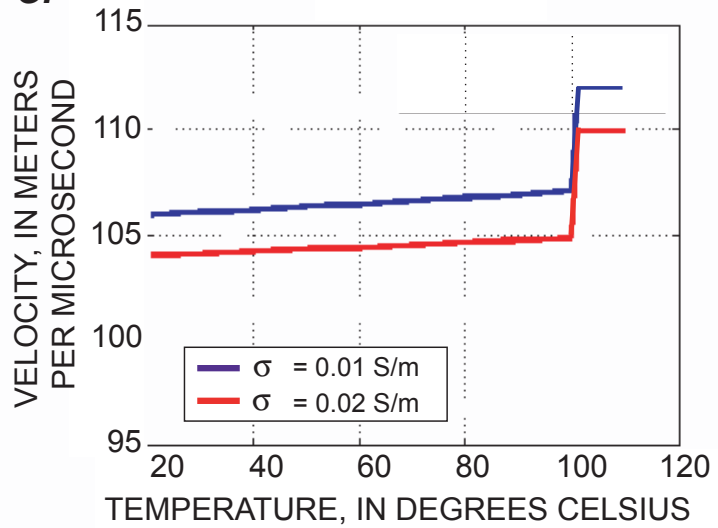

B.

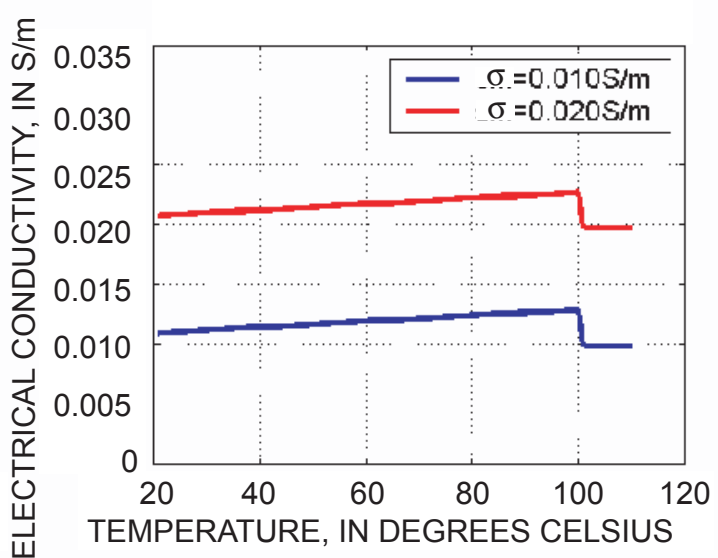

D.

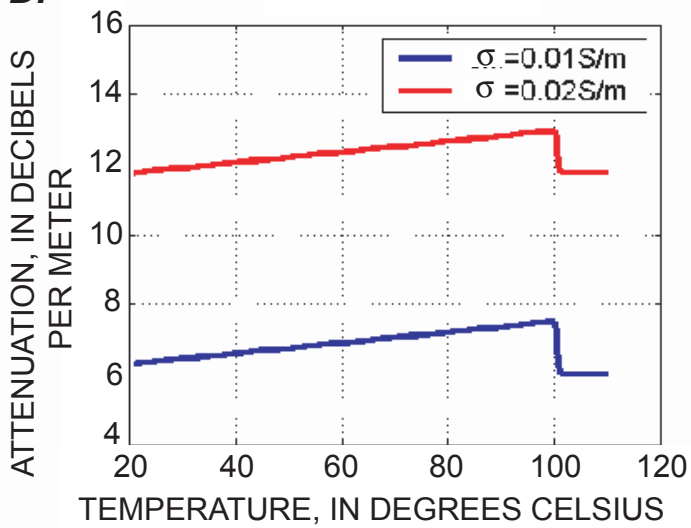

Figure 5. Model results for the $(A)$ relative dielectric permittivity, and $(B)$ electrical conductivity of fractured limestone, and the resultant $(C)$ velocity, and $(D)$ attenuation of 100-megahertz radar waves as a function of temperature and conductivity $(\sigma)$, in siemens per meter $(S / m)$.

coefficient (reflectivity) of a water-filled fracture in limestone

(with $\varepsilon_{\text {water }}=7.2, \sigma_{\text {water }}=0.01 \mathrm{~S} / \mathrm{m}$ ) was calculated as a function of temperature. Above a temperature of $100^{\circ} \mathrm{C}$, steam is assumed to replace the water in the fracture and the electric properties will change $\left(\varepsilon_{\text {steam }}=1.013, \sigma_{\text {steam }}=0.0 \mathrm{~S} / \mathrm{m}\right)$. Fracture openings of several apertures were considered$10 \mathrm{~mm}$ (fig. 8), $5 \mathrm{~mm}$ (fig. 9), $2 \mathrm{~mm}$ (fig. 10), and $1 \mathrm{~mm}$ (fig. 11).

When the water in the fracture is heated, a decrease in the reflection coefficient is predicted, which will decrease the amplitude of a reflected wave relative to background measurements at $20^{\circ} \mathrm{C}$. The ratio between the reflectivity at a given temperature and the reflectivity at $20^{\circ} \mathrm{C}$ was calculated. For a frequency of $100 \mathrm{MHz}$, this ratio is approximately equal to 0.9 at $40^{\circ} \mathrm{C}, 0.8$ at $60^{\circ} \mathrm{C}$, and 0.65 at $100^{\circ} \mathrm{C}$, independent of the aperture (figs. 8B, 9B, 10B, and 11B). Analysis of the reflectivity phase indicates that a change of polarity occurs when steam replaces water. For fractures of aperture $5 \mathrm{~mm}$ or less, the reflection coefficient resulting from a water-filled fracture (less than $100^{\circ} \mathrm{C}$ ) is low-around 0.1 or smaller; for a $1-\mathrm{mm}$ fracture, the predicted reflectivity is about 0.02 . In the case of such small-aperture fractures, the effect of heating will probably be difficult to detect because of the low signal-to-noise ratio common to these measurements.

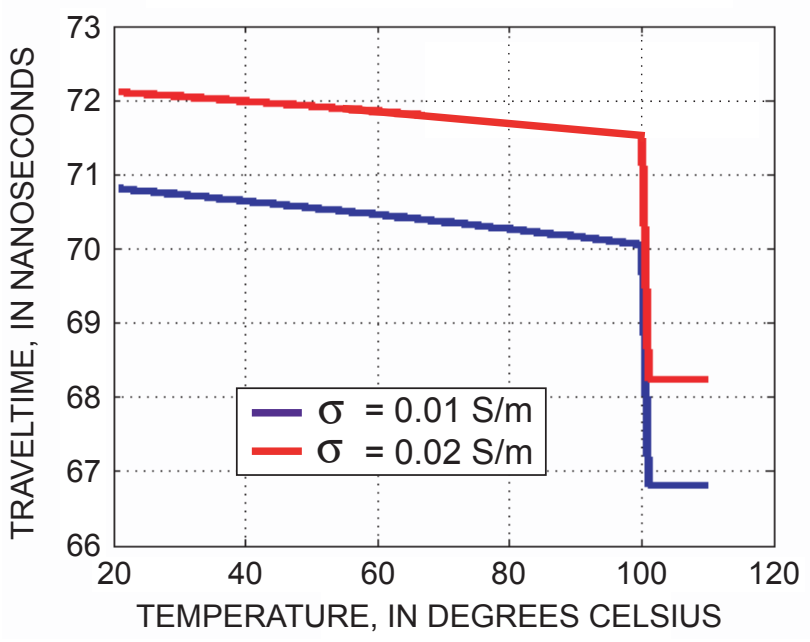

Figure 6. Theoretical results for radar-wave traveltimes as a function of temperature and conductivity $(\sigma)$, in siemens per meter $(\mathrm{S} / \mathrm{m})$, for an antenna-separation distance of 7.5 meters. 
A.

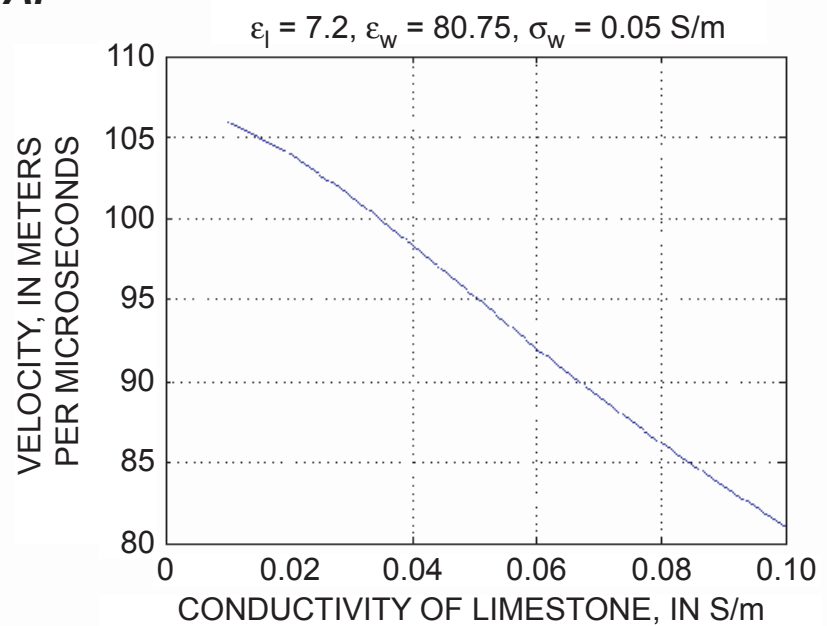

C.

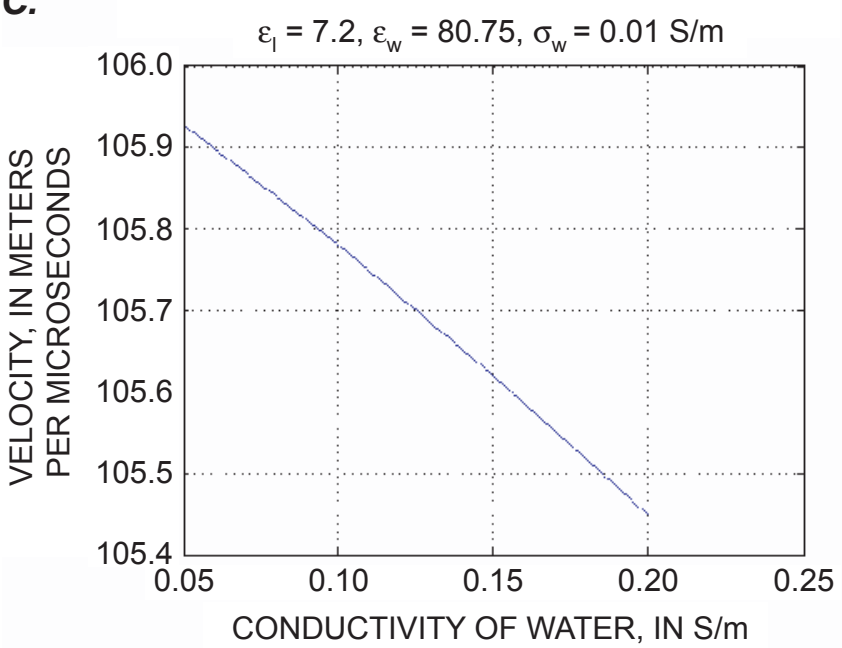

E.

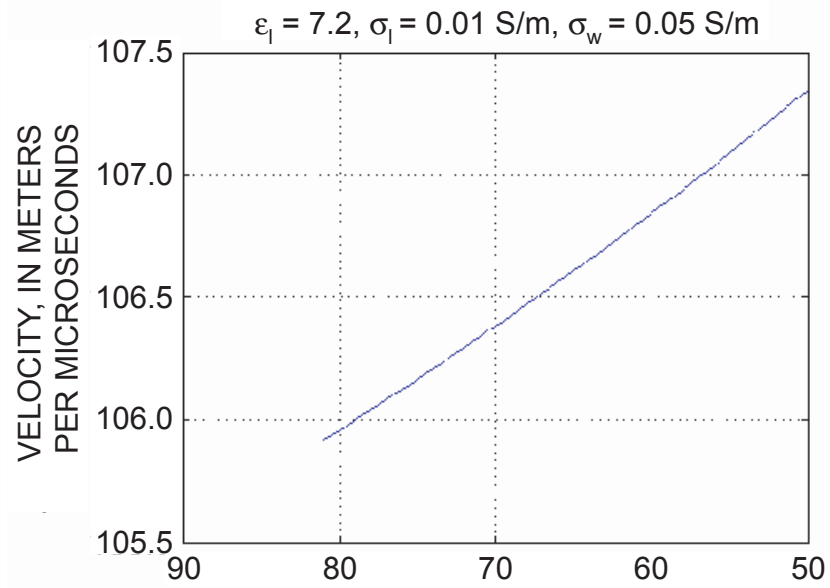

RELATIVE DIELECTRIC PERMITTIVITY OF WATER
B.

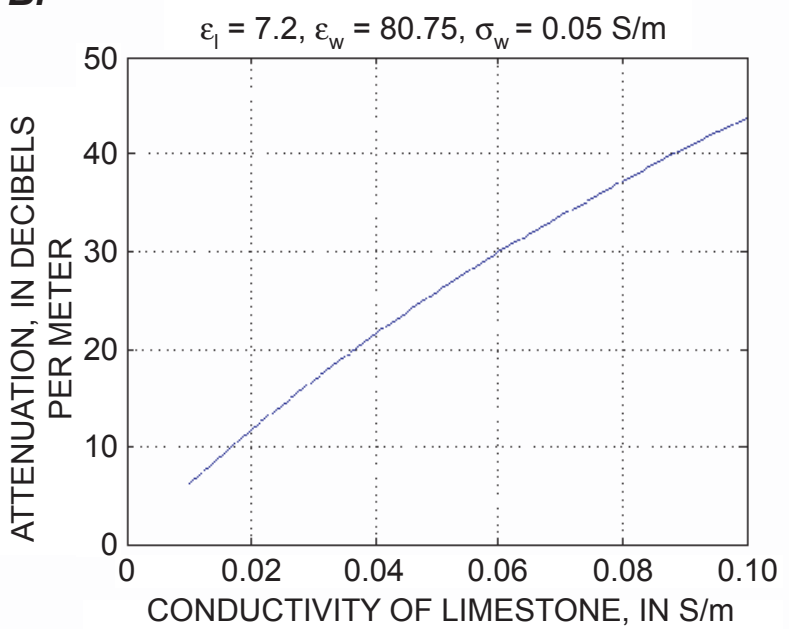

D.

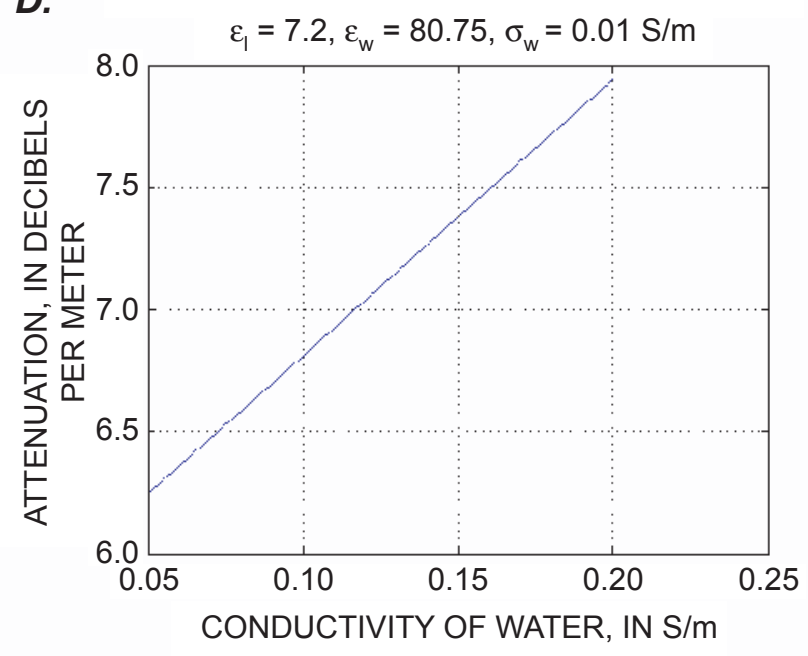

F.

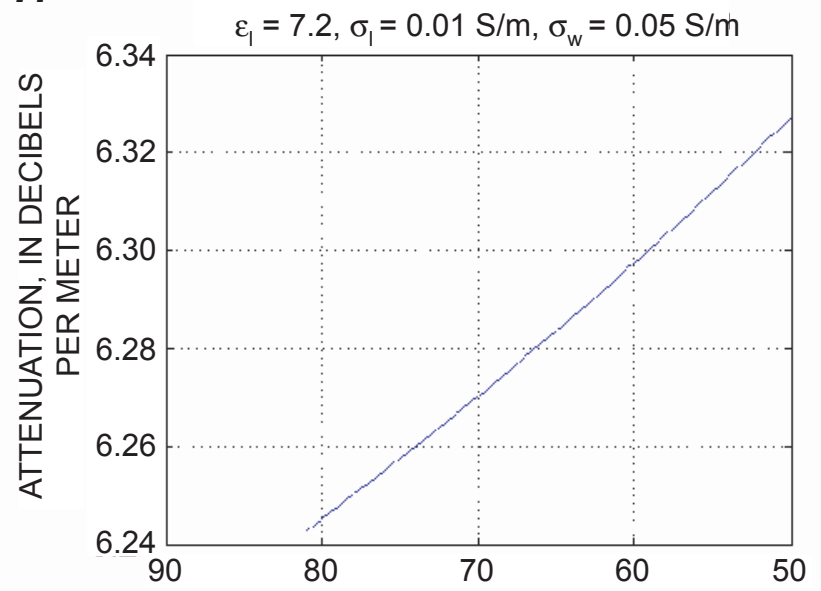

RELATIVE DIELECTRIC PERMITTIVITY OF WATER

Figure 7. Effects of the $(A$ and $B)$ conductivity of limestone, $(C$ and $D)$ conductivity of water, and $(E$ and $F$ relative dielectric permittivity of water on radar-wave velocity and attenuation. $\varepsilon_{1}$ is the relative dielectric permittivity of limestone, $\varepsilon_{w}$ is the relative dielectric permittivity of water, $\sigma_{1}$ is the conductivity of limestone, in siemens per meter $(\mathrm{S} / \mathrm{m})$, and $\sigma_{w}$ is the conductivity of water, in $S / m$. 
A.

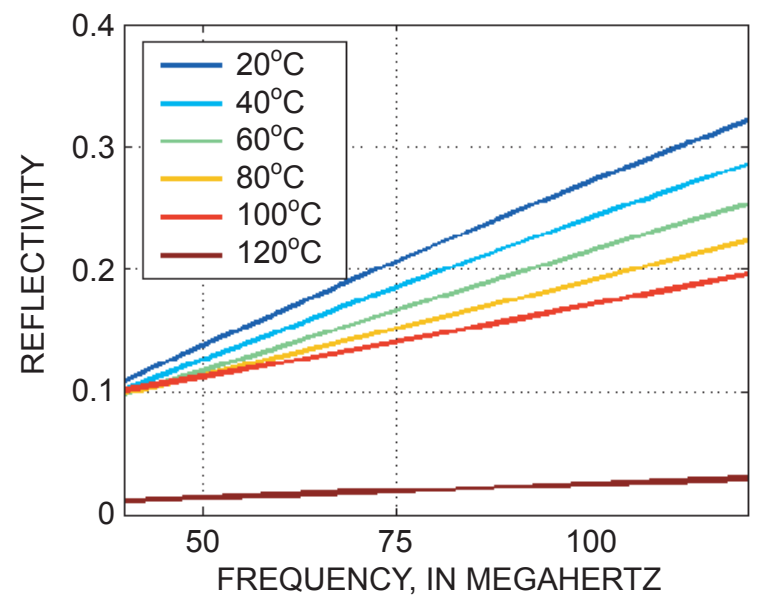

C.

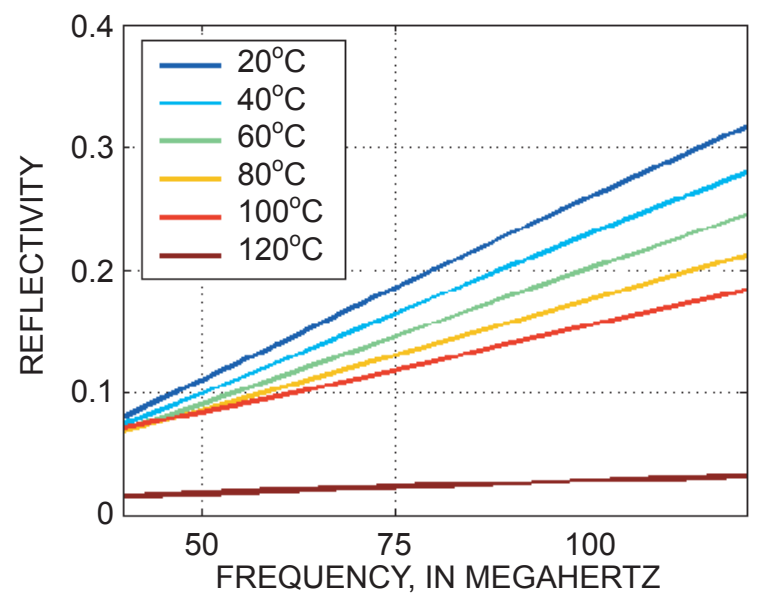

B.

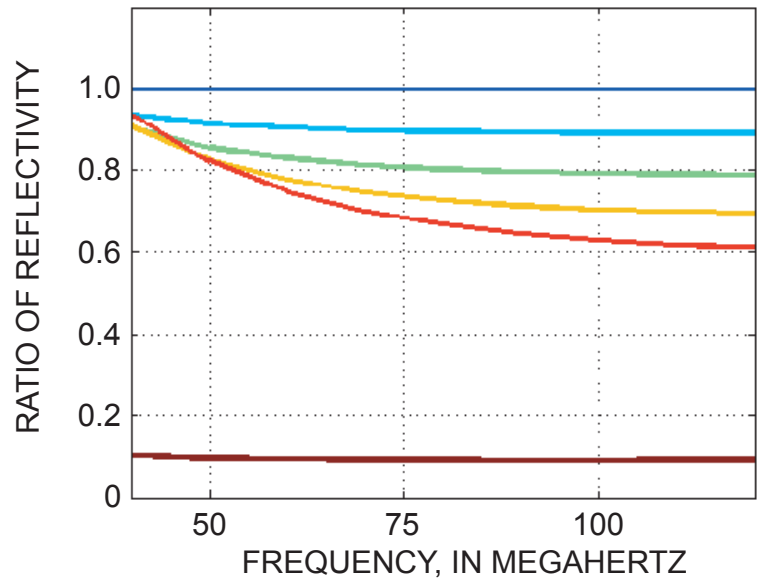

D.

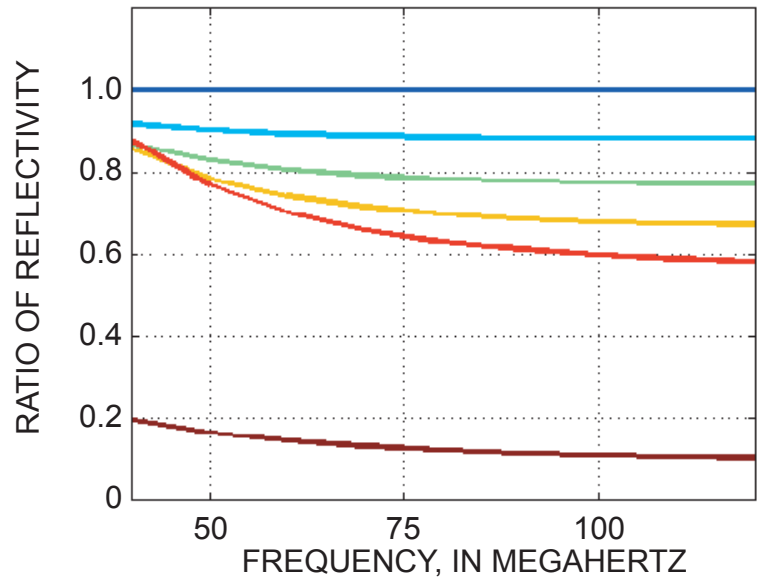

Figure 8. Reflectivity of a 10-millimeter-thick fracture as a function of temperature, and the ratio of the reflectivity at temperature to the reflectivity at 20 degrees Celsius $\left({ }^{\circ} \mathrm{C}\right)$ for formation conductivities of $(A$ and $B)$ 0.01 siemens per meter and $(C$ and $D) 0.03$ siemens per meter.

A.

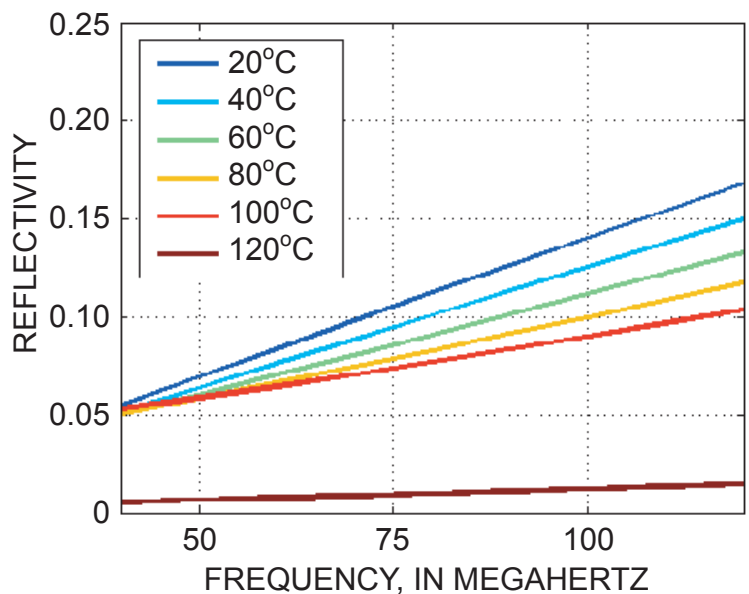

B.

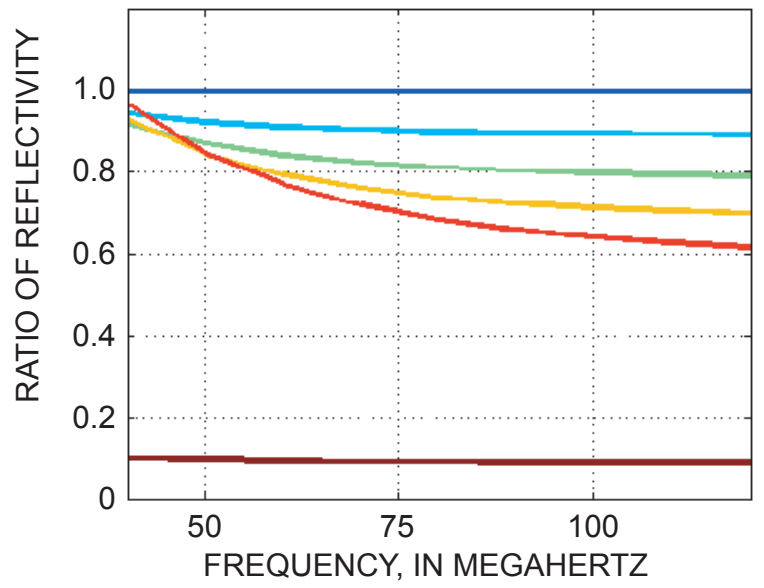

Figure 9. (A) Reflectivity of a 5-millimeter-thick fracture as a function of temperature, and $(B)$ the ratio of the reflectivity at temperature to the reflectivity at 20 degrees Celsius $\left({ }^{\circ} \mathrm{C}\right)$ for a formation conductivity of 0.01 siemens per meter. 
For all fracture openings that were considered, the reflection coefficient of the fracture filled with steam is a factor of 10 lower than the reflection coefficient of the same fracture filled with water. If steam replaces water in a fracture, the reflectivity will become so low that the reflection will likely disappear. Comparison of pre- and post-steam injection surveys to identify locations where reflection amplitudes decrease substantially or disappear completely should delineate zones where steam has replaced water in a fracture.

To summarize, if the water in a fracture is heated (in the absence of replacement by steam), the following changes are expected:

- A decrease of the reflectivity; if the heating is high enough, the decrease will be substantial, by a factor of about 0.6.

A.

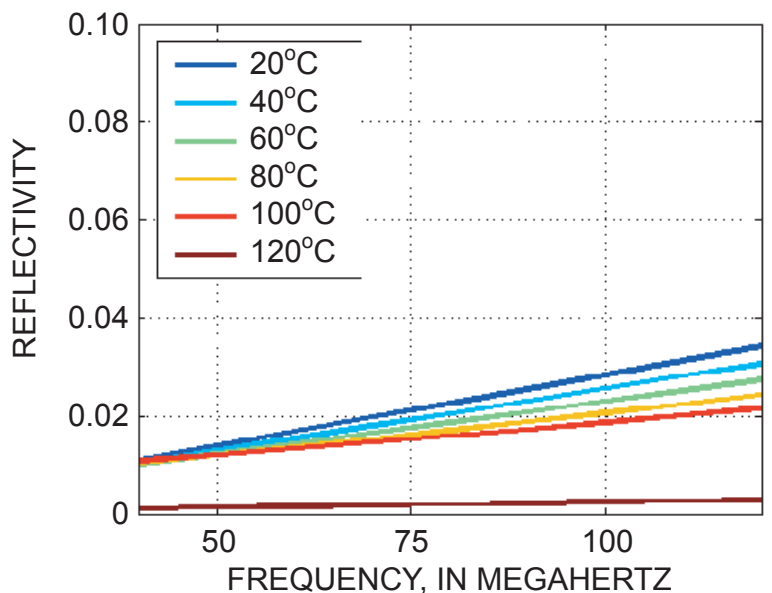

- No change of polarity.

- If the fracture has an aperture of $5 \mathrm{~mm}$ or less, then the decrease of reflectivity will probably be negligible compared to the level of the noise.

On the other hand, if steam replaces water, the following changes are expected:

- A decrease of the reflectivity amplitude by at least a factor 10 .

- A change of polarity of the radar reflection.

The effect of the limestone matrix conductivity on the reflection coefficient also was considered. An increase in the limestone conductivity of $0.03 \mathrm{~S} / \mathrm{m}$ produced a small decrease in the reflectivity (fig. 8). Although this increase of

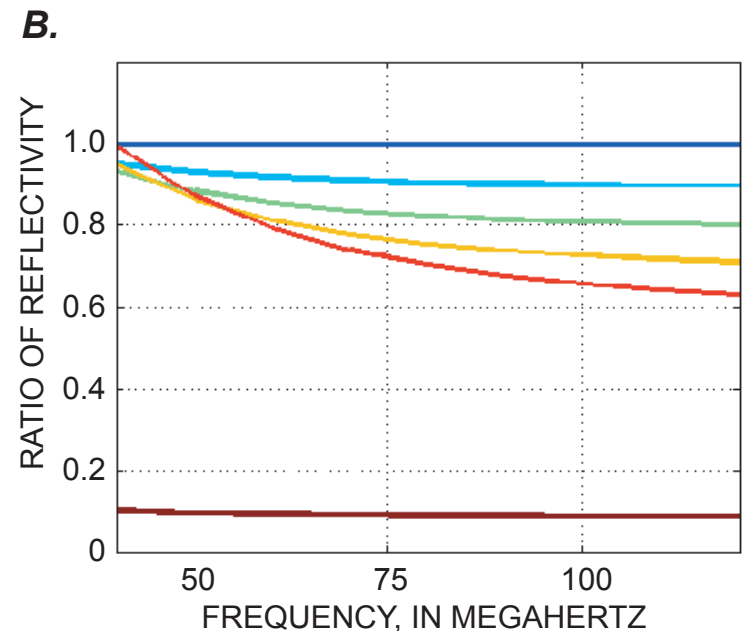

Figure 10. (A) Reflectivity of a 2-millimeter-thick fracture as a function of temperature, and $(B)$ the ratio of the reflectivity at temperature to the reflectivity at 20 degrees Celsius $\left({ }^{\circ} \mathrm{C}\right)$ for a formation conductivity of 0.01 siemens per meter.

A.

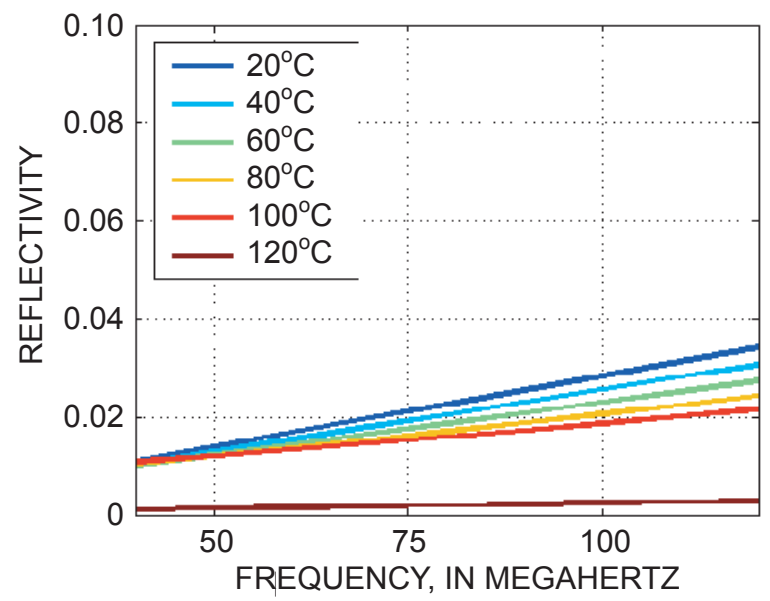

B.

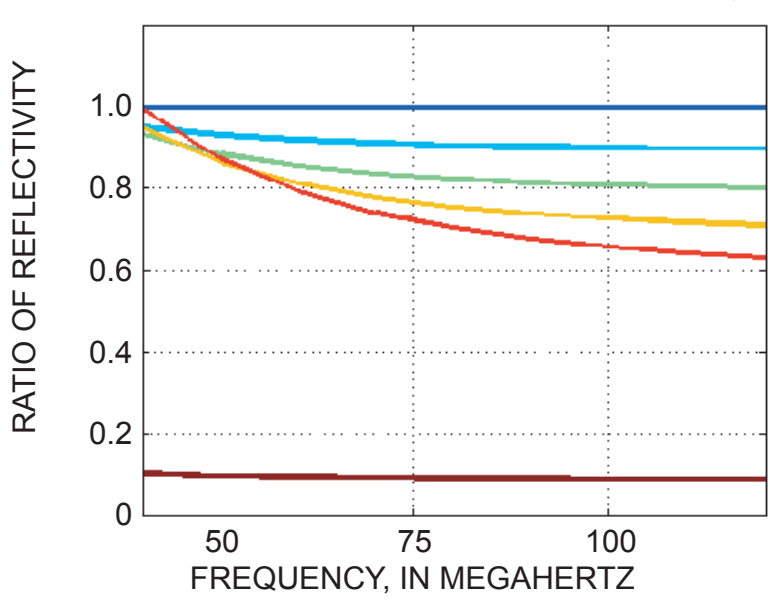

Figure 11. (A) Reflectivity of a 1-millimeter-thick fracture as a function of temperature, and $(B)$ the ratio of reflectivity at temperature to the reflectivity at 20 degrees Celsius $\left({ }^{\circ} \mathrm{C}\right)$ for a formation conductivity of 0.01 siemens per meter. 
conductivity did affect the reflection coefficient, it affected the amplitude of the signal by attenuation, resulting in a reflected wave with lower amplitude.

The effect of water salinity on radar reflections also was considered, and the results of those theoretical calculations are shown in figure 12 . The reflectivity of a $10-\mathrm{mm}$ thick fracture filled with a $0.2923 \mathrm{~g} / \mathrm{L} \mathrm{NaCl}$ solution is compared to the reflectivity of a 10-mm thick fracture filled with a $0.5845 \mathrm{~g} / \mathrm{L}$ $\mathrm{NaCl}$ solution. In both cases, the conductivity of the limestone rock is $0.01 \mathrm{~S} / \mathrm{m}$. The reflectivity of the water-filled fracture increases with the salinity of the water filling the fracture, especially at lower frequencies. This result was previously observed in experiments where a saline solution was injected in a fracture (Lane and others, 1998, 1999, 2000).

It is important to note that the analytical modeling performed for this study was simple, and should be viewed as the initial effort required to predict the effects of heating and steam on EM wave reflection behavior in fractured rock environments. Fundamentally, the models predict reflection behavior changes resulting from physical properties changes of the rock matrix and fracture fluid on a single, isolated fracture. The modeling does not address the constructive and destructive reflection interference effects induced by multiple, closely spaced, sub-parallel fractures (expected to exist in a fracture zone), does not account for the weathered zone surrounding a fracture, nor do the models address the complicated effects of a partial change in fracture fluid that could be induced by sub-wavelength scale fracture channeling or preferred pathways of heated water or steam within a given fracture or fracture zone. Assessment of EM reflection behavior for more complicated and realistic scenarios would be facilitated by the use of full wave-form numerical modeling methods.
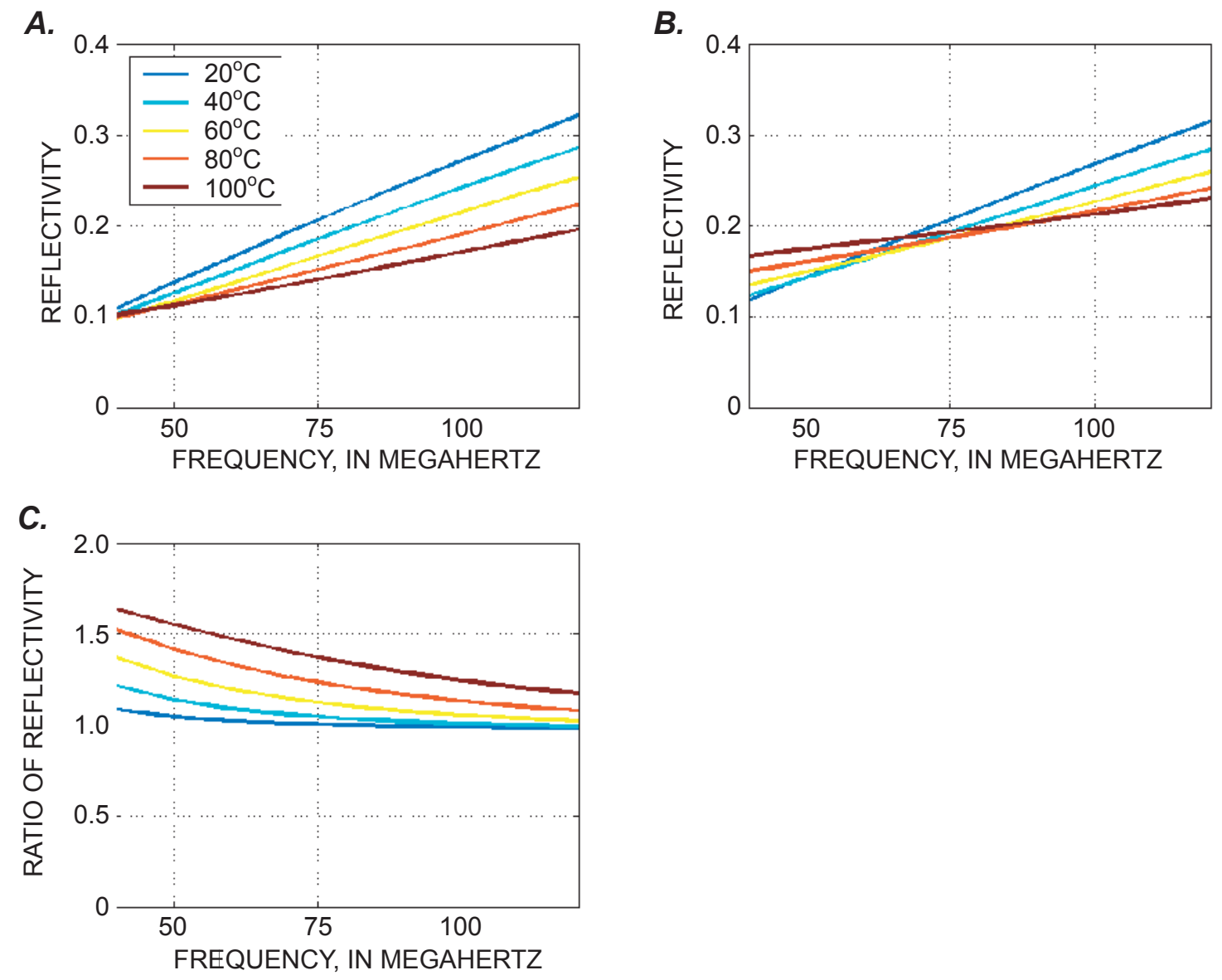

Figure 12. Effect of water salinity on the radar reflection. $(A)$ Reflectivity of a 10-millimeter water-filled fracture. Concentration of the saline solution is 0.2923 grams per liter $(\mathrm{g} / \mathrm{L}) \mathrm{NaCl}$. (B) Reflectivity of a 10-millimeter-thick water-filled fracture. Concentration of the saline solution is $0.5845 \mathrm{~g} / \mathrm{L} \mathrm{NaCl}$. (C) Ratio of the reflectivity with $0.5845 \mathrm{~g} / \mathrm{L} \mathrm{NaCl}$ to the reflectivity with $0.2923 \mathrm{~g} / \mathrm{L} \mathrm{NaCl}$. Temperature is in degrees Celsius $\left({ }^{\circ} \mathrm{C}\right)$. 


\section{Conclusions of the Theoretical Modeling}

Results of theoretical analytical modeling indicate that increases in temperature will induce changes in EM-wave velocity, attenuation, and reflectivity, and these changes are predominantly controlled by physical property changes in water-filled fractures.

With heating of the matrix, EM-wave velocity:

- Increases slightly with temperature if the conductivity of the matrix is assumed to be constant (fig. 5C)

- Increases substantially if steam replaces water in the fractures and if the conductivity of the matrix is assumed to be constant (fig. 5C)

- Decreases substantially if the conductivity of the limestone matrix increases (fig. 7A)

- Decreases negligibly if the conductivity of the water increases, (because of the low primary and fracture porosity of the limestone) (fig. 7C)

- Increases slightly if the dielectric permittivity of the water decreases as a result of heating (fig. 7E)

With heating of the matrix, EM-wave attenuation:

- Increases slightly with temperature (about $1 \mathrm{~dB} / \mathrm{m}$ over a temperature range of $20-90{ }^{\circ} \mathrm{C}$ ) if the conductivity of the matrix is assumed to be constant (fig. 5D)

- Decreases slightly if steam replaces water and the conductivity of the matrix is assumed to be constant (fig. 5D)

- Increases substantially if the conductivity of the limestone matrix increases (fig. 7B)

- Increases if the conductivity of the water increases (fig. 7D)

- Increases only slightly if the dielectric permittivity of the water decreases as a results of heating (fig. 7F)

With heating of the matrix, the reflection coefficient (reflectivity) of a thin fracture:

- Decreases because of the decrease in dielectric permittivity of the water with increasing temperature (figs. 8-11)

- Decreases substantially (by a factor of 10) if steam replaces water (figs. 8-11)

- Increases as the salinity of water increases, because of the increase in electrical conductivity of the water (fig. 12)

\section{Collection, Processing, and Interpreted Results of Geophysical Data}

This section describes the collection and processing of geophysical data and presents the interpretation of the borehole radar data collected at the former Loring AFB study area. Conventional borehole geophysical logs were collected to augment the processing and interpretation of the radar-reflection and tomography data, which are the focus of this study.

The data were collected to evaluate the effectiveness of radar methods to monitor the movement of steam and the transport of heat in the subsurface during the SER. For the SER pilot study, the USEPA, the Maine Department of Environmental Protection, and the U.S. Air Force contracted with SteamTech Environmental Services, Inc., to design and perform the steam injection. Steam was injected in several wells on the northeastern side of the quarry site, and water and vapor were extracted by pumping a number of wells across the entire site (fig. 1). The steam was injected at depths from $20 \mathrm{~m}$ to the bottoms of the boreholes (about 30 to $40 \mathrm{~m}$ ), except in borehole I-6, where steam was injected into three separate intervals, including one as shallow as $10 \mathrm{~m}$. Steam injection was initiated September 1, 2002, and continued until November 19, 2002. Extraction of vapor and fluid was initiated August 30, 2002, and continued until November 26, 2002.

\section{Description of Monitoring Boreholes}

The geophysical logging was conducted in boreholes JBW-7816 and JBW-7817A (fig. 1) at the former Loring AFB study area. Borehole JBW-7816 extends to a depth of $46 \mathrm{~m}$ below top of casing, and borehole JBW-7817A extends to a depth of $30 \mathrm{~m}$ below top of casing. The two boreholes are $7.34 \mathrm{~m}$ apart, and the top of casing of JBW-7817A is $0.59 \mathrm{~m}$ higher in elevation than the top of casing of JBW-7816. Approximately $7 \mathrm{~m}$ of steel casing were installed at the top of each borehole when they were originally drilled for characterization studies. Each borehole was completed with solid fiberglass casing over the entire length. This prevented exposure of personnel and equipment to direct steam and contaminants while allowing radar and EM conductivity logging to survey the formation surrounding the borehole. The radar signal cannot penetrate steel casing, and polyvinyl chloride (PVC) casing can deform at high temperatures. The casings were capped at the bottom and sealed over the entire length of the boreholes using class $\mathrm{G}$ high-temperature grout to prevent flow and mixing between fractures intersecting the boreholes. The casings were filled with clean water. The installation and grouting of the fiberglass casings were completed before any of the geophysical logs were run in these boreholes. This precluded collecting many types of borehole logs that require an open borehole, such as fluid resistivity and televiewer data. 


\section{Conventional Borehole Geophysical Logs}

Borehole fluid-temperature and EM-conductivity logs were collected at the start of each day of field work. Deviation logs were collected to provide accurate borehole location profiles, which were needed for processing the crosshole radar tomography data.

\section{Fluid-Temperature Logs}

Fluid-temperature logs are used to measure the water temperature in boreholes and to identify areas of temperature change (Williams and Conger, 1990). Fluid-temperature logs were collected August 21, 2002, September 12-14, 2002, and November 5-8, 2002. Because the boreholes are lined with fiberglass casing and sealed with grout, accurate measurements of formation temperatures could not be made; however, the borehole temperature information was important for the safety of the equipment and its operators, and could provide general information about heating at the site. The largest temperature changes were expected at depth because the steam was injected in the interval between about 20 and $40 \mathrm{~m}$ below land surface. A Mount Sopris 2PFA-1000 temperature-fluid resistivity tool was used to collect the August and September data, and a Mount Sopris 2PCA-2SFB-1000 caliper-temperature tool was used to collect the November data. The background temperature logs were collected on August 21, 2002, about a week after the fiberglass casing was installed. Because the casing was sealed and the boreholes were filled with water at a temperature equivalent to ambient air temperature, the water in the boreholes may not have had enough time to fully equilibrate to ambient background temperatures of the formation.

The August and September field temperature data were recalibrated after the field work was completed because of an error in the original calibration file. In November, the temperature data were collected with a hybrid calipertemperature tool. The caliper arms did not stay closed, so the November temperature data were logged from the bottom of the borehole upwards, instead of from the top of the borehole downwards. This may not have allowed water to flow properly through the tool, and the differences in the temperature data may be underrepresented. The water in the borehole also may have been mixed by the upward log. As shown in figure 13, however, the November data in boreholes JBW-7816 and JBW-7817A generally are consistent with temperature data collected by the USGS using a hand-operated YSI Incorporated Model 3000 T-L-C (Temperature-LevelConductivity) meter and with thermocouple data collected by SteamTech Environmental Services, Inc. (Gregg Crisp, formerly of SteamTech Environmental Services, Inc., written commun., 2002)

Temperature data were collected in September 2002 on 3 consecutive days, about 2 weeks after the steam injection began. In JBW-7816, the temperature was unchanged from the background values (fig. 13A). In JBW-7817A, small daily increases in the temperature were observed; the highest temperature was about $12^{\circ} \mathrm{C}$ at depths ranging from about 20 to $25 \mathrm{~m}$ (fig. 13B).

Temperature data also were collected daily from November 5 to 8 , about 9 weeks after the steam injection began. In JBW-7816, the maximum temperature was about $10^{\circ} \mathrm{C}$ higher than the August background measurements. The highest temperature, about $18^{\circ} \mathrm{C}$, was recorded at a depth of about $22 \mathrm{~m}$. In JBW-7817A, the temperature increased as much as $40^{\circ} \mathrm{C}$ above the background measurements. The temperature increased with depth, with a maximum temperature of about $47^{\circ} \mathrm{C}$ recorded at a depth of about $29 \mathrm{~m}$, near the bottom of the borehole. Greater temperature changes were expected in JBW-7817A than in JBW-7816, because JBW-7817A is closer to steam-injection well I-4.

\section{Electromagnetic-Conductivity Logs}

EM-conductivity logs were collected to detect conductivity changes in the rock and fluids surrounding the boreholes (Williams and others, 1993). The EM-conductivity measurements were collected using a Mount Sopris 2PIA-1000 poly-induction probe. The tool detects changes in the conductivity over radial distances of 40 to $100 \mathrm{~cm}$ from the borehole. The EM-conductivity tool should not be strongly affected by the fiberglass casing and grout that line the boreholes. The EM-conductivity tool was not calibrated at the site because of the large amount of metal associated with the steam injection equipment. Steel casing also precluded logging in the upper $7 \mathrm{~m}$ of the borehole.

Temperature changes in the EM-conductivity probe result in small tool-dependent changes in the orientation of the coils, which changes the measured conductivity. Because the tool calibration has a thermal sensitivity, and because of the inability to calibrate the tool at the site, the calibration values were set at full scale for all logs so that all results were collected using the same calibration numbers.

In both boreholes, the variations in bulk formation conductivity with depth are quite similar for all three logging dates. In both boreholes, when the data sets are overlain using conductivity values for the upper part of the borehole as a guide, the values measured in November 2002 appear to decrease with depth. The change is greatest at the depths having the largest temperature changes, and is more pronounced in borehole JBW-7817A, which had a much larger temperature increase than in borehole JBW-7816. These results are inconsistent with theoretical and laboratory results that show the conductivity of rocks increases with temperature (Llera and others, 1990), but might be owing to the effect of thermal instability of the EM tool. 
A. JBW-7816

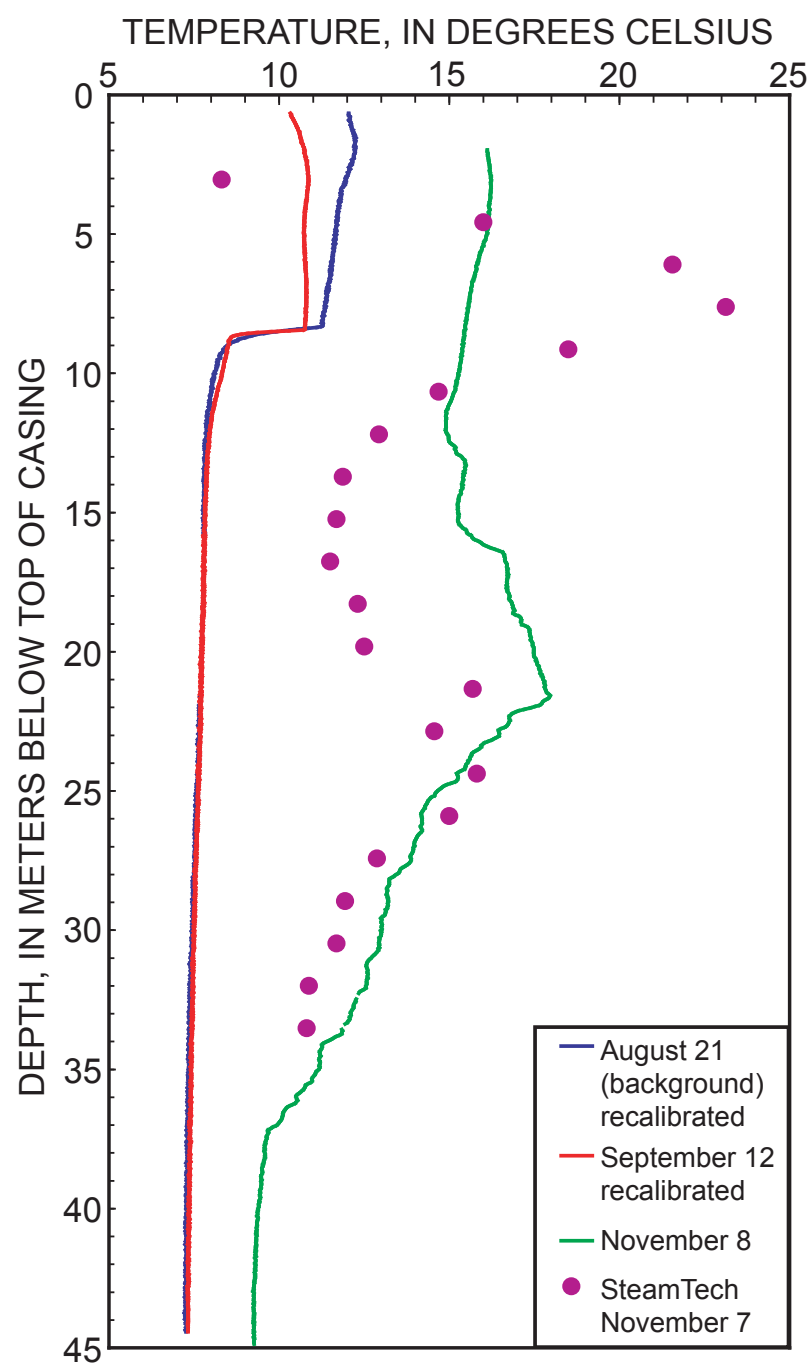

B. JBW-7817A

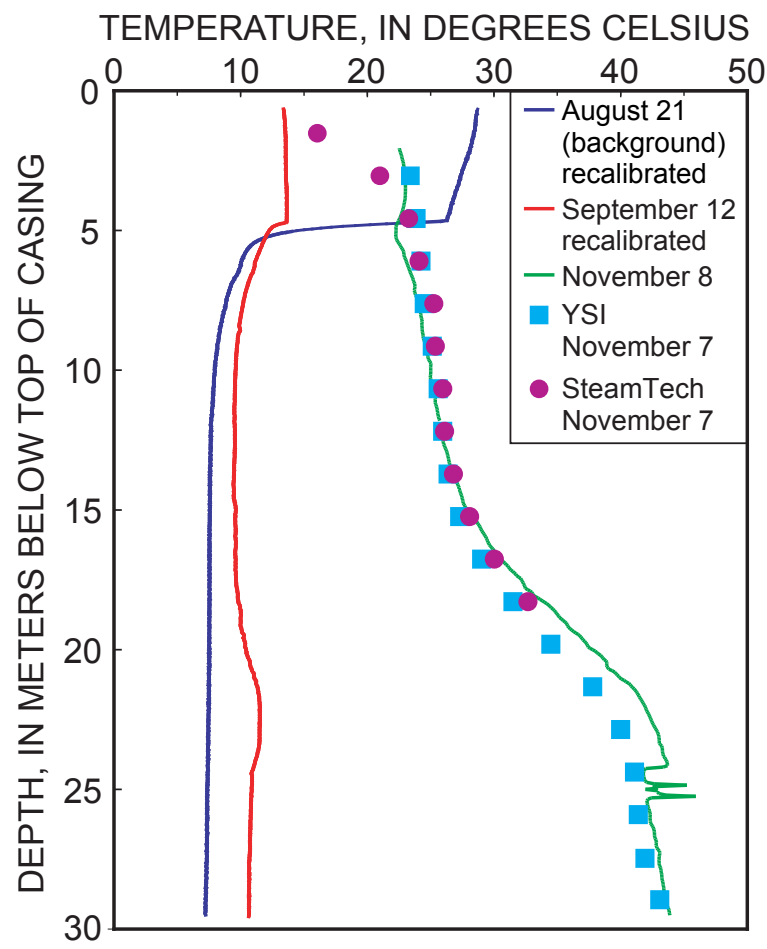

Figure 13. Temperature data collected in boreholes (A) JBW-7816 and (B) JBW-7817A during August, September, and November 2002 at the former Loring Air Force Base quarry, Limestone, Maine. The YSI measurements on November 7 in borehole JBW-7817A were made for this study using a hand-operated YSI Incorporated temperature-level-conductivity meter.

\section{Deviation Logs}

Borehole deviation measurements were collected to determine the exact location of the borehole in three dimensions (Keys, 1990). Accurate deviation data are critical for interpretation of the radar tomography data. Borehole deviations were measured using an Advanced Logic Technology (ALT)/Mount Sopris ABI-40 acoustic televiewer (ATV) tool, which collects deviation information using a three-component magnetometer for interpretation of televiewer data. Measurements were collected in November 2002 at $0.003-\mathrm{m}$ intervals along each borehole. The logs for boreholes JBW-7816 and JBW-7817A show deviations at the bottom of the boreholes of 1.8 and $0.8 \mathrm{~m}$, respectively, to the west.

\section{Single-Hole Radar Reflection}

Borehole-radar reflection surveys were collected to identify and monitor changes in individual fractures surrounding the boreholes. Data were collected August 13-16, 2002, as background data before the steam injection; September 11-16, 2002, about 2 weeks after the steam injection began; and November 4-8, 2002, about 9 weeks after the injection began and about 10 days before the end of the injection. The data were processed to correct for power variations, and the results of the theoretical modeling were used to interpret changes in the data as a result of heating from the steam injection. 


\section{Data Acquisition}

The radar-reflection logs were acquired in single-hole reflection mode using Malå GeoScience RAMAC electric dipole antennas having a central frequency in air of $100 \mathrm{MHz}$ and directional dual-loop antennas having a central frequency in air of $60 \mathrm{MHz}$. The 100-MHz electric dipole antennas offer superior resolution, but the omni-directional data cannot be used to determine the strike of reflectors.

The 100-MHz omni-directional reflection data were collected at 5-, 10-, and 20-cm intervals. A 1.00-m spacer was used between antennas for a total transmitterreceiver separation of $2.73 \mathrm{~m}$. The sampling frequency was 1,200 MHz, and 512 samples were collected per trace. As a result of antenna loading, the effective central EM frequency propagating in the formation is about $60 \mathrm{MHz}$. The boreholes were logged over their complete length by manually lowering the antennas and using a digital encoder on the tripod to trigger data collection at the desired intervals.

The $60-\mathrm{MHz}$ directional reflection data were collected at $20-\mathrm{cm}$ intervals, the smallest interval allowed by the system. A 1.00-m spacer was used between antennas for a total transmitter-receiver separation of $6.39 \mathrm{~m}$. A sampling frequency of $611.24 \mathrm{MHz}$ was used, and 512 samples were collected per trace. The directional receiver antenna can indicate reflector orientation using dual-loop antennas, which act as four different orthogonal receivers, coupled with a threecomponent magnetometer and a plunge sensor that monitor the orientation of the tool in the borehole. The sensitivity and effective radial penetration of directional dual-loop receiver antennas are inferior to those of omni-directional dipole receiver antennas (Falk, 1992; Lane and others, 2001). Because of the severe rotation of the antennas in the borehole during acquisition, the results were difficult to interpret and are not included in this report.

\section{Data Processing and Interpretation}

The omni-directional radar reflection profiles are shown in figures 14 (borehole JBW-7816) and 15 (borehole JBW-7817A). The vertical axis represents the length of the borehole, and the horizontal axis represents the twoway traveltime of the radar waves. The profiles are shown with the same time-gain function. The radar profiles in figures 14 and 15 were processed to improve the data quality and facilitate detection of reflectors. A background-removal filter was applied to suppress ringing and improve the signalto-noise ratio. This processing also attenuates reflections from reflectors parallel to the borehole, such as vertical fractures or nearby boreholes within the radar reflection time window. The uppermost $7 \mathrm{~m}$ of both boreholes were cased in steel, precluding penetration of the EM radar wave. The data collected near the bottom of the steel casings were more reflective because the antennas were above the water table.

In the background data from August 2002, the reflections show greater amplitude (greater reflection energy) because the transmitter output power was higher at that time. The penetration is lowest for the last set of measurements from November 2002 collected in borehole JBW-7817A; this profile is highly attenuated (fig. 15). No substantial change was seen in the penetration on the data sets collected in borehole JBW-7816, probably because of the low levels of thermal change in that borehole.

The omni-directional and directional data sets were examined both individually and as "differenced" data sets. Difference data were calculated by subtracting a trace in a given data set from the corresponding trace in the background data (August). The differencing procedure was performed to reveal changes in EM reflectivity that may be related to steam movement or heat transport.

\section{Analysis of the Radar Profiles}

The peak-to-peak amplitudes of the direct EM waves were measured for each data set collected in each of the two boreholes for the purpose of checking antenna stability and for monitoring changes to the formation (fig. 16). The output power of the transmitter antenna was much greater in the background data set (August) than in the other data sets. A small power decrease between the September and the November data sets also was observed. These changes are thought to be the result of a change in instrumentation, resulting from an antenna repair and possible instability of the antenna, resulting in small variations in the transmitter output or receiver effectiveness; these changes are not necessarily related to the movement of steam or transport of heat. A meaningful comparison and differencing of data sets requires application of a correction to trace amplitudes for the variable transmitter output power.

Most of the reflectors observed in the boreholes surveyed using the single-hole radar reflection method in August, September, and November 2002 do not appear to change with time (figs. 14 and 15); however, several important changes in reflector amplitude, lateral extent, and continuity were observed in the reflection data. For borehole JBW7816 , the amplitude and continuity of two parallel reflectors increased in the September data after the start of steam injection (Zone 1 indicated by a yellow box on fig. 14). In borehole JBW-7817A, the amplitude and continuity of several pre-existing reflectors increased between the August and September data sets. Two of the reflectors (Zone 2 and Zone 3 ) are indicated with yellow boxes in figure 15 . In the November data for borehole JBW-7817A, the continuity and amplitude of reflectors in the deepest portion of the borehole are noticeably reduced or disappeared entirely.

In borehole JBW-7817A, a strong reflector appears in the September data at depths below $20 \mathrm{~m}$ (Zone 3 on fig. 15) that was barely noticeable in the August data; however, this reflector is no longer visible in the November data. Several different explanations for the increase and decrease in the amplitude and lateral continuity of the reflector are possible. The appearance of the reflector does not indicate steam 


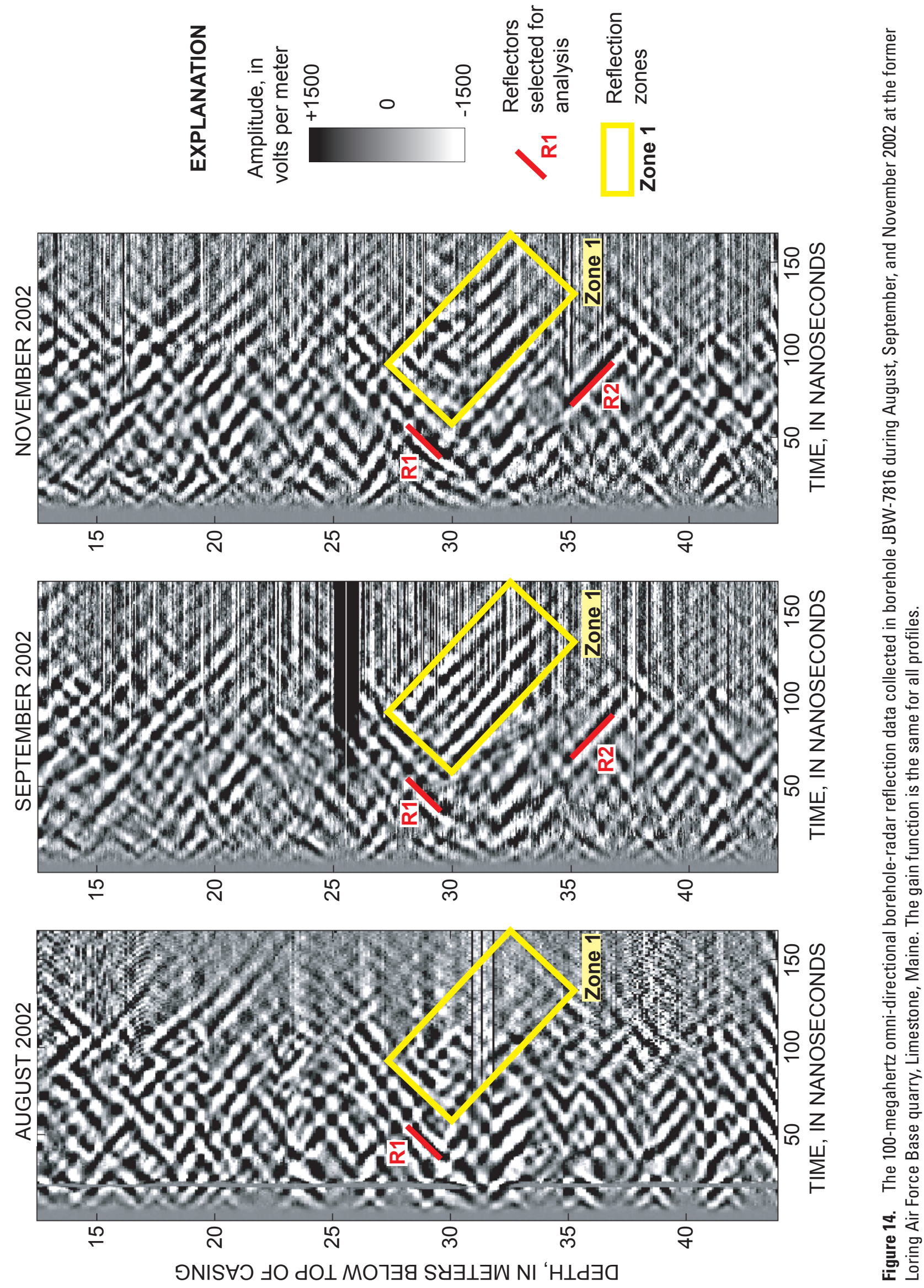



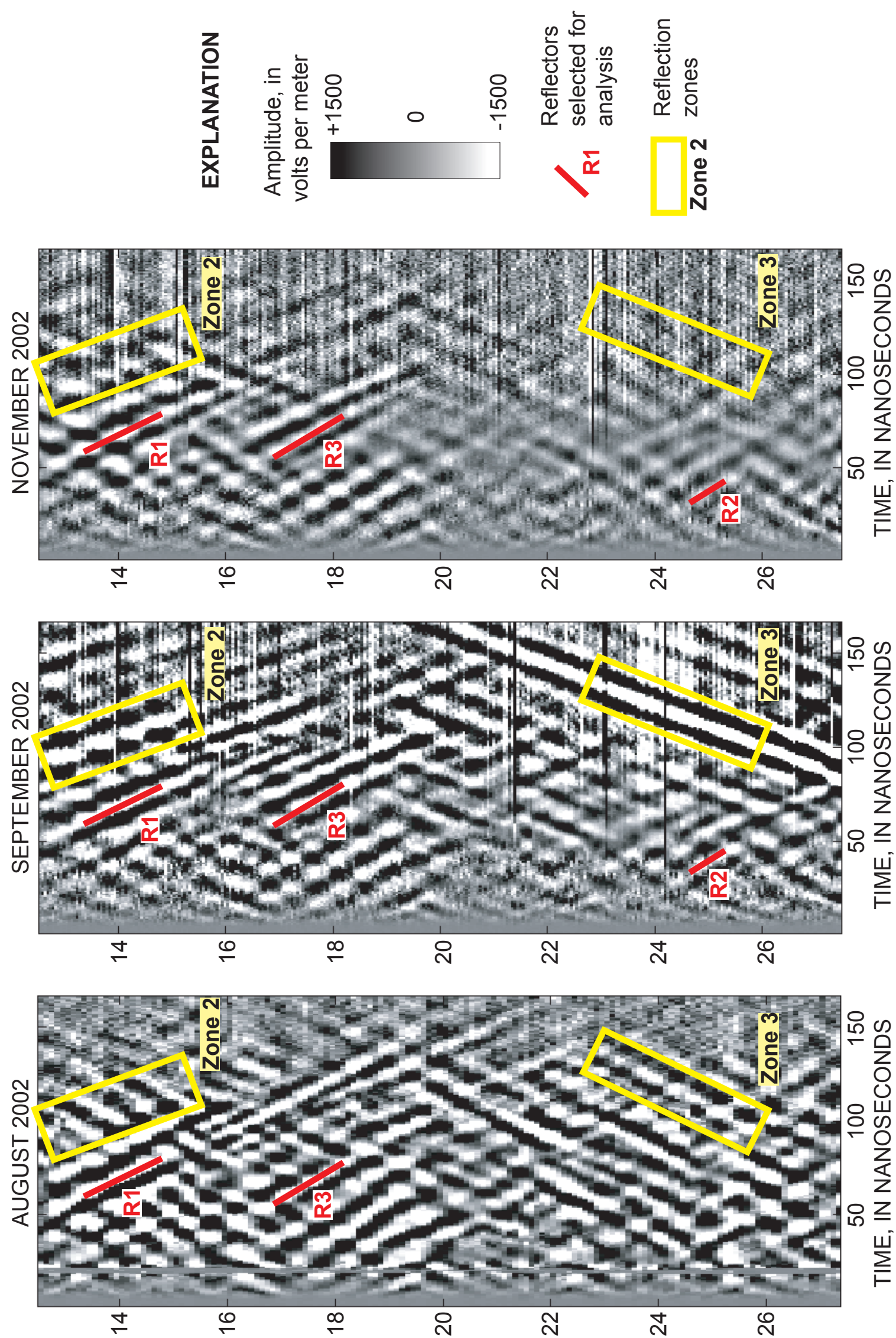

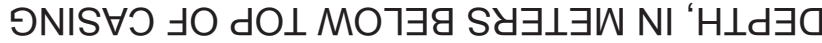

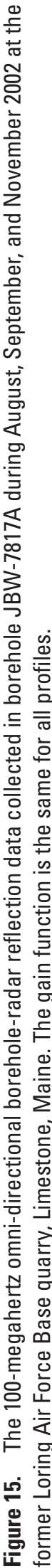


replacing water in a fracture because (a) it also would have been imaged in the November data set, (b) modeling predicted the reflectivity of a fracture filled with steam would be a factor of 10 less than a fracture filled with water, and (c) a phase change in the reflection data would have been observed between the background and later data sets if steam had replaced water in a fracture. Although theoretically possible, it is unlikely that the reflector is caused by a temporary increase in the conductivity of the fluid in the fracture. It is improbable that variations in the antenna power caused Zone 3, because all the reflections would be stronger. It also is unlikely that the reflection is off of a borehole, or equipment in a borehole, because there were no open boreholes within the radius of penetration. All boreholes surrounding the logged well were sealed, and the slope of the reflector indicates that, if the reflector were caused by a borehole, the borehole would have to be strongly deviated.
The most likely explanation is that the pressure of the injection increased the aperture of the fracture when it was imaged in the September data set. This could possibly happen by either forcing debris or weathered rock from the fracture, or by compressing the weathered rock along the fracture surface. The fracture may have filled with steam by the time that the November data set was collected. Steam injection borehole I-4 is less than $4 \mathrm{~m}$ away from borehole JBW-7817A, and within the area imaged by the reflection data. If steam had filled the fracture, the reflectivity should have decreased by a factor of 10. Because the reflector was not identified in the November data set, it can not be determined if a phase change occurred.

\section{Power Correction}

In order to compare the amplitudes of radar reflections from different data sets, a correction was applied to account for variation of output power between the three acquisition
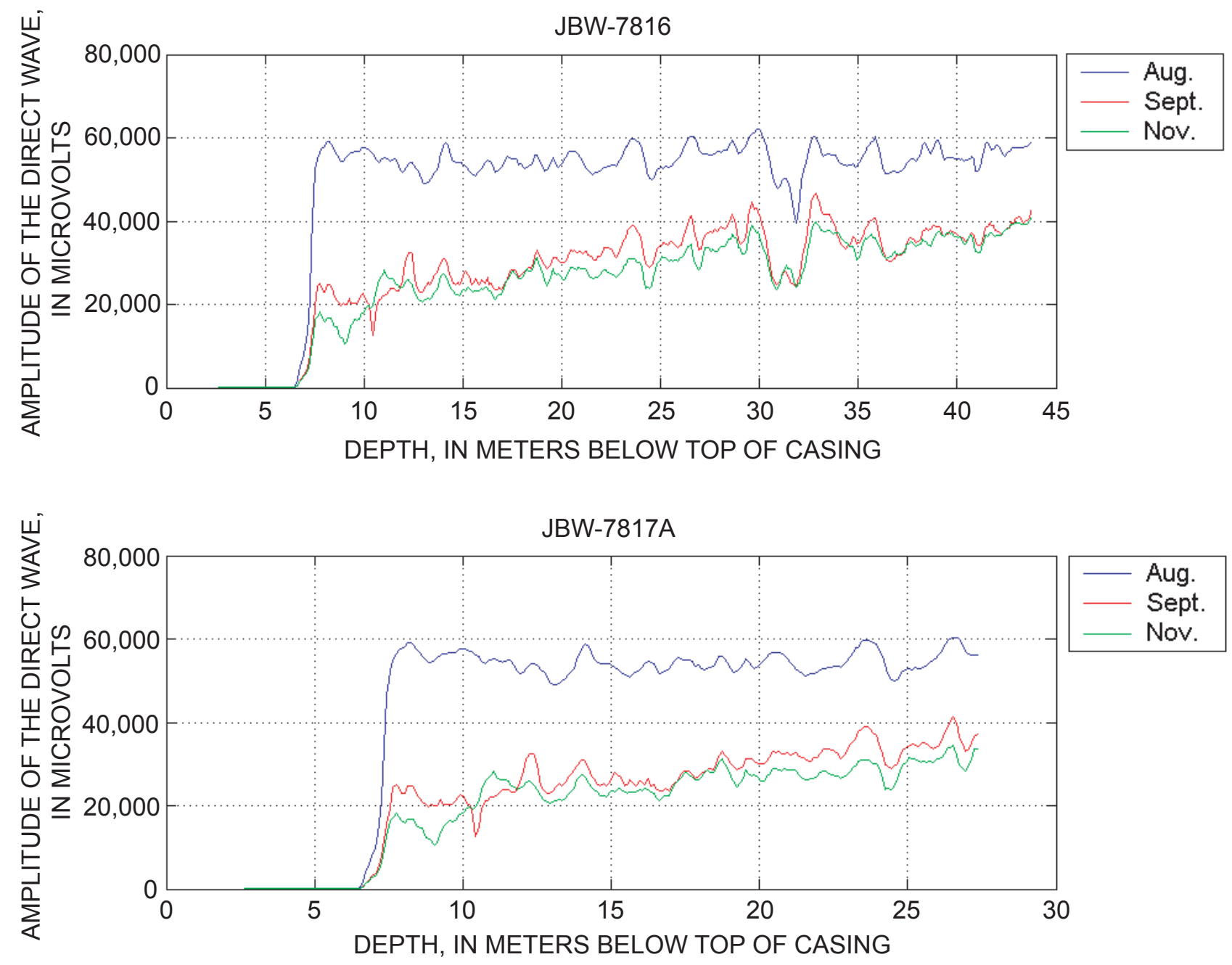

Figure 16. Peak-to-peak amplitude of the direct radar wave of single-hole radar reflection data collected during August, September, and November 2002 at the former Loring Air Force Base quarry, Limestone, Maine. 
periods. The correction procedure is based on the assumptions that the amplitude of the direct wave should be the same in all data sets, and that amplitude should decrease exponentially with distance. For each trace, a plot of $\log A_{i}^{2}$ and $i$ was constructed, where $A_{i}$ is the signal amplitude for sample $i$. The curves were smoothed and normalized. Examples of these curves for two different depths in each borehole are shown in figure 17. For each depth, the curves are shown for August, September, and November.

$\log A_{i}^{2}$ varies linearly with $i$ and can be approximated by $c(i)$,

where

$$
c(i) \quad \approx \log A_{i}^{2}=-0.0068 i+1 .
$$

This equation is unique and was derived specifically for this site.

To account for the power difference between any two data sets, 1 and 2, the correction for sample $i$ in trace $j$ is

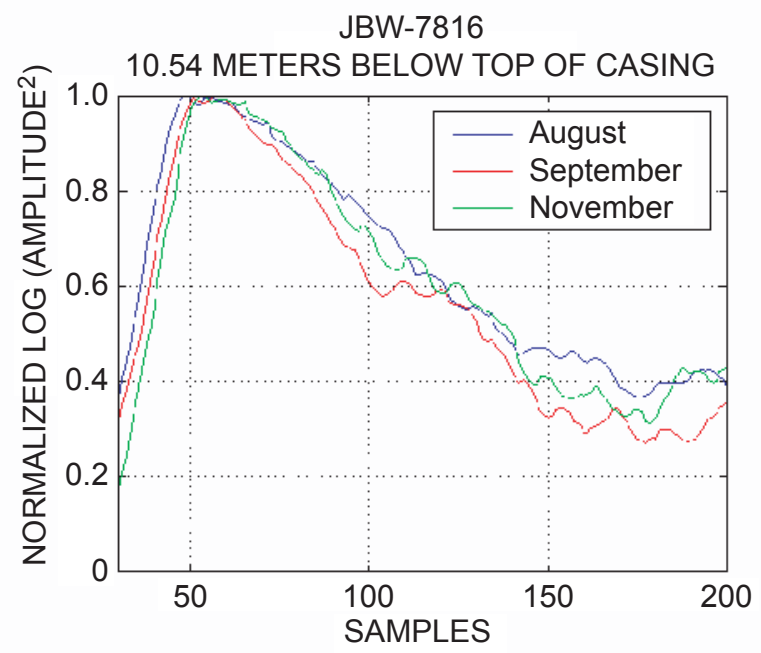

JBW-7817A

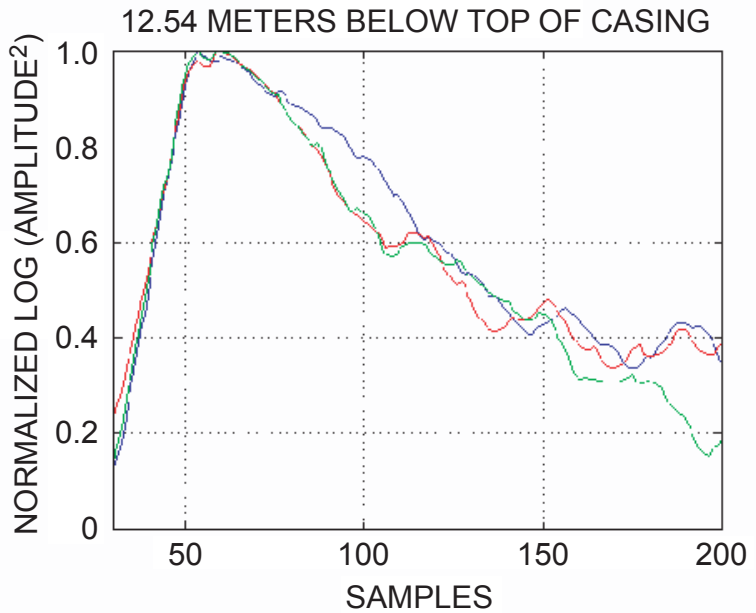

$\operatorname{correction}(i, j)=\sqrt{\exp \left(2 \log A_{2}(j) c(i)\right)-\exp \left(2 \log A_{1}(j) c(i)\right)}$,

where

$A_{1} \quad$ is the peak-to-peak amplitude of direct wave in data set 1 for trace $j$,

$A_{2} \quad$ is the peak-to-peak amplitude of direct wave in data set 2 for trace $j$,

and

$A_{2} \quad$ is greater than $A_{1}$.

Correction factors were calculated to account for the power difference between the August and September data sets and were applied to each sample in all of the traces of the September data set. Likewise, correction factors were calculated to account for the power difference between the August and November data sets and applied to the November data set.
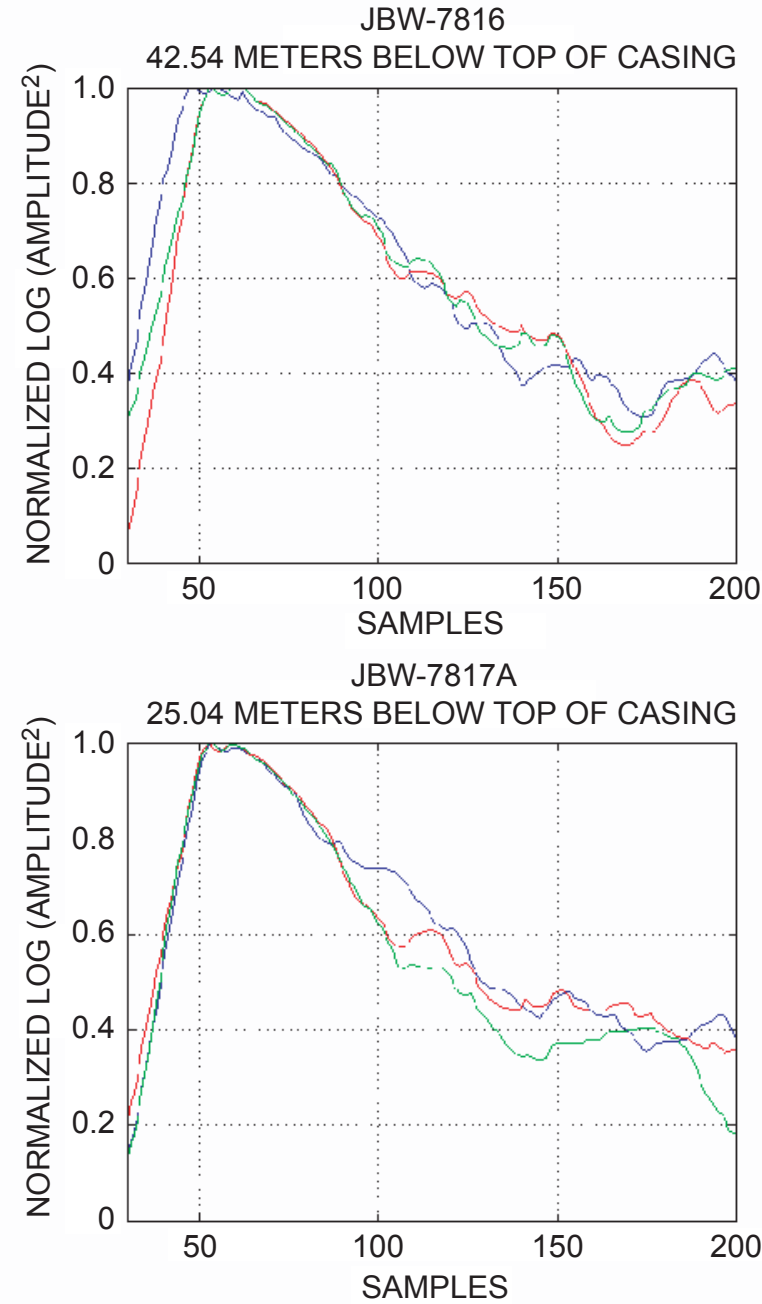

Figure 17. Power term calculated for selected single-hole radar reflection data sets from boreholes JBW-7816 and JBW-7817A during August, September, and November 2002 at the former Loring Air Force Base quarry, Limestone, Maine. The curves are normalized and smoothed. 


\section{Spectra Analysis}

The mean frequency spectra calculated for each of the six $100-\mathrm{MHz}$ omni-directional data sets (which is two boreholes, JBW-7816 and JBW-7817A, collected at three times, August, September, and November 2002) are shown in figure 18.

The spectra are shown for both the unprocessed data and the processed data after removal of the background. Removal of the background consists of subtracting an average trace from the radar profile, which removes consistent noise, the direct wave, and reflectors parallel to the borehole. The mean central frequency is about $60 \mathrm{MHz}$ for all data sets. The decrease of the magnitude of the central frequency between the three data sets for a given borehole can result from either a variation of radar-system power between the different acquisitions or

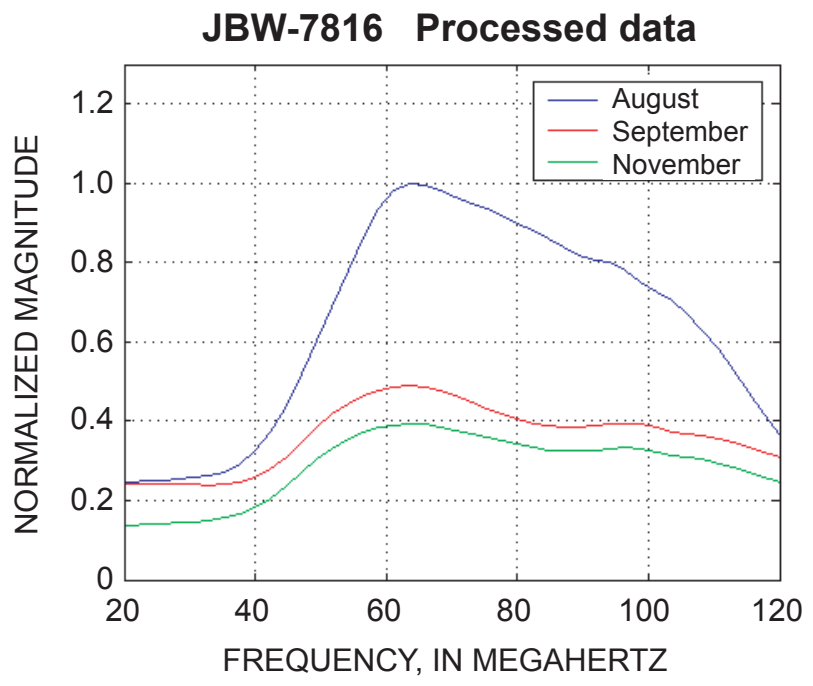

JBW-7816 Unprocessed data

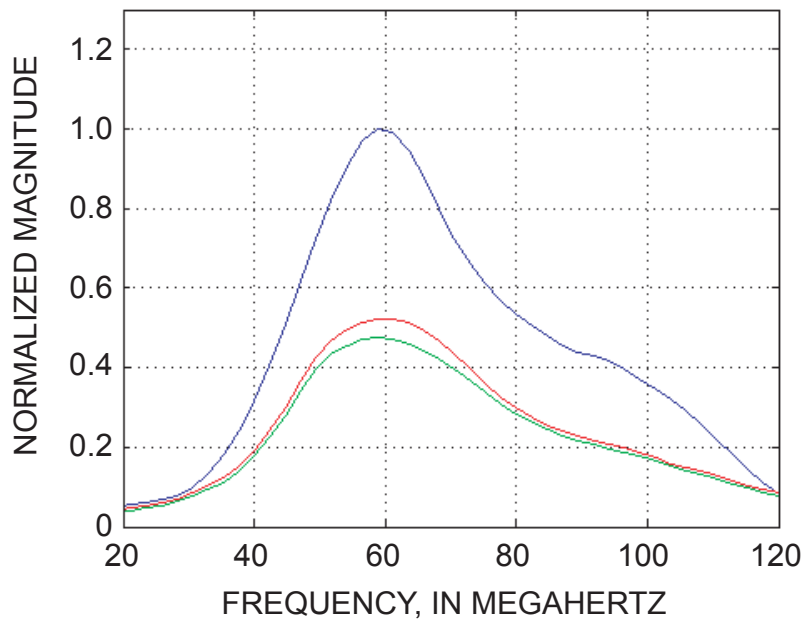

a change in the medium properties. In this case, most of the decrease is assumed to be the result of the power difference in the radar system used for the collection of each data set, although a small portion may be the result of a change in conductivity of the matrix or ground water. For the November data, the magnitude corresponding to the central frequency is slightly lower for the JBW-7817A data set compared to the JBW-7816 data set. This discrepancy could be a result of greater heating near JBW-7817A relative to JBW-7816 (fig. 13). The radar profile from borehole JBW-7817A also is more attenuated than the profile from borehole JBW-7816 (figs. 14 and 15), which is consistent with the hypothesis that temperature variation accounts for the difference in the magnitude of the central frequency.

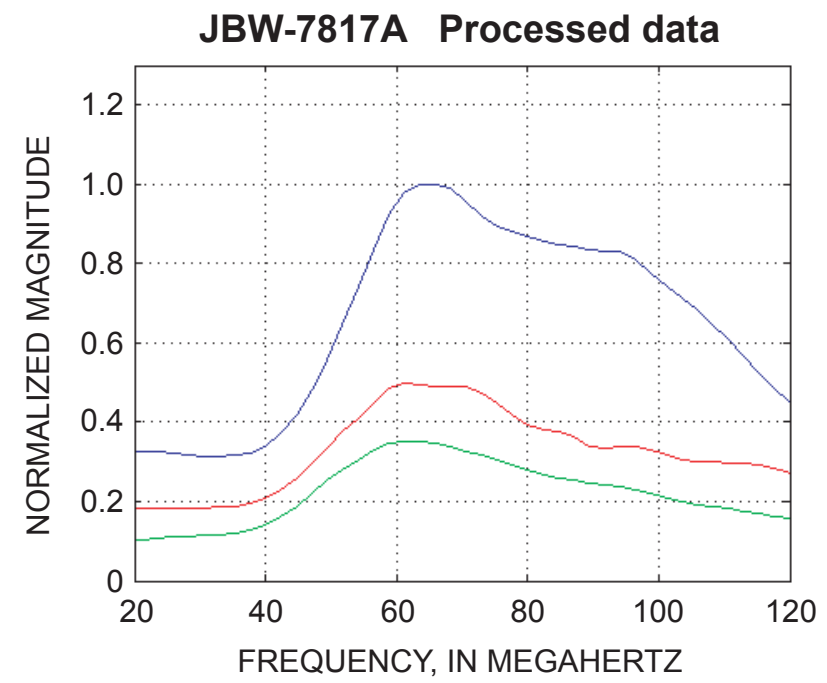

JBW-7817A Unprocessed data

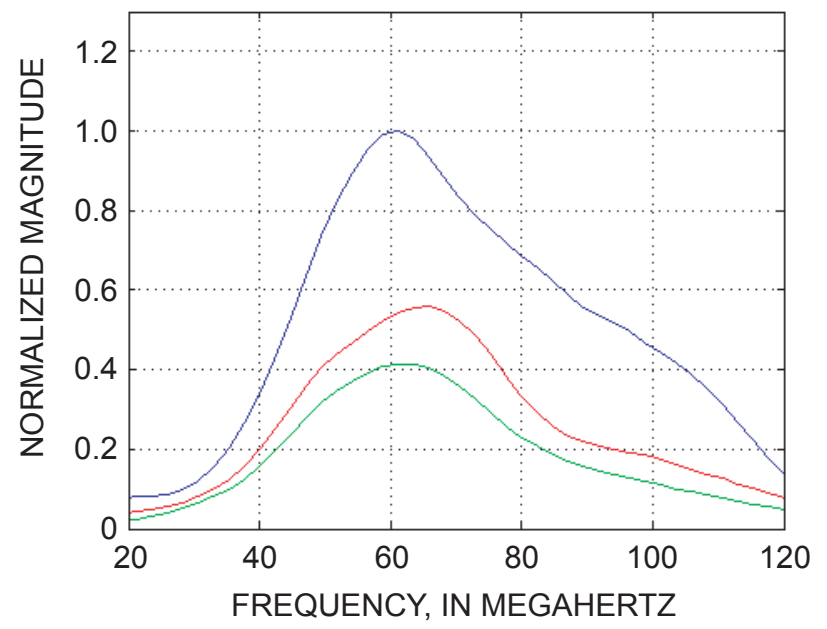

Figure 18. Mean frequency spectra calculated for each single-hole radar reflection data set from boreholes JBW-7816 and JBW-7817A during August, September, and November 2002 at the former Loring Air Force Base quarry, Limestone, Maine. Processed data (after removal of the background) and unprocessed data are shown. 


\section{Reflector Analysis}

The high density of reflectors in the limestone at the quarry resulted in interference between reflections in the radar profiles, thus complicating identification of individual reflectors. Further characterization of the reflectors required a more detailed analysis. A method based on spectral analysis of the radar reflection has been developed to characterize fracture properties such as the type of filling material and the fracture opening (Grégoire, 2001; Grégoire and Hollender, 2004). This method has previously been applied to evaluate open fractures in a salt mine (Grégoire and others, 2003).

To develop a reliable interpretation of the presence or absence of steam in fractures around the logged boreholes, the analysis focused on several well-defined reflections identified with red lines in figures 14 and 15 . Two reflectors were identified in the JBW-7816 profile (fig. 14; R1 and R2) and three reflectors were identified in JBW-7817A profile (fig. 15; $\mathrm{R} 1, \mathrm{R} 2$, and R3). These reflectors were chosen because of their high amplitude and the comparably large number of traces in which these reflections were observed. The reflector analysis consisted of several steps, some of which are shown in figure 19:

1. Selection of a section of the radar profile containing the reflectors of interest (several traces are selected) (fig. 19A).

2. Alignment of the traces based on the maximum peak amplitude.

3. Calculation of the mean trace signal.

4. Extraction of the wavelet corresponding to the mean reflection in the time domain (fig. 19B).

5. Calculation of the Fourier spectrum of the wavelet in the frequency domain (fig 19C).

The selected reflections and their characteristics are summarized in table 1 .
Comparison of the five reflectors in the August, September, and November data sets indicates there was no change of polarity with time after the steam injection. Also, no major differences in the traveltimes were observed. The corrected amplitude spectra for each reflector in each data set are shown in figure 20. Comparison of a particular reflector's amplitude spectra in different data sets requires the power correction discussed above. The changes in the spectra of the reflectors in borehole JBW-7816 were minimal. The reflectors in borehole JBW-7817A showed a decrease in amplitude with time (and heating) and a slight decrease in central frequency.

In order to compare the amplitude of a particular reflector at different times, amplitude ratios are calculated in the Fourier domain for each reflector. The amplitude ratio is the ratio between a reflector's maximum amplitude at two different times, with the August data set used as the reference. For example, the amplitude ratio of a reflector for the November data set would be calculated as $\mathrm{A}_{\mathrm{Nov}} / \mathrm{A}_{\mathrm{Aug}}$, where $\mathrm{A}_{\mathrm{Nov}}$ is the maximum amplitude observed in the corrected November data set, and $\mathrm{A}_{\text {Aug }}$ is the maximum amplitude observed for the same reflector in the August background data set. For several reflectors, August data are not available; in these cases, the September data set is used as reference. The results are given in table 2 and figure 21.

Based on the analysis of the reflection data, it does not appear that steam replaced water in the selected fractures surrounding the logged boreholes. The reflector analyses reveal no changes in polarity and no substantial changes in traveltime, and the decrease in amplitude is less than an order of magnitude. The largest decrease in amplitude ratio was 0.4 , whereas the results of numerical modeling indicate that the presence of steam in a fracture would result in a much larger decrease in amplitude such that the amplitude ratio would be much less than 0.1. The observed decreases in fracture reflectivity (after power correction) are too small to result from steam replacement, but are consistent with increased electrical conductivity resulting from increased fluid temperature.
A.

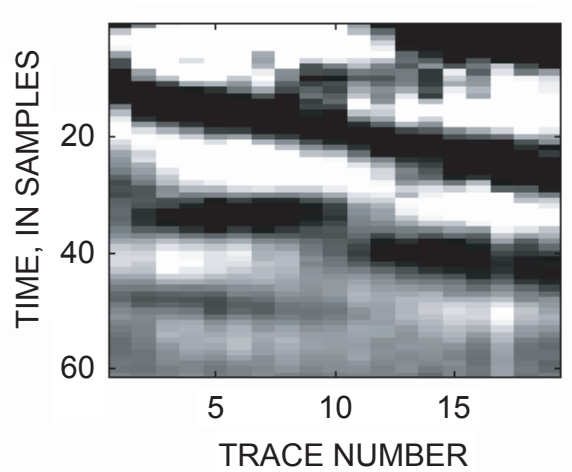

B.

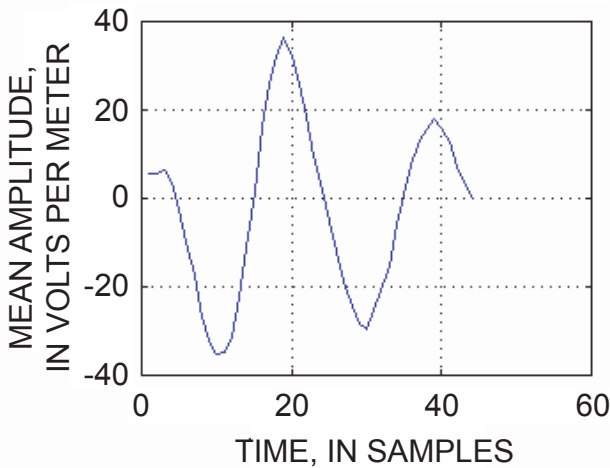

C.

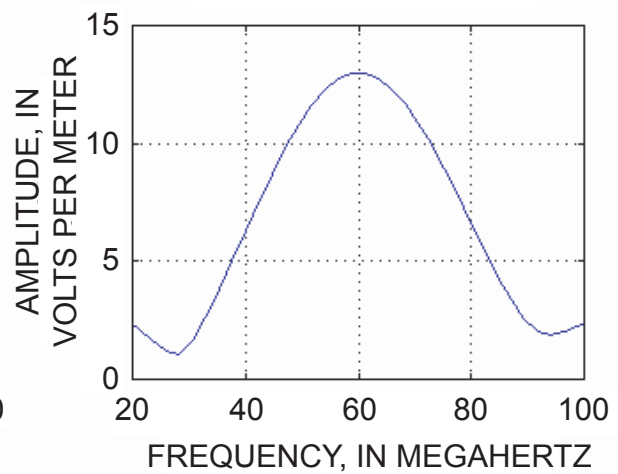

Figure 19. Example of reflector analysis of single-hole radar reflection data: $(A)$ reflector in section of radar profile, $(B)$ mean signal in the time domain, and $(C)$ amplitude spectrum in the frequency domain. 
Table 1. Power correction for selected reflectors seen in single-hole radar reflection data collected during 2002 in boreholes JBW-7816 and JBW-7817A at the former Loring Air Force base study area, Limestone, Maine.

[Distance from the borehole was calculated using a velocity of 101 meters per microsecond]

\begin{tabular}{|c|c|c|c|c|c|c|c|}
\hline JBW-7816-R1 & 1.36 & 1.42 & 1.04 & 1.55 & 28.54 & No & No \\
\hline JBW-7817A-R1 & 1.33 & 1.46 & 1.09 & 3.14 & 14.54 & No & No \\
\hline JBW-7817A-R2 & 1.52 & 2.16 & 1.42 & 1.50 & 25.54 & No & No \\
\hline
\end{tabular}

\section{Reflection Results}

The analysis of the radar reflection data indicates that steam did not replace water in most of the fractures surrounding boreholes JBW-7816 and JBW-7817A during the steam injection from September to November 2002. This conclusion is based on three observations: (1) no change of reflection polarity was observed, (2) no substantial variation in traveltimes was observed, and (3) the observed decrease in reflectivity was too small to result from the replacement of water by steam. One possible exception is the reflector identified as Zone 3 in the data collected in borehole JBW-7817A. The reflector is present in the August data and obvious in the September data, but not visible in the November data.

The decrease in radar reflection amplitude is larger for data collected from JBW-7817A than for data collected from JBW-7816, which might be a result of greater heating around borehole JBW-7817A. The decrease in amplitude could be explained by increased attenuation in the limestone because of heating or by the power correction. Because steam has not replaced the water in most of the fractures, it is not possible to estimate fracture aperture using the reflection data. Moreover, for openings that are small relative to the radar wavelength (approximately $1 \mathrm{~m}$ in limestone at $100 \mathrm{MHz}$ ), the ratio of reflection coefficients corresponding to two different temperatures seems to be independent of the fracture aperture.

\section{Crosshole Radar Tomography}

Crosshole radar tomography surveys were run between boreholes JBW-7816 and JBW-7817A to identify changes in radar velocity and attenuation in the interborehole region. Data were collected August 13-16, 2002, as background data before the steam injection; September 11-16, 2002, about 2 weeks after the steam injection began; and November 4-8, 2002, about 9 weeks after the injection began and 10 days before the end of the injection. The results of the theoretical modeling were used to interpret changes in the crosshole radar traveltime and amplitude data as a result of heating from the steam injection.

\section{Data Acquisition}

Borehole-radar tomography data were collected with Malå GeoScience 100-MHz borehole antennas using a sampling frequency of 2,000 MHz and 1,024 samples per trace. The transmitting antenna was fixed at different depths in borehole JBW-7817A while the receiving antenna was lowered from the top of casing to a depth of $32 \mathrm{~m}$ in borehole JBW-7816. For each antenna, measurements were collected every $0.20 \mathrm{~m}$; however, because of size limitations of the processing software, the measurement interval was later increased to $1.0 \mathrm{~m}$.

In the levelrun configuration, the transmitting and receiving antennas are always at the same depth (fig. $3 \mathrm{~A}$ ). Levelruns were collected every $0.20 \mathrm{~m}$ from the top of casing to the bottom of JBW-7816. Levelrun data can be interpreted in the field to quickly identify areas of change. Levelruns also are used to quantify change in the antenna power and to correct tomography data for deviations in traveltime or amplitude between different data sets. Levelrun surveys were conducted before and after acquisition of each tomography data set. Also, measurements in air were collected at the start and finish of each tomography survey to provide quality control for the stability of the radar equipment.

The temperature of the water in the borehole may affect the response of the radar antennas. To test the response of 

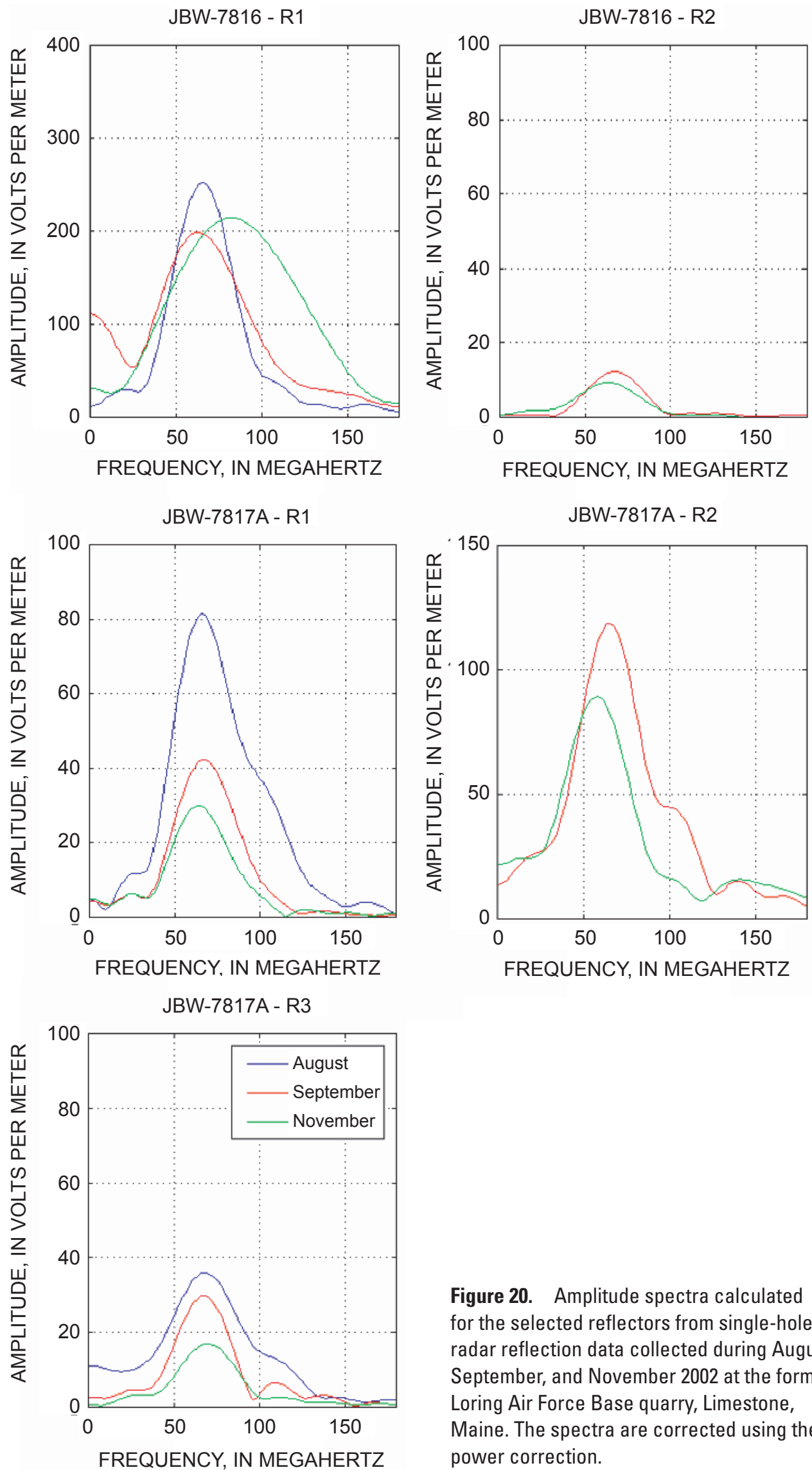

Figure 20. Amplitude spectra calculated for the selected reflectors from single-hole radar reflection data collected during August, September, and November 2002 at the former Loring Air Force Base quarry, Limestone, Maine. The spectra are corrected using the power correction. 
Table 2. Amplitude ratios calculated at central frequency for the selected reflectors identified in single-hole radar reflection data collected during 2002 in boreholes JBW-7816 and JBW-7817A at the former Loring Air Force Base study area, Limestone, Maine.

$[-$, no data available $]$

\begin{tabular}{lccc}
\hline Reflector & $\begin{array}{c}\text { September/ } \\
\text { August }\end{array}$ & $\begin{array}{c}\text { November/ } \\
\text { August }\end{array}$ & $\begin{array}{c}\text { November/ } \\
\text { September }\end{array}$ \\
\hline $7816-\mathrm{R} 1$ & 0.8 & 0.85 & 1.1 \\
$7816-\mathrm{R} 2$ & - & - & .75 \\
$7817 \mathrm{~A}-\mathrm{R} 1$ & .5 & .4 & .7 \\
$7817 \mathrm{~A}-\mathrm{R} 2$ & - & - & .8 \\
$7817 \mathrm{~A}-\mathrm{R} 3$ & .8 & .5 & .6 \\
\hline
\end{tabular}

the antennas at different temperatures, two PVC pipes were placed vertically $8.07 \mathrm{~m}$ apart and filled with water of different temperatures. The 100-MHz transmitter and receiver used for the tomography data collection were placed in the pipes and allowed to equilibrate for a minimum of 20 minutes. Traveltime measurements collected when both pipes were filled with hot water (approximately $50^{\circ} \mathrm{C}$ ) and both with cold water (approximately $22^{\circ} \mathrm{C}$ ) were within one sample $(0.50 \mathrm{~ns})$ of each other. Traveltime measurements collected with the transmitter in the hot water and the receiver in the cold water were five samples faster ( $2.5 \mathrm{~ns})$ than when the transmitter and receiver were both in water of the same temperature. Measurements collected with the transmitter in cold water and the receiver in hot water arrived four samples slower ( $2.0 \mathrm{~ns}$ ) than when the transmitter and receiver were both in water of the same temperature. It is possible that the thermal instability of the antennas, combined with the difference in temperature between the boreholes, may have affected the results of the tomograms.

\section{Data Processing and Interpretation}

Tomographic inversion is the process by which radar wave velocity and attenuation are calculated from field data. This process is sensitive to data having a low signal-to-noise ratio; thus, the first step in data processing is to eliminate traces that are highly attenuated because of large transmitterreceiver raypath distances. Data for raypaths below the bottom of borehole JBW-7817A also were eliminated to improve the symmetry and reduce distortions in the tomograms. Some shallow rays located close to the water table were eliminated; amplitudes for these rays were higher in the August data set than in the September and November data sets, perhaps because of water-table fluctuation. After a preliminary analysis of the data, it was decided to further reduce the data set because of its size (more than 8,000 measurements). Although data were collected every $0.20 \mathrm{~m}$, only data for 1-m measurement intervals were retained for tomographic inversion. Borehole deviation data were included in the array geometry to accurately calculate the antenna locations in three dimensions. Traveltime and maximum peak-to-peak amplitude data for the edited data set were picked using the Malå GeoScience RAMAC TOMOCG software package.

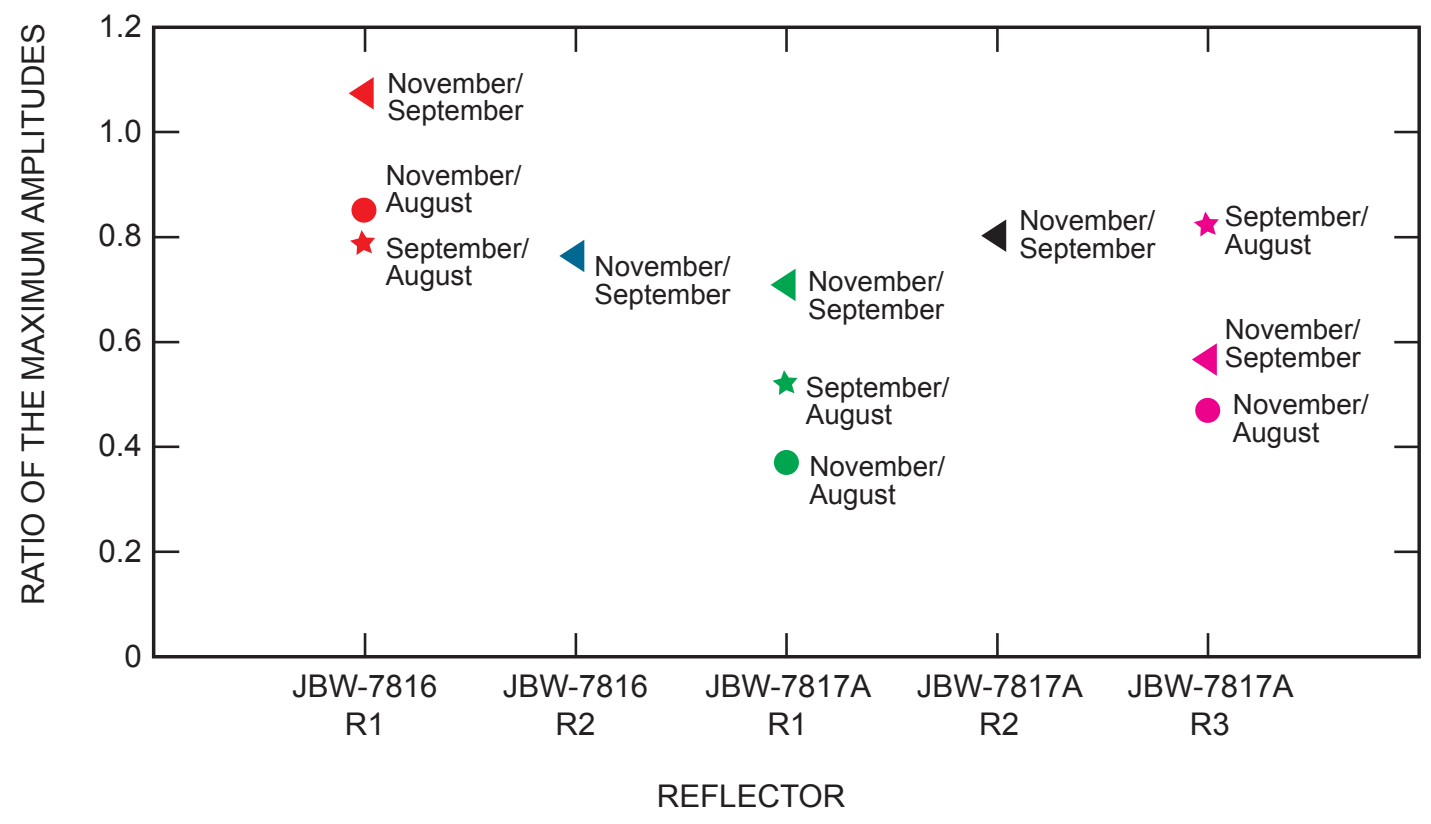

Figure 21. Ratio of the maximum amplitudes in the frequency domain of selected reflectors in single-hole radar reflection data from boreholes JBW-7816 and JBW-7817A collected during August, September, and November 2002 at the former Loring Air Force Base quarry, Limestone, Maine. 


\section{Traveltime Data}

For each trace, the time that the transmitter actually fires (called "zero time") must be determined prior to tomographic inversion or interpretation of levelrun data. Based on a measurement taken in air at the surface between the two boreholes, the zero time was calculated based on the sampling frequency. After identifying the zero time, levelrun data sets were corrected. For each tomography survey, a mean levelrun data set is calculated from data collected before and after the tomography. The differential traveltimes from the calibrated levelruns are shown in figure 22. These data are used to calibrate the tomography data because it is assumed that there would be minimal changes in the subsurface properties during this short acquisition time.

The calibrated traveltimes for the tomography data are shown in figure 23A. An increase in the mean traveltimes for deeper raypaths occurs in November 2002 near the end of the steam injection. The mean and standard deviation of the traveltimes are $0.0818 \pm 0.0117,0.0817 \pm 0.0119$, and 0.0835 \pm 0.0132 microsecond ( $\mu$ s), for August, September, and November, respectively.

Velocities were calculated from the traveltime data for the known geometry, assuming straight-line raypaths (fig. 23B). The mean and standard deviation of the velocities for August, September, and November are 105.07 $\pm 3.98,105.2 \pm 3.93$ and $103.10 \pm 2.51 \mathrm{~m} / \mu \mathrm{s}$, respectively. Differences in traveltimes between the three data sets are shown in figure 24 . When the differences were less than or equal to the sampling period, they were assumed to be zero.

Because of the small changes in traveltimes between the data sets, it was decided to invert the traveltime differences instead of inverting the traveltime data. The traveltimedifference values were calculated trace-by-trace using the August background data as the reference data set. The tomographic inversion was performed in several steps:
1. Levelrun data were inverted in order to generate an initial model.

2. This model was input to an algorithm that uses the simultaneous iterative reconstruction technique (SIRT) (Dines and Lytle, 1979; Censor, 1983; McMechan and others, 1987; Stewart, 1992; Lane and others, 2003) to generate the tomogram.

3. A smoothing filter was applied to the resulting tomogram to suppress artifacts caused by data errors or low raypath density in regions of the tomogram.

4. The smoothed tomogram was used as the starting model for a second application of the SIRT algorithm to the levelrun data, which refines the smoothed tomogram and improves the match to the data.

The traveltime-difference tomograms are shown in figure 25 in terms of slowness. The September-August traveltime-difference tomogram reveals no substantial changes in traveltime. For the September data set (corresponding to the beginning of the steam injection), changes of medium properties appear to be small. The second difference tomogram (November-August) shows a small increase in slowness (increase in traveltime) at depths below about $20 \mathrm{~m}$. The decrease in velocity could be explained by increases in the conductivity of the limestone matrix and decreases in the permittivity of the water.

\section{Amplitude Data}

Examination of the peak-to-peak amplitude of the levelrun data shows a change in amplitudes between the three acquisition periods (fig. 26). The amplitudes were higher in the September acquisition than in the August acquisition, which is inconsistent with the expected heating of the rock
A.

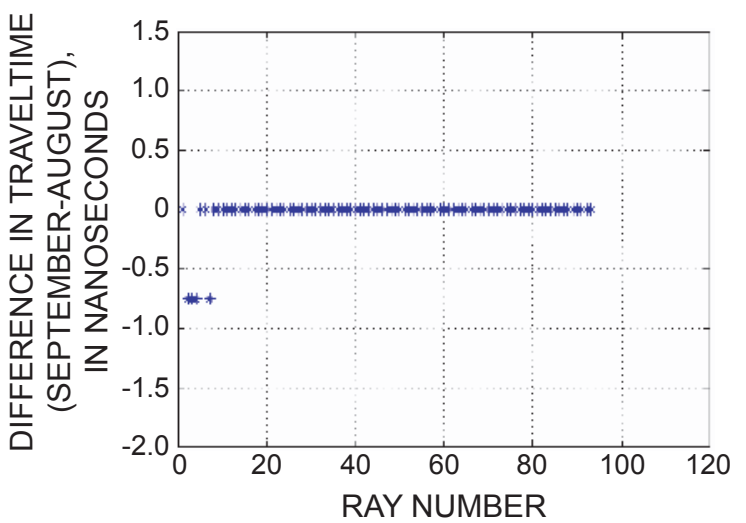

B.

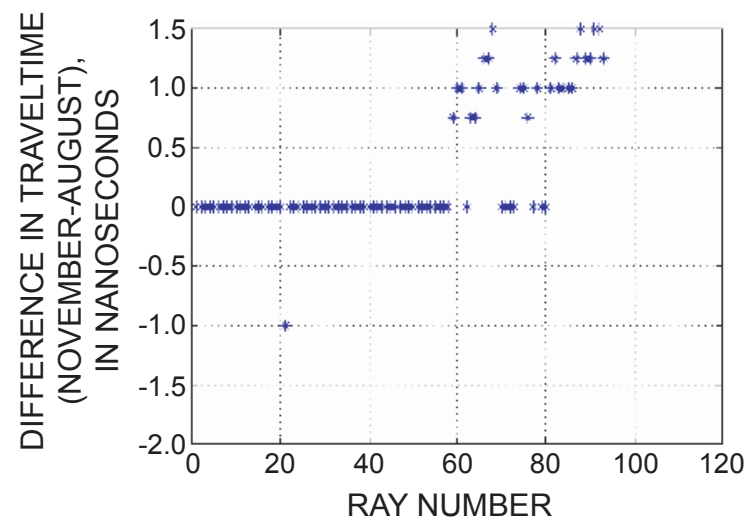

Figure 22. Calibrated crosshole radar levelruns. Differences in traveltimes: $(A)$ September-August 2002 and $(B)$ November-August 2002 at the former Loring Air Force Base quarry, Limestone, Maine. 
A.

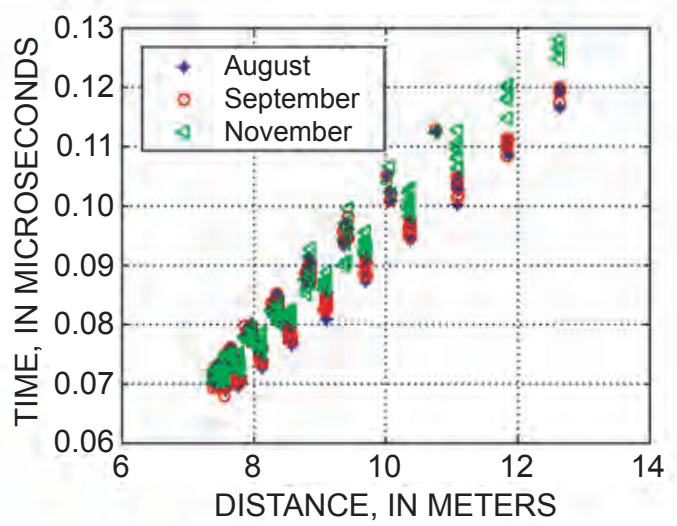

B.

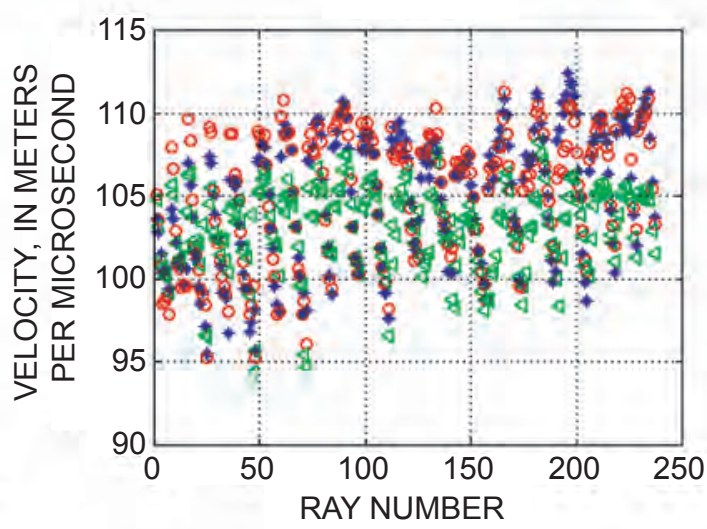

Figure 23. (A) Traveltimes of crosshole radar tomography data collected during August, September, and November 2002 and $(B)$ radar-wave velocity in August, September, and November 2002 at the former Loring Air Force Base quarry, Limestone, Maine.

A.

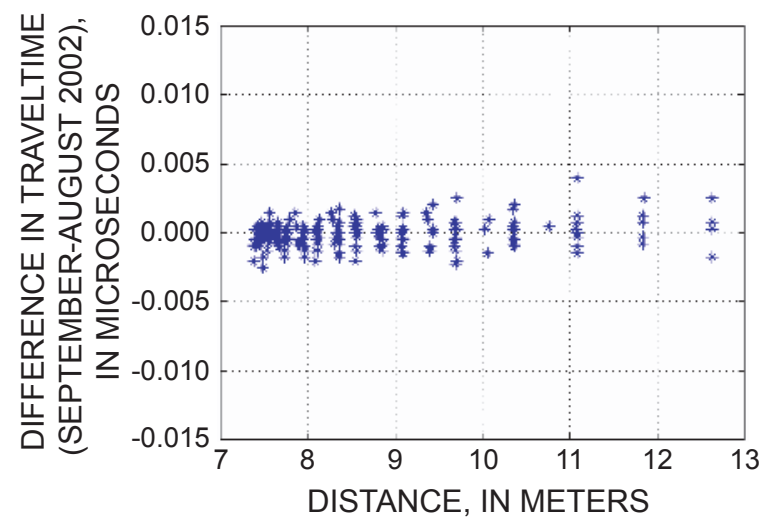

B.

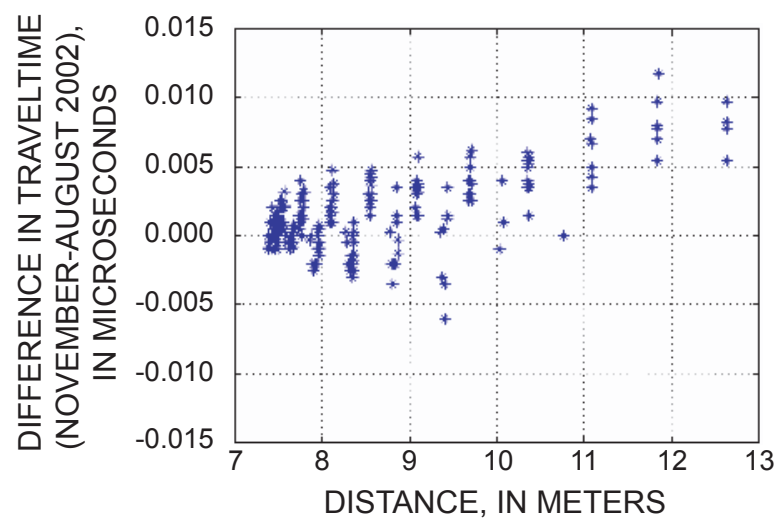

Figure 24. Differences in crosshole radar tomography traveltimes: $(A)$ September-August 2002 and $(B)$ NovemberAugust 2002 at the former Loring Air Force Base quarry, Limestone, Maine.

medium during the intervening period; thus, it is assumed that the change is a result of variable transmitter output power. To account for the variation, the levelrun and tomography amplitude data were calibrated. The calibration procedure is based on two assumptions: (1) there is no power variation during a particular levelrun acquisition, and (2) the radar equipment is not affected by changes in temperature during a particular levelrun acquisition. The assumed stability is because of the short acquisition time needed for the levelrun survey. The background data (August, before injection) are used as reference and are not modified by the calibration.

The amplitudes of the data sets acquired in September and November were calibrated using the function:

$$
\exp [a \ln (A)+b],
$$

where

$A$ is the peak-to-peak amplitude.

The values of the coefficients $a$ and $b$ were chosen by visually fitting the peak-to-peak amplitude data to the background data at depths of about 13 to $17 \mathrm{~m}$, where the traveltime tomography indicates no substantial changes between data sets (fig. 25).

The mean attenuation of the medium was calculated from the calibrated peak-to-peak amplitudes. The means and standard deviations of the attenuation determined from the levelrun data were $3.26 \pm 0.324,3.39 \pm 0.413$, and $3.43 \pm 0.424 \mathrm{~dB} / \mathrm{m}$, for August, September, and November, respectively.

The attenuations of the tomography data also were calculated from the peak-to-peak amplitudes for each data 
A.

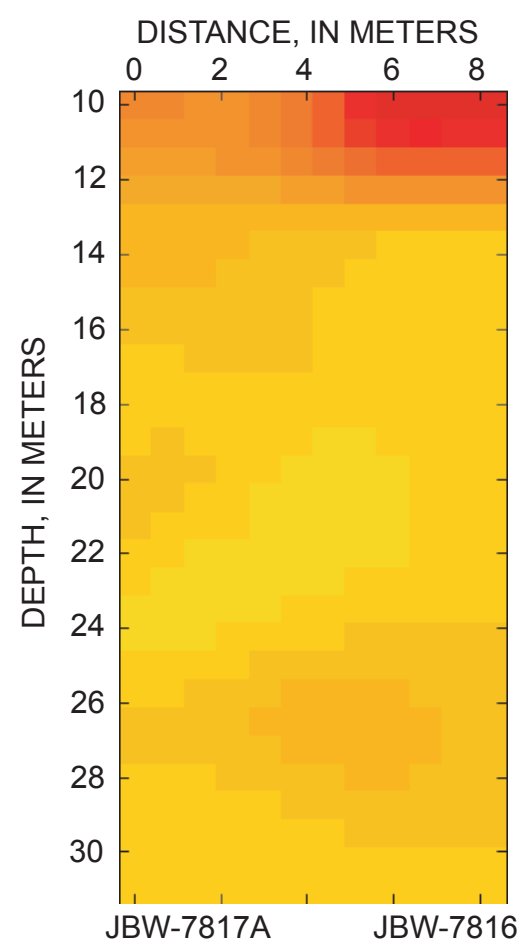

B.

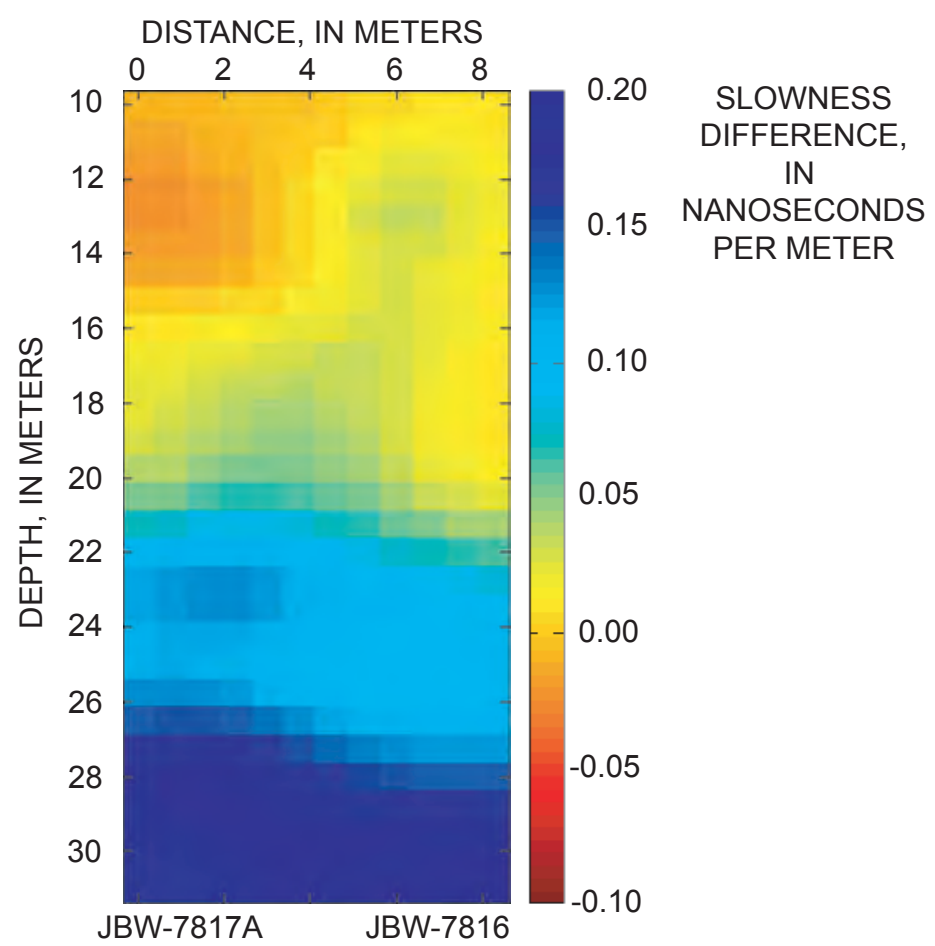

Figure 25. Results of the inversion of the traveltime-difference tomography data: $(A)$ September-August 2002 and $(B)$ November-August 2002 at the former Loring Air Force Base quarry, Limestone, Maine.

set. Because the output power of the transmitter and the capabilities of the receiver change as a function of battery life, antenna temperature, and time, calibration of the tomography data was necessary. The tomographic data sets were calibrated using the levelrun data collected at the same time. Levelrun data are more stable than tomography data because the levelrun surveys are completed in about 10 minutes as opposed to 6 hours for a full tomography survey. For each tomography data set, the same correction was applied for data with the same transmitter position. The calibrated attenuations are shown in figure 27 for each data set.

The means and standard deviations of the attenuation determined from the tomography data were $3.68 \pm 1.04,3.65$ \pm 0.97 , and $3.80 \pm 1.09 \mathrm{~dB} / \mathrm{m}$ for August, September, and November, respectively. The increase in the mean value of the attenuation over the course of the steam injection is small.

Amplitude differences (fig. 28) were calculated in a procedure analogous to the calculation of traveltime differences discussed previously. Nearly all the attenuation differences are lower than $1 \mathrm{~dB} / \mathrm{m}$, and many values are negative, which cannot be explained by the presence of steam or heating. Data for raypaths traversing the deepest part of the interborehole regions, however, show mostly positive differences in attenuation; this is consistent with the conclusion from the theoretical modeling that heating, or the presence of steam, will attenuate the radar signal.

The tomographic inversion of attenuation data followed the same procedure used for traveltime data. Inversions of levelrun attenuation data were used as starting models for inversion of the tomography data. The results of the inversions are presented as attenuation differences in figure 29. For the data set collected near the end of the steam injection in November, a small increase in attenuation can be seen at depths below about $20 \mathrm{~m}$, just as an increase in slowness (decrease of velocity) was observed.

\section{Tomography Results}

The traveltime- and attenuation-difference tomograms show no substantial changes in velocity and attenuation between the background data collected before the steam injection (August) and the data collected about a week after the steam injection began (September). For data collected about 2 months after the injection began (November), the difference tomograms show small increases in slowness (indicating a decrease in velocity) and increases in attenuation at depths greater than about $20 \mathrm{~m}$. These are the same depths where the greatest increase in heating was observed in both boreholes based on the fluid temperature logs (fig. 13). Although these changes are small, they are consistent with an interpretation that (1) increases in the conductivity and permittivity of the limestone matrix are caused by heating of the rock between boreholes JBW-7816 and JBW-7817A, and (2) steam from the injection was not detected near these boreholes by the crosshole radar tomography surveys. 
A.

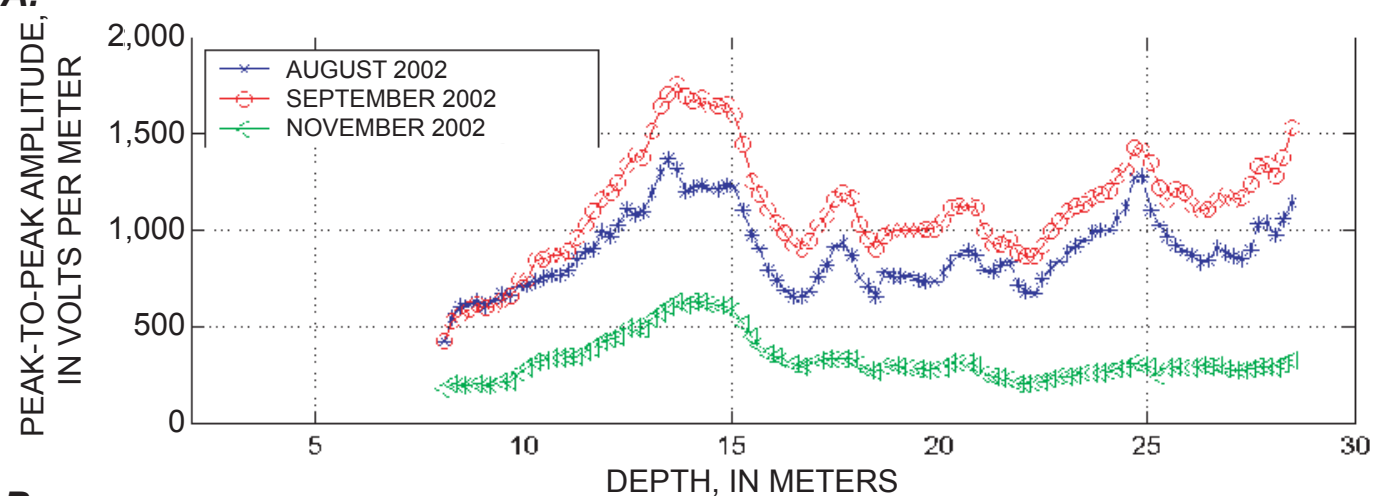

B.

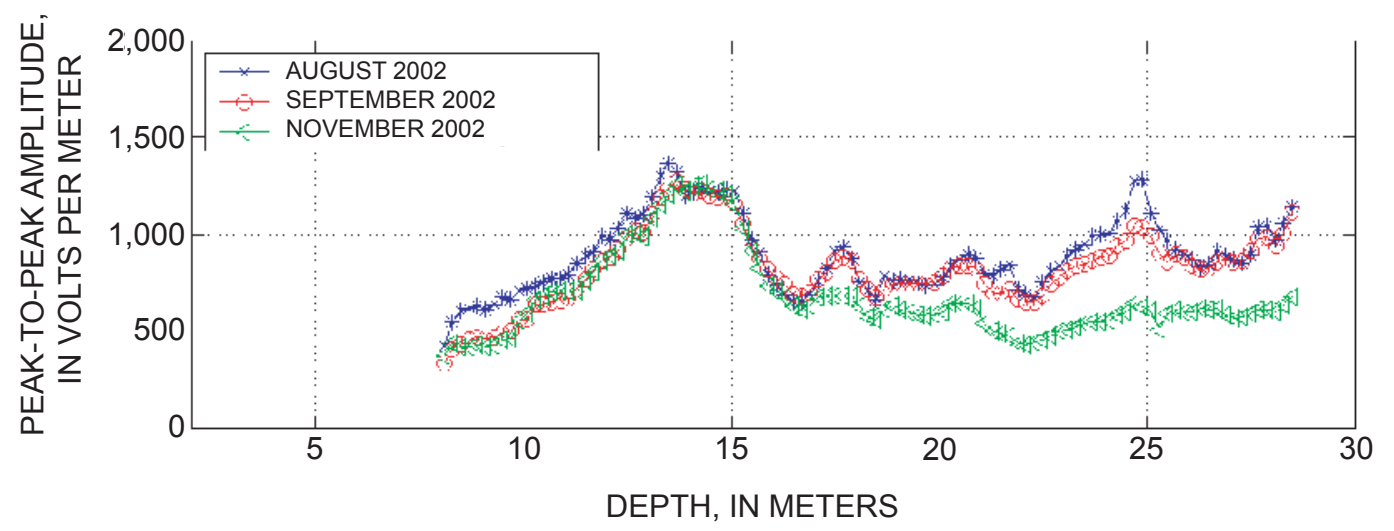

Figure 26. Peak-to-peak amplitude of the crosshole radar levelrun data: $(A)$ unprocessed data and (B) calibrated data collected during August, September, and November 2002 at the former Loring Air Force Base quarry, Limestone, Maine.

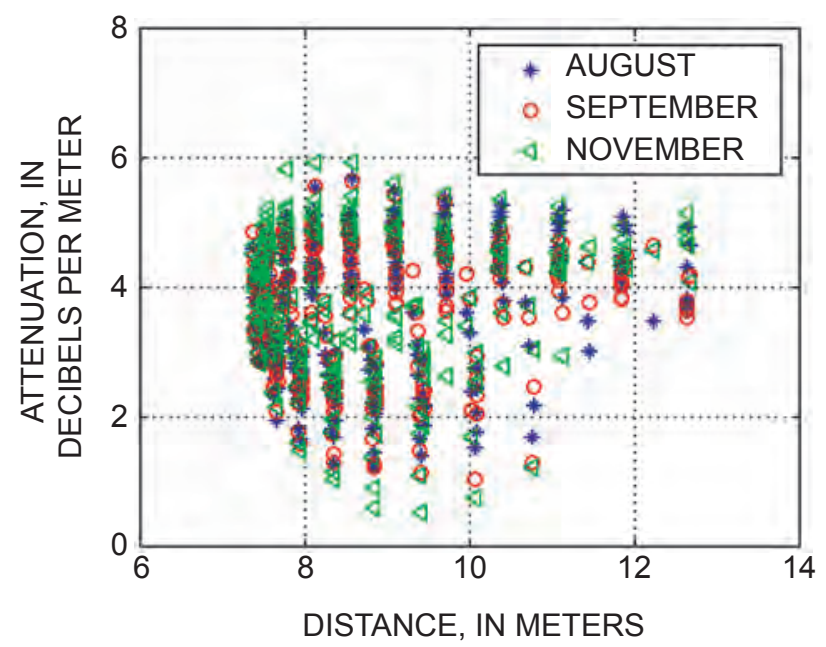

Figure 27. Attenuation measurements from calibrated crosshole radar tomography data collected during August, September, and November 2002 at the former Loring Air Force Base quarry, Limestone, Maine. 
A.
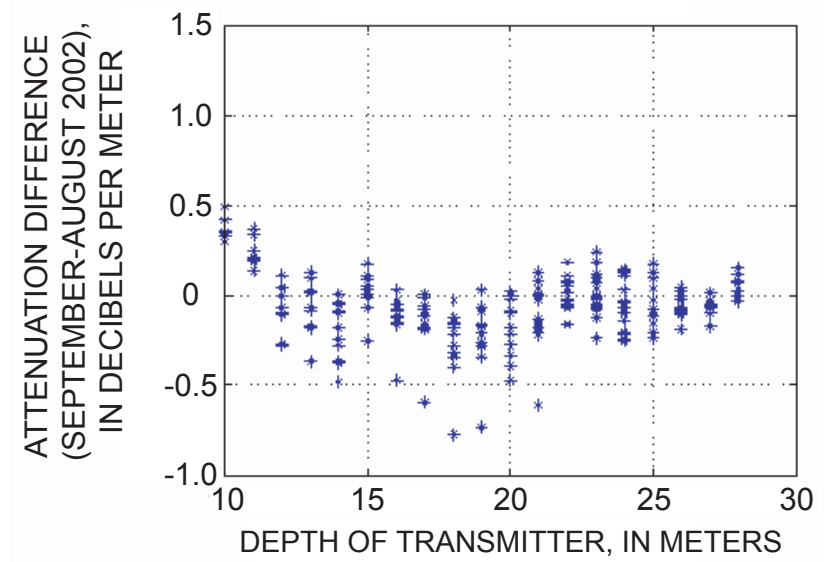

B.

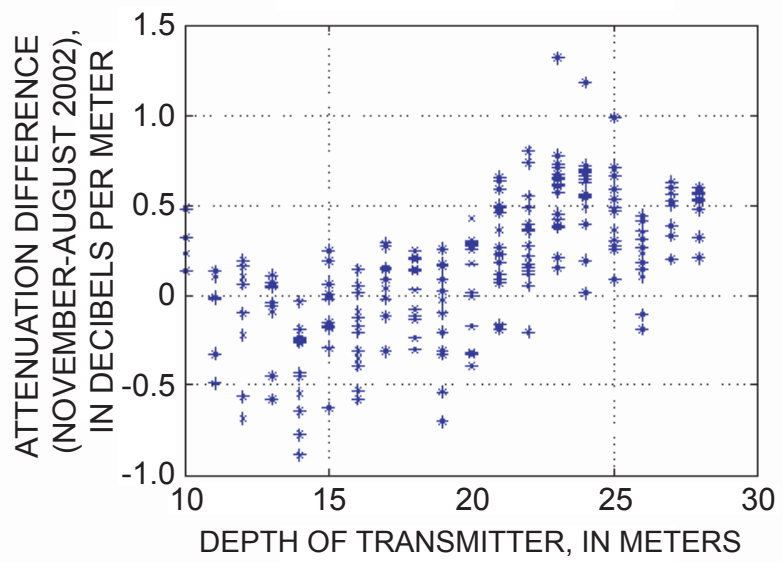

Figure 28. Attenuation differences in crosshole radar tomography data: $(A)$ September-August 2002 and (B) November-August 2002 at the former Loring Air Force Base quarry, Limestone, Maine.

A.

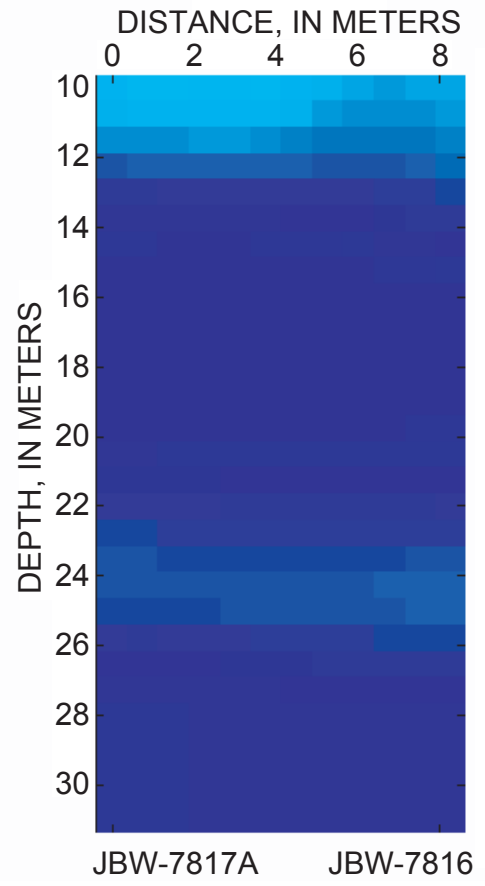

B.

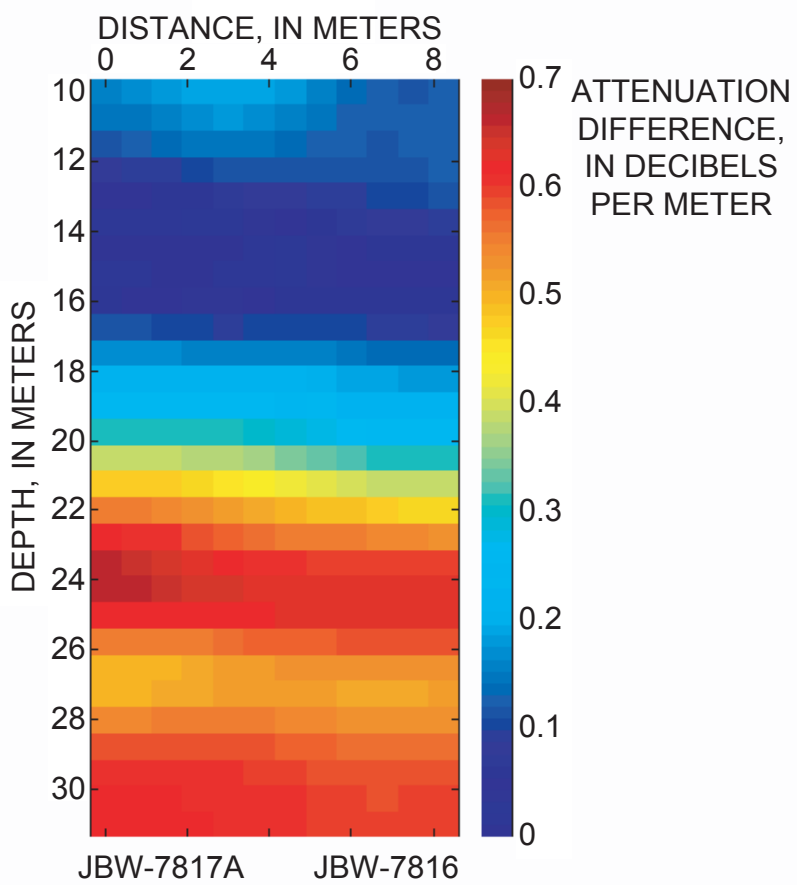

Figure 29. Results of the inversion of the attenuation-differences in crosshole radar tomography data: (A) September-August 2002 and (B) November-August 2002 at the former Loring Air Force Base quarry, Limestone, Maine. 


\section{Summary and Conclusions}

The U.S. Geological Survey conducted a geophysical investigation in an abandoned limestone quarry at the former Loring Air Force Base, Limestone, Maine, to evaluate the effectiveness of borehole radar methods to monitor the movement of steam and transport of heat in the subsurface. The investigation was undertaken in cooperation with the U.S. Environmental Protection Agency during a steamenhanced remediation pilot study being conducted at the fractured-rock site.

Numerical modeling performed as part of this study examined the effect of heating on radar-wave propagation. Changes in subsurface temperature cause changes in radarwave velocity, attenuation, and reflectivity of fractures. Radar-wave velocity was predicted to increase slightly in heated water, but to decrease in heated limestone. If steam replaced water in the fractures, the velocity of the radar wave is higher in steam than in water. Radar-wave attenuation was predicted to increase slightly in heated water in the fractures and to increase more substantially in heated limestone matrix. The attenuation of the radar wave in steam in the fractures was slightly less than in water. The radar-wave reflection coefficient (reflectivity) of a thin, water-filled fracture decreased with heating, and decreased by a factor of 10 if steam replaced water in the fracture. The reflectivity increased if the conductivity of the water in the fractures increased.

In theory, if steam were present in a fracture, it should be detectable by radar methods; however, the $100-\mathrm{MHz}$ (megahertz) radar system used for this study is not likely to detect steam in the small-aperture fractures $(<0.1 \mathrm{~mm}$ (millimeter)) identified at the site because of the wavelength of the radar wave. These results indicate that borehole radar may be an effective tool for detecting the change in fracture filling from water to steam at sites where the fracture apertures are greater than $1 \mathrm{~mm}$. The results also indicate that borehole radar has potential to detect substantial changes in temperature in the rock matrix near a borehole.

Single-hole radar reflection and crosshole radar tomography data were collected before the steam injection, in August 2002; about a week after the start of the steam injection, in September 2002; and near the end of the steam injection, in November 2002. Conventional borehole geophysical logs, including fluid temperature, electromagnetic (EM) conductivity, and borehole deviation, were collected to aid in interpreting and processing the radar data. The radar data were interpreted based on the results of the numerical modeling.

Temperature in borehole JBW-7816 increased about $10^{\circ} \mathrm{C}$ (degrees Celsius) above the August background measurements. A maximum temperature of about $17^{\circ} \mathrm{C}$ was recorded at a depth of about 20 to 22 meters (m). In borehole JBW-7817A, temperature increased as much as $40^{\circ} \mathrm{C}$ above the background measurements. Temperature increased with depth, with the maximum temperature of about $47^{\circ} \mathrm{C}$ recorded near the bottom of the borehole at a depth of about $29 \mathrm{~m}$. Larger temperature changes were expected in JBW-7817A than in JBW-7816, because JBW-7817A is closer to steaminjection well I-4. Larger temperature changes were expected at depth because the steam was injected in the interval between about 20 and $40 \mathrm{~m}$ below land surface in most of the injection boreholes.

The EM-conductivity data for each borehole are quite similar all three times that data were collected. Because of the numerous metallic objects at the site, the EM tool was not calibrated, and the data were collected using a fixed scale so only relative comparisons could be made. The tool is temperature sensitive, and the measured increases and decreases in conductivity were in response to changes in temperature as well as formation conductivity. Therefore, although the conductivity measured in November appears to decrease with depth, there is little confidence in this result, because theoretical and laboratory results show that the conductivity of rocks increases with temperature.

Profiles of the single-hole radar reflection data show substantial attenuation of the radar data in borehole JBW7817A in November. No attenuation is obvious in the data from borehole JBW-7816. From the two boreholes, a total of five reflectors were selected for detailed analyses across the three temporal data sets. Amplitude data were corrected for antenna power variations. The spectral content of the reflectors showed a small decrease with time. Minimal changes in the reflector amplitudes with time were observed in borehole JBW-7816, and decreases in reflector amplitudes were observed in borehole JBW-7817A. The analysis of the radar reflections indicates that steam did not replace water in most of the fractures surrounding boreholes JBW-7816 and JBW-7817A. This conclusion is based on three observations: (1) no change of reflection polarity was observed, (2) no substantial variation in traveltimes was observed, and (3) the observed decrease in reflectivity was too small to have been a result of replacement of water by steam in the fractures. There is one fracture, identified as Zone 3 in borehole JBW$7817 \mathrm{~A}$, where steam may have replaced water in a fracture. The fracture is identifiable in the August data, obvious in the September data, but could not be detected in the November data set. The strong decrease in the amplitude, and thus the reflectivity, of the feature prevented the analysis of the polarity or the possible change in traveltime.

The decrease in radar reflection amplitude is larger for data collected from JBW-7817A than JBW-7816, which is consistent with the greater heating around that borehole. The decrease in amplitude could be owing to heating of the limestone or use of a power correction that was not high enough. Because steam did not replace the water in the fractures, it was not possible to estimate fracture aperture using the reflection data.

Crosshole radar tomography data were examined for changes in traveltime and amplitude. Small changes in traveltime show about a 2-percent decrease in velocity between August and November. Traveltime difference 
tomograms show no change in velocity between August and September and show a small decrease in velocity between August and November for depths below about $20 \mathrm{~m}$. The attenuation data required corrections for power differences between the data sets. Attenuation difference tomograms show no change between August and September, but show a small increase in attenuation between August and November for depths below about $20 \mathrm{~m}$. This is the same depth where the greatest increase in heating was observed in the temperature logs of both boreholes. Although these changes are small, they are consistent with the interpretation of the single-hole radar reflection data: the conductivity of the limestone increased as a result of heating of the limestone matrix between boreholes JBW-7816 and JBW-7817A, and steam was not found near the boreholes.

\section{References Cited}

Birchak, J.R., Gardner, C.G., Hipp, J.E., and Victor, J.M., 1974, High dielectric constant microwave probes for sensing soil moisture: Proceedings of the Institute of Electrical and Electronics Engineers, v. 62, p. 93-98.

Bregman, N.D., Bailey, R.C., and Chapman, C.H., 1989a, Crosshole seismic tomography: Geophysics, v. 54, no. 2, p. 200-215.

Bregman, N.D., Bailey, R.C., and Chapman, C.H., 1989b, Ghosts in tomography-The effects of poor angular coverage in 2-D seismic traveltime inversion: Canadian Journal of Exploration Geophysics, v. 25, no. 1, p. 7-27.

Censor, Y., 1983, Finite series-expansion reconstruction methods: Proceedings of the Institute of Electrical and Electronics Engineers, v.71, no. 3, p. 409-419.

Daniels, J.J., 1989, Fundamentals of ground penetrating radar, in Symposium on the Application of Geophysics to Engineering and Environmental Problems, March 13-16, 1989, Golden, Colorado, Proceedings: Society of Engineering and Mineral Exploration Geophysics, p. 62-142.

Davis, E.L., 1997, How heat can enhance in-situ soil and aquifer remediation-Important chemical properties and guidance on choosing the appropriate technique: U.S. Environmental Protection Agency, Ground Water Issue Paper, EPA/540/S-97/502, April 1997, 18 p.

Davis, J.L., and Annan, A.P., 1989, Ground penetrating radar for high-resolution mapping of soil and rock stratigraphy: Geophysical Prospecting, v. 37, p. 521-551.

Day-Lewis, F.D., Harris, J.M., and Gorelick, S.M., 2002, Time-lapse inversion of crosswell radar data: Geophysics, v. 67 , no. 6 , p. $1740-1752$.
Day-Lewis, F.D., and Lane, J.W., Jr., 2004, Assessing the resolution-dependent utility of tomograms for geostatistics: Geophysical Research Letters, v. 31, L07503, doi:10.1029/2004GL019617, 4 p.

Dines, K.A., and Lytle, R.J., 1979, Computerized geophysical tomography: Proceedings of the IEEE, v. 67, p. 1065-1073.

Falk, L., 1992, Directional borehole antenna-Theory: Stockholm, Sweden, Stripa, Project 92-16, SKB 138 p.

Grégoire, Colette, 2001, Fracture characterisation by ground penetrating radar: Heverlee, Belgium, Katholieke Universiteit Leuven, PhD dissertation, 191 p., 109 figs.

Grégoire, Colette, Halleux, Lucien, and Lukas, Volker, 2003, GPR capabilities for the detection and characterisation of open fractures in a salt mine: Near Surface Geophysics (Journal of European Association of Geoscientists and Engineers (EAGE)), v. 1, p. 139-147.

Grégoire, Colette, and Hollender, Fabrice, 2004, Discontinuity characterization by the inversion of the spectral content of ground penetrating radar (GPR) reflections-Application of the Jonscher model: Geophysics, v. 69, no. 6, p. 1414-1424.

Haeni, F.P., Lane, J.W., Jr., and Lieblich, D.A., 1993, Use of surface-geophysical and borehole-radar methods to detect fractures in crystalline rocks, Mirror Lake area, Grafton County, New Hampshire, in Banks, S., and Banks, D., eds., Hydrogeology of Hard Rocks, Memoires of the 24th Congress, June 28-July 2, 1993: Oslo, Norway, International Association of Hydrogeologists, v. 29, part 1, p. 577-587.

Helgeson, H.C., and Kirkham, D.H., 1974, Theoretical prediction of the thermodynamic behavior of aqueous electrolytes at high pressures and temperatures - II. DebyeHückel parameters for activity coefficients and relative partial-molal properties: American Journal of Science, v. 274 , p. 1199-1261.

Itamura, M.T., and Udell, K.S., 1995, An analysis of optimal cycling time and ultimate chlorinated hydrocarbon removal from heterogeneous media using cyclic steam injection, in Proceedings of the ASME Heat Transfer and Fluids Engineering Divisions: New York, American Society of Mechanical Engineers, HTD_321, p. 651-660.

Keys, W.S., 1990, Borehole geophysics applied to groundwater investigations: U.S. Geological Survey Techniques of Water-Resources Investigations, book 2, chap. E-2, 149 p.

Knight, Rosemary, 2001, Ground penetrating radar for environmental applications: Annual Review of Earth and Planetary Sciences, v. 29, p. 229-255. 
Lane, J.W., Jr., Day-Lewis, F.D., Harris, J.M., Haeni, F.P., and Gorelick, S.M., 2000, Attenuation-difference radar tomography-Results of a multiple-plane experiment at the U.S. Geological Survey fractured rock research site, Mirror Lake, New Hampshire, in Noon, D.A., Stickely, G.F., and Longstaff, D., eds., Eighth International Conference on Ground Penetrating Radar: Bellingham, Wash., International Society for Optical Engineering (SPIE), formerly Society of Photo-Optical Instrumentation Engineers, v. 4084, p. 666-675.

Lane, J.W., Jr., Day-Lewis, F.D., Versteeg, R.J., and Casey, C.C., 2003, Object-based inversion of crosswell radar tomography data to monitor vegetable oil injection experiments, in Symposium on the Application of Geophysics to Environmental and Engineering Problems, April 6-10, 2003, San Antonio, Texas, Proceedings: Denver, Colo., Environmental and Engineering Geophysics Society, CD-ROM, p. 1134-1160.

Lane, J.W., Jr., Haeni, F.P., and Day-Lewis, F.D., 1998, Use of time-lapse attenuation-difference radar tomography methods to monitor saline tracer transport in fractured crystalline bedrock, in GPR'98, Seventh International Conference on Ground Penetrating Radar, Lawrence, Kansas, May 27-30, 1998, Proceedings: Lawrence, Kans., University of Kans., p. 533-538.

Lane, J.W., Jr., Haeni, F.P., Soloyanis, Susan, Placzek, Gary, Williams, J.H., Johnson, C.D., Buursink, M.L., Joesten, P.K., and Knutson, K.D., 1996, Geophysical characterization of a fractured-bedrock aquifer and blastfractured contaminant-recovery trench, in Bell, R.S., and Cramer, M.H., eds., Symposium on the Application of Geophysics to Engineering and Environmental Problems, April 28-May 2, 1996, Keystone, Colorado, Proceedings: Denver, Colo., Environmental and Engineering Geophysical Society, p. 429-441.

Lane, J.W., Jr., Haeni, F.P., and Williams, J.H., 1994, Detection of bedrock fractures and lithologic changes using borehole radar at selected sites, in Fifth International Conference on Ground-Penetrating Radar (GPR '94), Kitchener, Ontario, Canada, June 12-16, 1994, Proceedings: Kitchener, Ontario, Canada, Waterloo Centre for Groundwater Research, p. 577-592.

Lane, J.W., Jr., Joesten, P.K., Pohll, Greg, and Mihevic, Todd, 2001, Analysis of borehole-radar reflection logs from selected HC boreholes at the Project Shoal Area, Churchill County, Nevada, U.S. Geological Survey Water-Resources Investigations Report 01-4014, 23 p.
Lane, J.W., Jr., Wright, D.L., and Haeni, F. P., 1999, Borehole radar tomography using saline tracer injections to image fluid flow in fractured rock, in U.S. Geological Survey Toxic Substances Hydrology Program, Proceedings of the Technical Meeting, Charleston, South Carolina, March 8-12, 1999: U.S. Geological Survey Water-Resources Investigations Report 99-4018C, v. 3, p. 747-756.

Llera, F.J., Sato, M., Nakatsuka, K., and Yokoyama, H., 1990, Temperature dependence of the electrical resistivity of water-saturated rocks: Geophysics, v. 55, no. 5, p. 576-585.

McMechan G.A., Harris, J.M., and Anderson, L.M., 1987, Cross-hole tomography for strongly variable media with applications to scale model data: Bulletin of the Seismological Society of America, v. 77, no. 6, p. 1945-1960.

Newmark, R.L., and Aines, R.D., 1994, Demonstration of dynamic underground stripping at the LLNL Gasoline Spill Site: Livermore, Cali., Lawrence Livermore National Laboratory, Final Report UCRL-ID-116964, v. 1-4.

Olsson, Olle, Andersson, Per, Carlsten, Seje, Falk, Lars, Niva, Börje, and Sandberg, Eric, 1988, Fracture characterization in crystalline rock by borehole radar, in Workshop on Ground-Penetrating Radar, May 24-26, 1998, Ottawa, Canada: 24 p.

Olsson, Olle, Andersson, Per, Carlsten, Seje, Falk, Lars, Niva, Börje, and Sandberg, Eric, 1992a, Fracture characterization in crystalline rock by borehole-radar, in Pilon, J., ed., Ground-Penetrating Radar: Geological Survey of Canada Paper 90-4, p. 139-150.

Olsson, Olle, Falk, L., Forslund, O., Lundmark, L., and Sandberg, Eric, 1992b, Borehole radar applied to the characterization of hydraulically conductive fracture zones in crystalline rock: Geophysical Prospecting, v. 40, no. 2, p. 109-142.

Osberg, P.H., Hussey, A.M., and Boone, G.M., (eds.) 1985, Bedrock geologic map of Maine: Maine Geological Survey, scale 1:500,000.

Pavlides, Louis, 1968, Stratigraphic and facies relationships of the Carys Mills Formation of Ordovician and Silurian Age, northeast Maine: U.S. Geological Survey Bulletin 1264, 44 p., 1 map folded in pocket.

Rector, J.W., and Washbourne, J.W., 1994, Characterization of resolution and uniqueness in crosswell direct-arrival traveltime tomography using the Fourier projection slice theorem: Geophysics, v. 59, no. 11, p. 1642-1649. 
Reynolds, J.M., 1997, An introduction to applied and environmental geophysics: West Sussex, England, John Wiley \& Sons Ltd.

Roy, Dave, 1980, Sedimentology of Silurian flysch, Ashland Sinclinorium, Maine, in Roy, D.C., and Naylor, R., eds., New England Intercollegiate Geologic Conference, $72^{\text {nd }}$ annual meeting Presque Isle, Maine, October 10-14, 1998, A guidebook to the geology of northeastern Maine and neighboring New Brunswick: Chestnut Hill, Mass., Boston College, Department of Geology, p. 232-252.

Sandberg, E.V., Olsson, O.L., and Falk, L.R., 1991, Combined interpretation of fracture zones in crystalline rock using single-hole, crosshole tomography, and directional borehole-radar data: The Log Analyst, v. 32, no. 2, p. 108-119.

SteamTech Environmental Services, Inc., 1999, Steam stripping and hydrous pyrolysis pilot project for the Portsmouth Gaseous Diffusion Plant, Portsmouth, Ohio:

San Diego, Calif., SteamTech Environmental Services, Inc., Final report for DOE \# DOE/OR/11-3032\&D1.

SteamTech Environmental Services, Inc., 2001, Pilot study of steam enhanced remediation for mitigation of residual DNAPL in fractured rock, Loring Air Force Base, Limestone, Maine: Bakersfield, Calif., SteamTech Environmental Services, Inc., Work Plan Preliminary Draft, 04/2001, $31 \mathrm{p}$.

Stephenson, Kyle, and Novakowski, Kent, 2003, Interconnectivity of the fracture system present at the quarry site, former Loring Air Force Base, Limestone, Maine: Kingston, Ontario, Queens University, Department of Civil Engineering, $39 \mathrm{p}$.
Stewart, L.D., and Udell, K.S., 1988, Mechanisms of residual oil displacement by steam injection: SPE Reservoir Engineering, v. 3, p. 1233-1242.

Stewart R.R., 1992, Exploration seismic tomographyFundamentals, in Domenico, S.N., ed., Course Notes Series, v. 3: Tulsa, Okla., Society of Exploration Geophysicists, $190 \mathrm{p}$.

Udell, K.S., 1996, Heat and mass transfer in clean-up of underground toxic wastes, in Tien, D.-L., ed., Annual reviews of heat transfer, v. 7: New York, Begell House, Inc., p. 333-405.

Wharton, R.P., Hazen, G.A., Rau, R.A., and Best, D.L., 1980, Electromagnetic propagation logging-Advances in technique and interpretation: Society of Petroleum Engineers, 55th Annual Technical Conference, Paper 9267.

Williams, J.H., and Conger, R.W., 1990, Preliminary delineation of contaminated water-bearing fractures intersected by open-hole bedrock wells: Ground Water Monitoring Review, v. 10, no. 4, p. 118-126.

Williams, J.H., Lapham, W.W., and Barringer, T.H., 1993, Application of electromagnetic logging to contamination investigations in glacial sand-and-gravel aquifers: Ground Water Monitoring and Remediation Review, v. 13, no. 3, p. $129-138$.

Williamson, P.R., and Worthington, M.H., 1993, Resolution limits in ray tomography due to wave behavior-Numerical experiments: Geophysics, v. 58, no. 5, p. 727-735. 

질

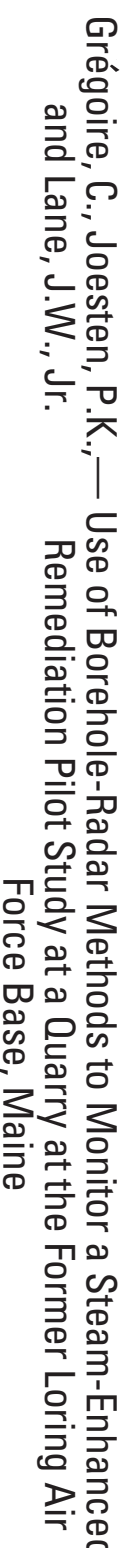

里

บ 응.

象:

등

$\sum \frac{\mathbb{D}}{D}$

든

즈

为

으

ㅁ

옹음

음 음

믐ำ

노응

끄음

سם

क 응

ฏ。

지

采

ํㅜ

es

.

궁

$=$

르ำ

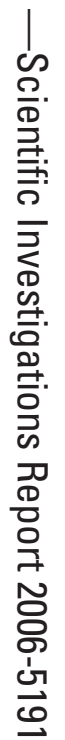

